\title{
The multi-dimensional challenges of controlling SARS-CoV-2 transmission in indoor spaces: Insights from the linkage of a microscopic pedestrian simulation and virus transmission models
}

\author{
Dorine Duives ${ }^{1, * \wedge}$, You Chang ${ }^{2, * \wedge}$, Martijn Sparnaaij ${ }^{1}$, Berend Wouda ${ }^{3}$, Doris Boschma ${ }^{3}$, Yangfan Liu ${ }^{2}$, Yufei Yuan $^{1}$, \\ Winnie Daamen, Mart de Jong ${ }^{2}$, Colin Teberg ${ }^{4}$, Kevin Schachtschneider ${ }^{4}$, Reina Sikkema ${ }^{5}$, Linda van Veen ${ }^{3}$, \\ Quirine ten Bosch ${ }^{2, *}$ \\ *Corresponding authors, ^ contributed equally \\ ${ }^{1}$ Department of Transport \& Planning, Delft University of Technology, The Netherlands \\ ${ }^{2}$ Department of Quantitative Veterinary Epidemiology, Wageningen University \& Research, The Netherlands \\ ${ }^{3}$ Gamelab, Delft University of Technology, The Netherlands \\ ${ }^{4}$ Steady State Scientific Computing, Chicago, USA \\ ${ }^{5}$ ViroScience, Erasmus Medical Center, The Netherlands
}

Email addresses: d.c.duives@tudelft.nl (Dorine Duives), quirine.tenbosch@wur.nl (Quirine ten Bosch)

\begin{abstract}
Since its introduction in December of 2019, SARS-CoV-2, the virus that causes COVID-19 disease, has rapidly spread across the world. Whilst vaccines are being rolled out, non-pharmaceutical interventions remain the most important tools for mitigating the spread of SARS-CoV-2. Quantifying the impact of these measures as well as determining what settings are prone to instigating (super)spreading events is important for informed and safe reopening of spaces and the targeting of interventions. Mathematical models can help decipher the complex interactions that underlie virus transmission. Currently, most mathematical models developed during the COVID-19 epidemic evaluate interventions at national or subnational levels. Smaller scales of transmission, such as at the level of indoor spaces, have received less attention, despite the central role they play in both transmission and control. Models that do act on this scale use simplified descriptions of human behavior, impeding a valid quantitative analysis of the impact of interventions on transmission in indoor spaces, particularly those that aim for physical distancing. To more accurately predict the transmission of SARS-CoV-2 through a pedestrian environment, we introduce a model that links pedestrian movement and choice dynamics with SARS-CoV-2 spreading models.

The objective of this paper is to investigate the spread of SARS-CoV-2 in indoor spaces as it arises from human interactions and assess the relative impact of non-pharmaceutical interventions thereon. We developed a world-wide unique combined Pedestrian Dynamics - Virus Spread model (PeDViS model), which combines insights from pedestrian modelling, epidemiology, and IT-design. In particular, an expert-driven activity assignment model is coupled with the microscopic simulation model (Nomad) and a virus spread model (QVEmod).

We first describe the non-linear relationships between the risks of exposure to the virus and the duration, distance, and context of human interactions. We compared virus exposure relative to a benchmark contact (1.5meters for 15 minutes): a threshold often used by public health agencies to determine 'at risk' contacts. We discuss circumstances under which individuals that adhere to common distancing measures may nevertheless be at risk. Specifically, we illustrate the stark increase in exposure at shorter distances, as well as longer contact durations. These risks increase when the infected individual was present in the space before the interaction occurred, as a result of buildup of virus in the environment. The latter is particularly true in poorly ventilated spaces and highlights the importance of good ventilation to prevent potential virus exposure through indirect transmission routes. Combining intervention tools that target different routes of transmission can aid in accumulating impact. We use face masks as an example, which are particularly effective at reducing virus spread that is not affected by ventilation. We then demonstrate the use of PeDViS using a simple restaurant case study, focussing on transmission between guests. In this setting the exposure risk to individuals that are not seated at the same table is limited, but guests seated at nearby tables are estimated to experience exposure risks that surpass that of the benchmark contact. These risks are larger in low ventilation scenarios. Lastly, we illustrate that the impact of intervention measures on the number of new infections heavily depends on the relative efficiency of the direct and indirect transmission routes considered. This uncertainty should be considered when assessing the risks of transmission upon different types of human interactions in indoor spaces.

The PeDViS case study shows the multi-dimensionality of SARS-CoV-2 that emerges from the interplay of human behaviour and the spread of respiratory viruses in indoor spaces. A modelling strategy that incorporates this NOTE: This preprint reports new research that has not been certified by peer review and should not be used to guide clinical practice.
\end{abstract}


medRxiv preprint doi: https://doi.org/10.1101/2021.04.12.21255349; this version posted April 19, 2021. The copyright holder for this preprint

(which was not certified by peer review) is the author/funder, who has granted medRxiv a license to display the preprint in perpetuity. It is made available under a CC-BY-NC 4.0 International license .

The multi-dimensional challenges of controlling SARS-CoV-2 transmission in indoor spaces

in risk assessments can be an important tool to inform policy makers and citizens. It can empower them to make better design and policy decisions pertaining to the most effective use of measures to limit the spread of SARS-CoV2 and safely open up indoor spaces.

\section{INTRODUCTION}

Since its introduction in December of 2019, SARS-CoV-2, the virus that causes COVID-19 disease, has rapidly spread across the world. With over 98,794,942 registered cases and 2,124,193 reported deaths worldwide as of 25th January 2021, the impact of this virus is unprecedented (WHO, 2021). In the absence of effective therapeutics and vaccines, control has largely relied on far reaching non-pharmaceutical interventions (NPI's). Many of these restrictions aim to limit interactions in indoor spaces, where most infection events occur (CDC (2020), RIVM (2021), WHO (2021), Fouda et al., (2021)). Schools and higher educational facilities have been closed, restaurants and cafes shut down, and visits to previously busy public spaces (e.g. theaters and shopping malls) discouraged and/or restricted.

NPIs are currently the most important tools for mitigating the spread of SARS-CoV-2. These include physical distancing (i.e., keeping 1-2 meters distance from individuals from another household or infected household contacts), the use of face masks in public spaces, cough-, hand- and environmental hygiene measures, and limiting crowding (CDC (2020), RIVM (2021), WHO (2021), Fouda et al., (2021)). While effective at reducing transmission in many settings (Flaxman et al. (2020), Delikhoon et al. (2021)), the contributions of each non-pharmaceutical measure vary as a result of i) contextual variables, such as poor ventilation, crowding, prolonged durations of stay (Tang et al., 2020), ii) environmental conditions (temperature, humidity), iii) individual variation in infection kinetics, and human behaviours, including singing, shouting, iv) and imperfect adherence to distancing measures and selfisolation methods (Barreda et al., 2020). Understanding how these factors interact and affect the outcomes of NPI's is important for informed and safe reopening of spaces and a more targeted implementation of interventions.

Mathematical models can help decipher these complex interactions that underlie virus transmission. Currently, most mathematical models developed during the COVID-19 pandemic evaluate interventions at national or subnational levels (Giordano et al. (2020), Prem et al. (2020), Tuite et al. (2020)). Fewer efforts focus on smaller scale transmission (Evans et al., 2020). Indoor spaces have received little attention for this and other respiratory illnesses (Arav et al. (2020), Gao et al. (2016), Qian et al. (2009)), despite the central role they play in transmission and the fact that most control strategies are targeted at these settings. In addition, with $80 \%$ of new cases being caused by $10 \%$ of infected individuals, individual-level variation is an important driver of the transmission of SARSCoV-2 (Endo et al., 2020). This is likely to be driven by a combination of individual-level differences in the infectiousness of individuals, as well as the individual behaviours that affect the level and amount of close contacts they encounter. Lastly, the settings where these encounters take place can greatly affect transmission risks, which may be affected by temperature, humidity, ventilation, and airflows.

Yet, despite the recognized importance of the duration and types of interactions that are made in indoor spaces, many models use simplified descriptions of human behaviour (Giordano et al. (2020), Zhang et al. (2020)), impeding quantitative analysis of the impact of changes in human behaviour and the impact of interventions on transmission in indoor spaces. Various simplified adapted pedestrian models have been used to identify the number of potential infections in certain spaces (Xiao et al. (2020), Xu \& Chraibi (2020)), where all interactions at a distance of less than 1.5 meters (and longer than 10 minutes) are counted as newly infected or exposed individuals. Even though incorporating pedestrian dynamics make the movement dynamics more realistic, this oversimplified use of pedestrian simulation models potentially over or underestimates the number of potential infections within a certain time frame within a space. Consequently, to more accurately predict the transmission of SARS-CoV-2 in indoor spaces, a combined model is required that links pedestrian movement and choice dynamics and detailed SARS-CoV2 spreading models that incorporate both direct (large droplets) and indirect (small airborne droplets and contaminated surfaces) transmission routes.

The objective of this paper is to examine SARS-CoV-2 transmission risks in indoor environments and the relative impact of non-pharmaceutical interventions that are targeted at such settings. To do so we developed a world-wide unique combined Pedestrian Dynamics - Virus Spread model (PeDViS model). Recent insights from pedestrian modelling, virology, epidemiology, and IT-design are combined to develop an open-access software package to model the transmission of SARS-CoV-2 in indoor spaces. In particular, a data-driven activity assignment model is coupled with a force-base microscopic simulation model (Nomad) and a virus spread model (Model for Quantifying Viruses in Environments, QVEmod). 
medRxiv preprint doi: https://doi.org/10.1101/2021.04.12.21255349; this version posted April 19, 2021. The copyright holder for this preprint

(which was not certified by peer review) is the author/funder, who has granted medRxiv a license to display the preprint in perpetuity. It is made available under a CC-BY-NC 4.0 International license.

The multi-dimensional challenges of controlling SARS-CoV-2 transmission in indoor spaces

The following sections will elaborate on these endeavours. Section 2 discusses the state-of-the-art pertaining pedestrian choice \& movement modelling, virus spread, and attempts to combine insights from both disciplines. Subsequently, section 3 details the PeDViS model, and introduces the three models that form its foundation. Section 4 briefly introduces the user-interface designed to allow facility managers and public health decision makers to use the PeDViS model. Afterwards, section 5 illustrates the usage of the PeDViS model by means of a case study in which the relative impact of several interventions on virus spread and transmission are compared. We investigate the relative contribution of different transmission routes and illustrate how uncertainty surrounding these estimates affects our ability to predict the relative impact of NPIs. This paper finishes with a brief recap of the most important findings and a discussion pertaining to the necessary future developments of the PeDViS model.

\section{BACKGROUND}

The objective mentioned in the previous section can be solved by combining three types of models, namely a model that determines the choices of individuals, a model that simulates the resulting movements of those individuals, and a model that quantifies the virus transmission risk as a result of individuals' choices, movements, infection status, and environmental factors and fluid dynamics. The following section describes the existing work on these three types of models. The first section (2.1) discusses the state-of-the-art pertaining pedestrian strategic and tactical choice models for indoor environments. Section 2.2 continues with an elaboration on simulation models for operational movement behaviour. Section 2.3 reviews existing models that simulate the spread of respiratory viruses in indoor spaces. This section ends with an overview of the attempts to use pedestrian simulation models and virus spread models to determine SARS-CoV-2 transmission risks (section 2.4).

\subsection{Modelling pedestrian strategic and tactical choice behaviours}

The movements of individuals are governed by choices at three levels, namely strategic (activity, activity location, departure time choice), tactical (mode and route choice) and operational choices. In particular, this section will focus on the state-of-the-art of activity and route choice behaviour literature because these two choices are influential in the case of individuals movement behaviour in indoor spaces. More specifically, we will focus on models that determine the order of individuals' activities and their routing.

\subsubsection{Activity scheduling and location choice modelling}

Most studies focussed on activity choice modelling feature the movements of pedestrians across city-scale networks. Borgers and Timmermans (2010) were one of the first to develop a set of three connected models that jointly identify pedestrian movements in shopping areas. Dijkstra and Jessurum (2016) simulate visitor's activity scheduling in shopping areas. Clifton et al. (2016) and Oyama \& Hato (2018) determine pedestrian destination choices in a citynetwork. Vukadinovic et al. (2011) developed an activity simulation model for another leisure activity, namely theme parks. Danalet et al. (2014) and Danelet \& Bierlaire (2014) adopted discrete choice models to identify the restaurant choices and activity patterns of students and staff of the university.

More recently, several studies featured activity choice modelling inside buildings. Hoogendoorn \& Bovy (2004), for instance, developed a continuous utility maximization framework that makes a trade-off between activity performance and the waiting and walking costs. This model is often applied in real-life cases, where the parameters of the activity utility were estimated using data of a benchmark situation. Ton et al. (2015) established a set of singleand multi-factor MNL models to identify the activity schedules of travellers inside train stations. Kalakou et al. (2014) applies the same approach to model activity schedules at airports. Liu et al. (2014) used a nested logit model to predict activity travel patterns for airport travellers. Shelat et al. (2020) developed a markov-chain model to simulate the activity scheduling of individuals working in an office building. The transition probabilities were derived from movement data inside the building.

What all of these activity location \& scheduling modelling approaches have in common is that they require large amounts of data to be correctly estimated and that they are often difficult to generalize. Yet, for indoor scenarios, and specifically restaurants, little data is available regarding individuals' activity scheduling. Thus, the modelling approaches presented above are difficult to use. Yet, the literature also shows that if one can estimate the transition probabilities between activities, the resulting activity scheduling behaviour is relatively realistic. Thus, in this first, pragmatic attempt to model activity choices in restaurants, an expert-driven approach is adopted. For more information, see section 3.2. 
medRxiv preprint doi: https://doi.org/10.1101/2021.04.12.21255349; this version posted April 19, 2021. The copyright holder for this preprint

(which was not certified by peer review) is the author/funder, who has granted medRxiv a license to display the preprint in perpetuity. It is made available under a CC-BY-NC 4.0 International license .

The multi-dimensional challenges of controlling SARS-CoV-2 transmission in indoor spaces

\subsubsection{Route choice modelling}

Early works on pedestrian route choice modelling, such as Hill (1984), indicate that route choice selection strategies are largely subconscious, but that directness is the most commonly identified reason for choosing a particular route. Various studies have afterwards identified the impact of the built environment on pedestrian route choices in cityscale networks (e.g. Borgers \& Timmermans (2005), Guo et al. (2013), Lue \& Miller (2019), Shatu et al. (2019)). Often discrete choice models, such as the path size logic model and the multinomial probit models, are estimated. Some, more data-driven approaches directly infer the likelihood of a given path based on a large set of realized traces and their characteristics, such as speed distribution and nearby WiFi spots (e.g. Chen \& Bierlaire (2015).

Yet, with respect to indoor route choice behaviour, most works empirically studied indoor navigation, see Kalakou \& Moura (2014) for an overview. Additionally, some utility-based route choice models have been developed for specific contexts (e.g. Cheung \& Lam (1998), Hughes (2000), Hoogendoorn \& Bovy (2005) and Daamen et al. (2005). Yet, given that the models are difficult to generalize and/or estimate due to their high data requirement. Consequently, the shortest route towards one's destination is frequently adopted in simulation approaches. Often local biases or forces are introduced to account for crowding at the scene (e.g., Campanella et al. (2009), Usher et al. (2010)). The adoption of the shortest-distance path can, however, lead to unrealistic 'suboptimal' pedestrian choice behaviour. Asano et al. (2010), Kretz et al. (2011) and Stubenschrott et al. (2014) developed more sophisticated route choice models that determine the shortest path dynamically, thus improving local route choice.

Even though dynamic route choice models are most sophisticated, their computational effort is relatively high. Moreover, in case of low demand locations (due to physical distancing restrictions), we expect the adverse effects of suboptimal routing to be limited. Thus, because we favour fast computation times and expect limited routing issues, this study will apply the utility-based routing approach presented by Hoogendoorn \& Bovy (2004), also coined Nomad, to globally route pedestrians between activity locations.

\subsection{Modelling individuals' operational movement dynamics}

Over the years various pedestrian movement models have been presented. The level of details pertaining to the spatial representation of the environment, agents' choice behaviour and agents' movement behaviour differs greatly. Six distinctive types of models can be identified, namely i) Graph-based models, ii) Continuous models, iii) Cellular Automata models, iv) Force-base models, v) Velocity-based models and vi) discrete choice models. All model types are discussed below, for a more in-depth discussion of the (dis)advantages of all model types the reader is referred to Duives et al. (2013).

The first two types both make use of a macroscopic representation of pedestrian flows, using the fundamental relation between density and walking speed (P-FD) to determine the flow of pedestrians across boundaries. Graph-based models simulate the movements of pedestrians along a simplified graph (e.g. Chalmet et al. (1982), Hanseler et al. (2017)) consisting of vertices and nodes. Continuous pedestrian simulation models discretize pedestrian spaces in cells along 2 dimensions, but still make use of a continuous representation of pedestrian flows (Hughes (2000; 2002), Treuille et al. (2006)). Few macroscopic models can cope with heterogeneous crowds and multi-directional traffic, amongst which Hoogendoorn et al. (2014), Tordeux et al. (2018)). Continuous macroscopic models are best used for scenarios where large crowds move through relatively confined simply-shaped spaces.

Besides that, four major streams of microscopic pedestrian simulation models have been developed in the last four decades. These models all simulate the movements of discrete pedestrians. Cellular automata models were first developed by Blue \& Adler (1998), and have been further specialized ever since (e.g. Song et al. (2005), Schadschneider (2002), Sarmady (2010), Bandini et al (2011)). The environment is often spatially discretized in a regular grid, which can limit CA's validity in high-density situations and small or oddly shaped spaces. Force-based models have been on the rise since the seminal paper of Helbing et al. (1995). This second model type determines the next position of a pedestrian as the result of its current movement direction and force-based interactions with other agents, its destination and its surrounding. This popular model type has seen many extensions, amongst which other force-interpretations (e.g. Hoogendoorn \& Bovy (2004)), interaction biases (e.g. Parisi et al. (2009), Chen et al. (2020)), stairway behaviour (e.g. Qu et al. (2014)), corner rounding behaviour (e.g. Chen et al. (2020), Dias et al. (2019)), travel time (Kretz et al., 2011). Velocity-based models determine the next speed of an agent as the result of the agent's destination, kinetic energy dispensal, and collision-risk (Karamouzas \& Overmars (2010), Mousssaid et al. (2011), Paris et al. (2007)). Interactions directly influence the velocity of agent's, which tends to make agents' movements fairly unstable. The last type of microscopic model, i.e. discrete choice models, simulate pedestrians' operational movements as an optimization of its choice utility (e.g. Antonini et al. (2004), Robin et al. (2009)), which are the weighted sum of various elements of the potential next positions. This model type is not often applied, as it 
medRxiv preprint doi: https://doi.org/10.1101/2021.04.12.21255349; this version posted April 19, 2021. The copyright holder for this preprint

(which was not certified by peer review) is the author/funder, who has granted medRxiv a license to display the preprint in perpetuity. It is made available under a CC-BY-NC 4.0 International license .

The multi-dimensional challenges of controlling SARS-CoV-2 transmission in indoor spaces

is very difficult to create a flexible 'simple' movement model that can cope with the general interaction complexity of public spaces.

For the modelling of virus transmission, a detailed description of pedestrians' movements is essential. Thus, a microscopic model is better suited to simulate the necessary movements. Additionally, most SARS-CoV-2 transmissions occur in indoor spaces, where a multitude of complex interaction behaviours occur. This vouches for a microscopic model for which many specialist behaviours have already been implemented (e.g. force-base or velocity-based). At the same time, the current physical distancing rules require the model to correctly simulate complex social interactions at a distance (no physical forces). A force-based model is better equipped to handle social interactions at a distance due to its setup. Thus, a generalization of a force-base model will be used to simulate the pedestrian choice and movement dynamics in indoor spaces, in particular Nomad (Hoogendoorn \& Bovy (2004)) in the implementation of Campanella et al. (2014))

\subsection{Modelling indoor transmission of respiratory viruses}

Indoor transmission models have been developed to better understand transmission of respiratory viruses and assess the effectiveness of non-pharmaceutical interventions (NPIs) (Kriegel et al. (2020), Gao et al. (2020)). Models differ in the types and extent of heterogeneity that is taken into account. In general, three main aspects are considered, namely i) the virus distribution in the environment, which can be assumed well-mixed or distributed in space according to underlying biophysical mechanisms, individual homogeneity or heterogeneity in terms of ii) infectiousness and/or susceptibility, and iii) in terms of human movement. What model is best suited, depends on objectives of the research. In this section, we discuss the pros and cons of each model type.

In the most simple family of airborne transmission models, the Well-Riley models, one assumes that infectious particles are well mixed and the quantities are in steady-state. It uses an analytical expression, known as the Well-Riley equation, to relate the number of infected and susceptible individuals in an indoor space, the ventilation rate and the amount of infectious particles in the air to the predicted number of new cases over a certain time period. Wells (1955) used a hypothetical infectious dose unit "quantum of infection" to describe how much infectious particles an infected individual emits. A quantum unit is defined as the number of infectious particles required to cause $63 \%$ of people getting infected, and is usually back-calculated using data on numbers of individuals infected in well-defined indoor outbreaks. The Well-Riley model has been extensively used for predicting the number of infections expected to arise at large gatherings and assessing the effect of interventions such as capping the maximum of occupancy and reducing the total event duration (Bazant \& Bush (2020), Kriegel et al. (2020)). It is often used for quick risk assessments of large events. However, since every individual has the same risk of infection, the Well-Riley models do not allow for assessing the role of individual behaviours on transmission risks.

Aerosol infectious dose-response models allow individual heterogeneity in infectiousness and respiratory activities. These models model the risk of getting infected from being exposed to different amounts of a specific airborne pathogen. This exposure dose, the amount of pathogen that reaches the susceptible individuals, depends on the infectious people's emission rates, the room volume, the recipients' pulmonary ventilation rate (i.e. the amount of air inhaled per unit time), and the exposure duration. Like the Well-Riley model, these models assume infectious particles to be distributed homogeneously with the virions concentration equal to the ratio between the emitted infectious particles and the room volume. The probability of infection occurring given exposure to a certain dose can be modelled by mathematical functions, such as exponential dose-response relationship (Sze To \& Chao, 2010). This approach is more flexible than Well-Riley models since it allows individual-level heterogeneity in terms of infectiousness, respiratory activities, and exposure time, and can be used to calculate individuals' infection risk (Lelieveld et al., 2020). This approach can be used to compare the relative exposure risk of common indoors such as classroom and office (Jones et al., 2021). However, the assumed homogeneous spatial distribution of infectious particles has the consequence that the distance between susceptible and infectious individuals does not affect exposure to the virus. Therefore, just as with the Well-Riley models, the impact of physical distancing cannot be evaluated with this family of models.

Recently, more detailed infectious dose models have been developed that allow for spatial variation of the pathogen's distribution in the environment as well as multiple transmission routes (Gao et al., (2020)). In addition to airborne transmission, which was implicitly assumed in models mentioned above, these models consider transmission via droplets (i.e., larger respiratory particles that do not remain airborne) and fomites (i.e. contaminated objects). The inclusion of different transmission routes allows for increased granularity of the spatial and temporal dynamics of respiratory disease pathogens in their environments. In an early example of this model family, Nicas and Sun model virus-laden aerosols to be evenly distributed in a room, while viruses in droplets only distribute near the infectious individual in their respiratory cone puff (Mark Nicas \& Sun, 2006). The distribution of 
medRxiv preprint doi: https://doi.org/10.1101/2021.04.12.21255349; this version posted April 19, 2021. The copyright holder for this preprint

(which was not certified by peer review) is the author/funder, who has granted medRxiv a license to display the preprint in perpetuity.

It is made available under a CC-BY-NC 4.0 International license .

The multi-dimensional challenges of controlling SARS-CoV-2 transmission in indoor spaces

virus on fomites in turn depends on the deposition of these viral-laden droplets and may accumulate in time depending on the duration of stay of the infectious individual. This framework is formulated by discrete events and can be expanded on the details of the various processes involved, such as pathogens emission, pathogens survival in the environment, recipients' uptake and causation of infection (i.e. Atkinson \& Wein (2008), Li et al. (2009), and Spicknall et al. (2010)). Several event-based multiple routes infectious dose models have been built for COVID-19 (Arav et al. (2020), Gao et al. (2020)), which shed lights on how dominant routes depend on the duration and distance of infectious contacts. However, transmission is modelled as a static event between infected and susceptible individuals and ignores the dynamic nature of human interactions and its impact on exposure. Combining detailed pedestrian models with viral transmission models could counter this issue.

\subsection{Simultaneous modelling of individuals movement behaviour and SARS-CoV-2 transmission}

Pedestrian movement models have been integrated with viral transmission models before. Sallah et al. (2017) built a mathematical model that combines a graphic based mobility model and a SIR model to predict the spread of cholera in Haiti. While this model simulated the spread on (sub)national levels, other models are focussed on smallscale transmission, such as in indoor spaces. Harweg et al. (2020), Xiao et al. (2020), Fang et al. (2020), Romero et al. (2020), Ronchi et al. (2020) and Xu \& Chraibi (2020) developed hybrid models that combine microscopic forcebased models for simulating pedestrian dynamics with viral transmission models. Most often, the distance and duration of, what is considered an infectious contact, is predefined. The first group of hybrid models estimate the exposure time, as it relates to different definitions of 'risky contacts'. In the case of Xiao et al. (2020) a force based model was built to model pedestrian movement and the total duration of risky contacts was calculated to assess the impact of interventions such as shortening opening hours. Similarly to Fang et al. (2020), the duration of risky contacts is calculated based on cut-off distance, although different cut-off distances were assumed for breathing and coughing (one meter and two and a half meters respectively). Ronchi et al. (2020) classified exposure into five types with different distances which reflect different transmission mechanisms. The exposure time for each type of exposure was calculated to show the general exposure risk in the same indoor space.

The second group of hybrid models estimates infection probabilities, either by defining a probability per risky contact or assuming infection probabilities to be linearly related to exposure time. Fang et al. (2020) applied an infection probability curve that increases with the duration of the contact and assumed that people can get infected only when they have close contact with infectious individuals (less than one meter), while Bouchnita \& Jebrane (2020) assumed a cut-off distance of two meters. The total exposure time is calculated based on cut-off distance and compared to a confirmed duration within which close contact will definitely cause infection. The relation between exposure and infection is however hard to calibrate against epidemiological data and often not done explicitly.

Most hybrid models presented above predominantly assume contact transmission and ignore indirect transmission routes such as via aerosols and fomites. We will add to the state-of-the-art by developing an individual based model that combines a pedestrian movement model and a multi-route transmission model. By allowing for spatial and temporal heterogeneity in both human behaviour and viral spread, we aim to better understand the impact of human behaviours on transmission risks.

\section{Modelling methodology}

This section presents the modelling methodology. First, the overall modelling philosophy is elaborated upon in section 3.1. Accordingly, section 3.2 details the high-level pedestrian activity choice behaviour models, which comprise of an activity, destination, and departure choice assignment models. Section 3.3 continues with a description of the operational movement model, in particular Nomad. The last section (3.4) provides an overview of the epidemiological model that forms the last part of the modelling chain.

\subsection{Combining choice behaviour, movement dynamics and virus spread}

Section 2 indicates that a combined pedestrian movement dynamics - epidemiological model is required to model the transmission of SARS-CoV-2 in more detail. This research has designed and implemented a combined model coined PeDViS. This model chains an expert-driven strategic choice model with an existing microscopic pedestrian simulation model (i.e. Nomad) and an epidemiological model for Quantifying Viruses in Environments (i.e., QVEmod), see figure 1. 
medRxiv preprint doi: https://doi.org/10.1101/2021.04.12.21255349; this version posted April 19, 2021. The copyright holder for this preprint

(which was not certified by peer review) is the author/funder, who has granted medRxiv a license to display the preprint in perpetuity. It is made available under a CC-BY-NC 4.0 International license.

The multi-dimensional challenges of controlling SARS-CoV-2 transmission in indoor spaces

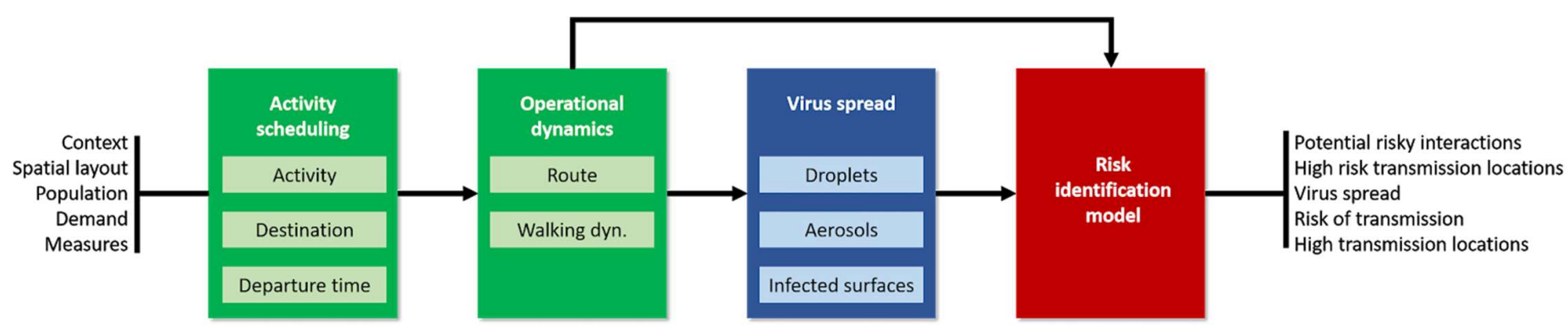

Figure 1. Model chain to simulate SARS-CoV-2 transmission in indoor spaces

The first model in the modelling chain transforms user input regarding the context, spatial layout, population, and demand into a set of personalized activity schedules. The strategic choice model consists of multiple sub-models, which jointly determine the activity choices, destination choices, and departure time choices of each pedestrian in the simulation model. In order to derive the personal schedules, the strategic choice model also assigns personal characteristics to each agent. Here, user-specified measures to limit SARS-CoV-2 transmission that impact activity choices are taken into account, for example the availability of toilets and paying at the table.

The second model uses the set of activity schedules and the list of personalized characteristics to determine the operational movement behaviour of each individual. The operational movement behaviour features two submodels, which for each activity in a pedestrian's activity schedule determine the (best) route towards each destination and their walking dynamics (i.e. walking velocity and acceleration) along the route. Both route and operational walking dynamics models take user-specified measures to limit SARS-CoV-2 transmission in their indoor spaces into account which impact the operational walking dynamics, for example the impact of physical distancing on collision avoidance behaviour and larger distances between queuing pedestrians. The result of the second model is a set of fully detailed trajectory for each of the individuals within the space.

The third model (i.e., QVEmodl) uses these trajectories, combined with epidemiological attributes of the individuals (most notably the infectious status of individuals), to simulate the spread of the virus in the environment and the extent to which susceptible individuals in the same space get exposed to it. How SARS-CoV-2 is distributed over time and in space is modelled as the accumulation of the virus in the environment, both in the air and on surfaces. This is informed by empirical data on the stability of both the virus and the airborne particles (i.e., droplets or aerosols) that carry it. Susceptible individuals may get exposed to the virus by inhaling or touching contaminated surfaces (see section 3.4). The result of this last modelling step is the virus load at any location in the indoor space at each moment in time and every individual's exposure to the virus via three transmission routes.

This spatial and temporal distribution of SARS-CoV-2 is accordingly used by the risk assessment model. This model identifies the risk of becoming infected with SARS-CoV-2 for each individual based on the total amount of SARS-CoV-2 they came into contact with during their stay in the space. This module further determines various other indicators that are helpful to space managers to identify the overall potential for SARS-CoV-2 transmission in their spaces. Two examples thereof are the number and location of interactions that are associated with relatively high virus exposure. The latter depends on both the duration and the proximity of a contact, as well as the time an infectious person has been present in the space before the contact took place. How these three determinants of infection risk relate to each other is described in the results section.

\subsection{Description activity scheduler}

The background section identified that there is limited work featuring the generic modelling of activity choice behaviour in buildings. Most activity assignment models are very specialized for certain types of buildings, predominantly offices. Thus, the authors have decided to develop a new pragmatic data-driven activity assignment model. Here, data-driven refers to the fact that the user has to enter the details of their specific scenario in order to start the assignment model. This data-driven route has been adopted in order to allow model users as much flexibility as possible regarding the specification of the dynamics that take place in their particular indoor space.

Figure 2 displays the functioning of the generic activity assignment model. This model comprises four parts, namely the generation of the groups, the visit characteristics, the person characteristics and the activity schedule. 
medRxiv preprint doi: https://doi.org/10.1101/2021.04.12.21255349; this version posted April 19, 2021. The copyright holder for this preprint

(which was not certified by peer review) is the author/funder, who has granted medRxiv a license to display the preprint in perpetuity.

It is made available under a CC-BY-NC 4.0 International license .

The multi-dimensional challenges of controlling SARS-CoV-2 transmission in indoor spaces

Each consecutive step further specifies the behaviour of the agents. Below these four elements of the activity scheduler have been further detailed.

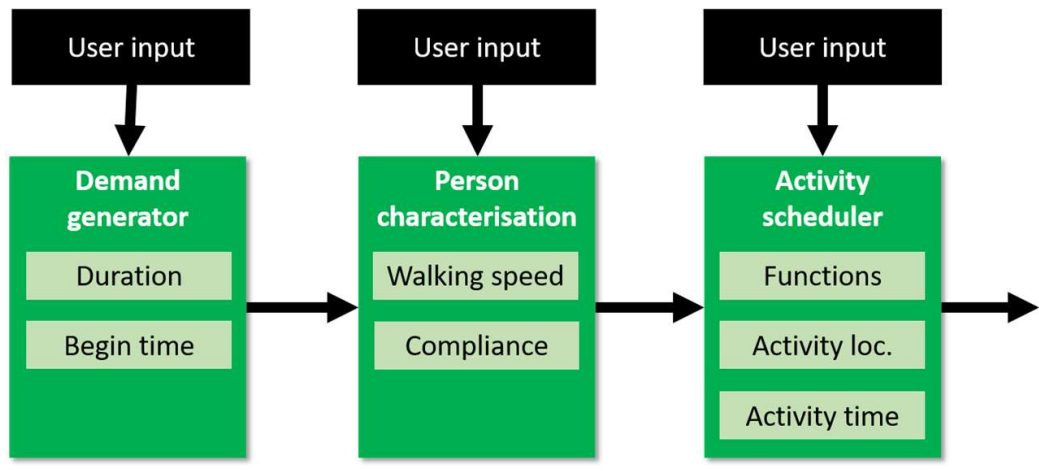

Figure 2. Illustration of the activity generation module

\subsubsection{Visit characteristics}

The activity duration and start time are dependent on the context. Under physical distancing restrictions, many venues control the number of individuals in the venue by means of reservations. As a result, the venue owners have detailed information on which (groups of) individuals will be present in the venue at what moment in time. In order to correctly model the overall demand, the user is requested his knowledge regarding the demand and average visit characteristics. In particular, they identify the opening times of the venue, the average duration of all visits, and the estimated demand per hour in which the restaurant is open. Accordingly, the demand generator determines at each time step whether new individuals need to be created. Here, new individuals are generated if $P($ draw $)<$ timestep simulation / time period demand* demand per hour. Consequently, the entrance demand is equally spread across each of the time periods for which the demand has been specified. Afterwards, each individual is assigned a similar visit duration. More sophistication is possible, by also drawing the visit duration from a probability distribution.

\subsubsection{Person characteristics}

Nomad is a microscopic simulation model that allows for the modelling of heterogeneous crowds. Often distributions of the most essential movement characteristics are assumed to model heterogeneous crowds. At entrance of the simulation, the characteristics of each individual are drawn from a gaussian distribution per characteristic. Here, no correlation between personal characteristics is accounted for. One can for instance vary walking speed, the size of individuals, reaction time and compliance to regulation. In this paper, we are only varying the walking speed slightly. The other characteristics are all statically assigned (compliance $=1$, size $=0.4 \mathrm{~m}$, reaction time $=0.4$ seconds). Also here, more sophistication is possible, by also drawing the other characteristics from a distribution.

\subsubsection{Activity scheduler}

The exact main activity of individuals is very dependent on the context. Yet, in many contexts, a pedestrian will have one location at which the pedestrian is located for an elongated period of time (e.g. office, restaurant table, theater seat). Because of the long duration of a pedestrian's stay at this location, this location is often person specific for a certain period of time. Other individuals will not sit at this location while the individual of focus is in the building. For simplicity, we do not (yet) assume that individuals at the main activity location occupy their seats at approximately the same moment in time. The activity location is randomly drawn from the set of available seats at the moment in time that an individual is created at one of the entrances of the simulation.

In many contexts, pedestrians visit various functional spaces whilst they are moving towards their main activity, stay at their main activity and are moving towards the exit. In restaurants, individuals put their coat on the coat rack, visit the toilet, and pay at the register. These intermediate activities are typically less important and are partly governed by the main activity location and visit characteristics. The user provides information regarding the available intermediate destinations and also identifies how often these are frequented during the visit.

For now, no limitations have been implemented in the assignment of main and intermediate destinations. Future research will further implement dependencies in the selection and ordering of activities. 
medRxiv preprint doi: https://doi.org/10.1101/2021.04.12.21255349; this version posted April 19, 2021. The copyright holder for this preprint

(which was not certified by peer review) is the author/funder, who has granted medRxiv a license to display the preprint in perpetuity.

It is made available under a CC-BY-NC 4.0 International license .

The multi-dimensional challenges of controlling SARS-CoV-2 transmission in indoor spaces

\subsection{Description routing and movement dynamics model - Nomad}

Nomad is a microscopic simulation model that simulates the operational movement dynamics of individuals. In particular, the walker model is implemented in PeDViS (see equations 1 - 6). The result of Nomad is a set of trajectories pertaining the coordinates and velocity of each individual in the simulation at each timestep of the simulation.

\subsubsection{Routing model - Nomad}

The routing model of Nomad is utility-based and developed by Hoogendoorn and Bovy (2004) and makes use of the minimum walking cost principle. In essence, individuals balance their desire to move towards their destination with other needs, for instance travel time, physical effort, closeness to attractive sights. In this implementation of Nomad, only the need to avoid static obstacles in their surroundings is accounted for. Using a floor field approach, the walking costs are computed for the complete walkable area of the pedestrian infrastructure. In particular, a grid of rectangular cells $(0.1 \times 0.1 \mathrm{~m})$ is adopted, each of which contains a cost value. Based on the static cost map, the desired direction of an individual in the centre point of each cell can be determined using the steepest descent method. Here, individuals are walking orthogonal to the equi-cost lines. A continuous representation of the desired direction can accordingly be calculated on the fly by means of linear interpolation between the actual location of an individual and the four nearest locations for which the desired direction was already computed. See Figure 3 for an illustration of three trajectories that could be the result of this routing model.

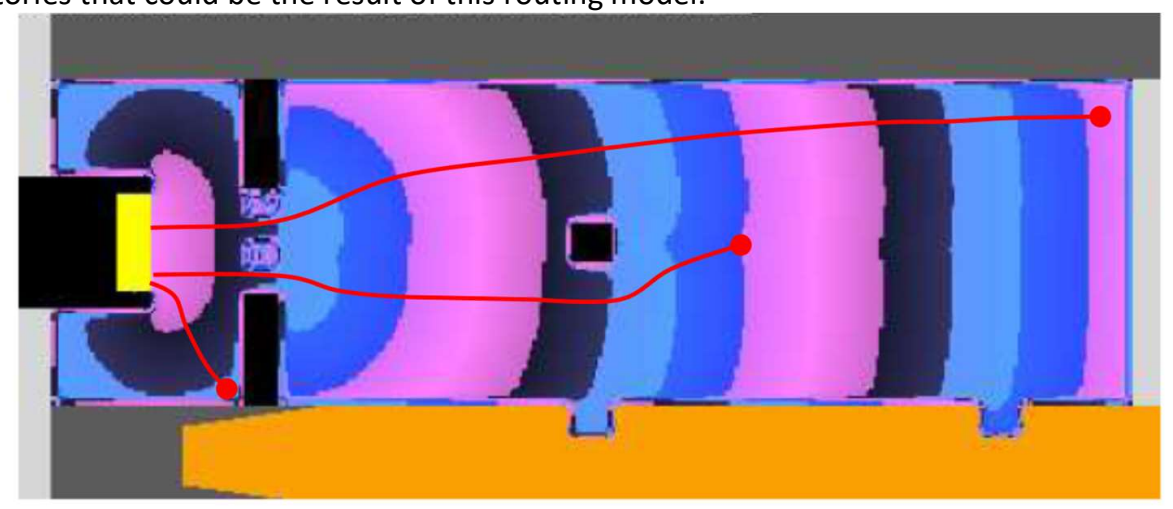

Figure 3. Floorfield Nomad with three resulting trajectories (Floorfield image from Campanella et al. (2009))

\subsubsection{Operational dynamics Nomad}

Underneath, the main elements of this model are briefly introduced. For an in-depth discussion of the walker model and its calibration one is referred to Campanella (2016).

$$
\begin{aligned}
& \frac{d}{d t} \vec{r}_{p}(t)=\vec{v}_{p}(t) \\
& \frac{d}{d t} \vec{v}_{p}(t)=\vec{a}(t) \\
& \vec{a}(t)=\vec{a}_{c}(t)+\vec{a}_{p}(t)+\vec{\varepsilon}(t) \\
& \vec{a}_{c}(t)=\vec{a}_{s}(t)+\vec{a}_{a}(t)+\vec{a}_{p q}(t) \\
& \vec{a}_{s}(t)=\frac{\left(v_{0}(t) \cdot \vec{e}_{g}\right)-\vec{v}(t)}{\tau} \\
& \vec{a}_{p q}(t)=-\vec{e}_{p q} \cdot A_{0} \cdot e^{\frac{-d_{p q}}{d_{i}}} \\
& \vec{a}_{O}(t)=-\vec{e}_{O} \cdot A_{O} \sum_{o \epsilon O} \begin{cases}1 & \text { for } 0<d_{p O}<d_{0} \\
1-\left(d_{p O}-d_{0}\right) & \text { for } d_{0}<d_{p O}<2 d_{0} \\
0 & \text { for } d_{p 0}>2 d_{0}\end{cases}
\end{aligned}
$$


medRxiv preprint doi: https://doi.org/10.1101/2021.04.12.21255349; this version posted April 19, 2021. The copyright holder for this preprint

(which was not certified by peer review) is the author/funder, who has granted medRxiv a license to display the preprint in perpetuity.

It is made available under a CC-BY-NC 4.0 International license.

The multi-dimensional challenges of controlling SARS-CoV-2 transmission in indoor spaces

Within Nomad, the movement of pedestrians is assumed to be due accelerations that are caused by signals and forces that pedestrians are subjected to. These accelerations are partly controlled $\vec{a}_{c}(t)$ and partly uncontrolled $\vec{a}_{p}(t)$. A noise term $\varepsilon(t)$ comprises the last part of the accelerations, which simulates the natural fluctuations of pedestrian movements. Together these three acceleration reactions shape the acceleration of an individual.

The controlled reaction $\vec{a}_{c}(t)$ is the result of the individual's desire for a certain velocity $\vec{v}_{0}$ (i.e. speed and direction), the physical interaction with other pedestrians, and surrounding objects. Here, $\vec{a}_{s}(t)$ represents the path straying component, $\vec{a}_{p q}(t)$ the pedestrian interaction component and $\vec{a}_{O}(t)$ represents the obstacle interaction component (see eq. 4-7). $A_{O}, A_{0}, d_{i}$, and $d_{0}$ represent parameters that respectively determine the strength of the pedestrian interaction and obstacle interaction forces. Please note, the parameters of Nomad do not influence the movement dynamics of the simulated crowd to a similar extent, since not all forces are always present. Forces with respect to obstacles and pedestrians are only significant if the pedestrian resides within range of obstacles or pedestrians.

\section{Path straying}

When walking, individuals have a desired velocity (combination of speed and direction) that is aligned along the optimal route and speed towards the destination of the pedestrian. Nomad assumes that deviations from the optimal speed and/or direction incur increasing costs. Therefore, pedestrians always attempt to return to their optimal velocity ${\underline{v_{0}}}_{0}$. Tau represents the relaxation term, which identifies the desire of pedestrians to keep moving $\vec{e}_{g}$ towards their goal along their intended global path. The smaller $\underline{\tau}$, the longer the time that individuals require to alter their speed and direction.

\section{Interaction with other pedestrians}

Nomad models the collision avoidance behaviour by means of a non-cooperative game theory strategy (Hoogendoorn \& Bovy, 2002). Pedestrians minimize walking costs by anticipating the movement of others and themselves. Besides that, Nomad's reaction to other pedestrians is anisotropic. That is, pedestrians have a limited ellipse area in which they interact with other pedestrians and obstacles. The interaction costs of an interaction between two individuals is the inverse of their heart-to-heart distance. Thus, the closer individuals are, the larger the collision avoidance forces, which are pointing in the direction opposite of the interaction. Here, $A_{0}$ identifies the interaction strength, $d_{i}$ interaction distance, $d_{p q}$ the anticipated distance and $\vec{e}_{p q}$ the unit vector pointing in the direction of the other pedestrian.

\section{Interactions with obstacles}

The strength of the interaction with obstacles is dependent on the distance to the obstacle $d_{p} O$, the interaction strength of objects in general $A_{O}$ and the direction of the nearest obstacle $\vec{e}_{O}$. Here, a step-based approach is used, where obstacles nearby have a very large influence and obstacles outside a range of influence $\underline{d_{0}}$ not influence individuals' movement dynamics at all. Two distance thresholds $\left(\underline{d_{0}}\right.$ and $\left.\underline{2 d_{0}}\right)$ are used to govern the gradual linear decline of the obstacle avoidance force. As a result of the formulation, agents within Nomad only react to obstacles when they are really close to the obstacle. This is an advantage in case of the modelling of indoor spaces, where lots of obstacles are present.

\subsection{Description virus spread model (QVEmod)}

A spatially explicit agent based model was developed that simulates the emission of viruses by infectious individuals, how these subsequently spread in space and time through the environment, and eventually may get taken up by susceptible individuals. The model consists of seven steps (Figure 4):

i. The infectious individual emits virus into the air through virus-laden aerosols and virus-laden droplets (further referred to as aerosols and droplets, depending on their size)

ii. Droplets deposit onto surfaces.

iii. Viruses lose infectivity at a rate that depends on its state in the environment (airborne or on surfaces).

iv. Viruses in the droplets and aerosols travel and diffuse.

v. Susceptible individuals can get exposed to viruses through inhaling air with viral-laden droplets and aerosols.

vi. The infectious individual contaminates surfaces by touching objects in the space (e.g., tables, chairs, and menus). 
medRxiv preprint doi: https://doi.org/10.1101/2021.04.12.21255349; this version posted April 19, 2021. The copyright holder for this preprint

(which was not certified by peer review) is the author/funder, who has granted medRxiv a license to display the preprint in perpetuity.

It is made available under a CC-BY-NC 4.0 International license.

The multi-dimensional challenges of controlling SARS-CoV-2 transmission in indoor spaces

vii. Susceptible individuals can be exposed by touching contaminated surfaces (fomites).

A description of the state variables and initialization processes is provided in sections 3.4.1-3.4.2. Subsequently, the submodels associated with the seven core steps are described in detail below in sections 3.4.3.1-3.4.3.7. The parameterisation of the model is described in 3.4.4.

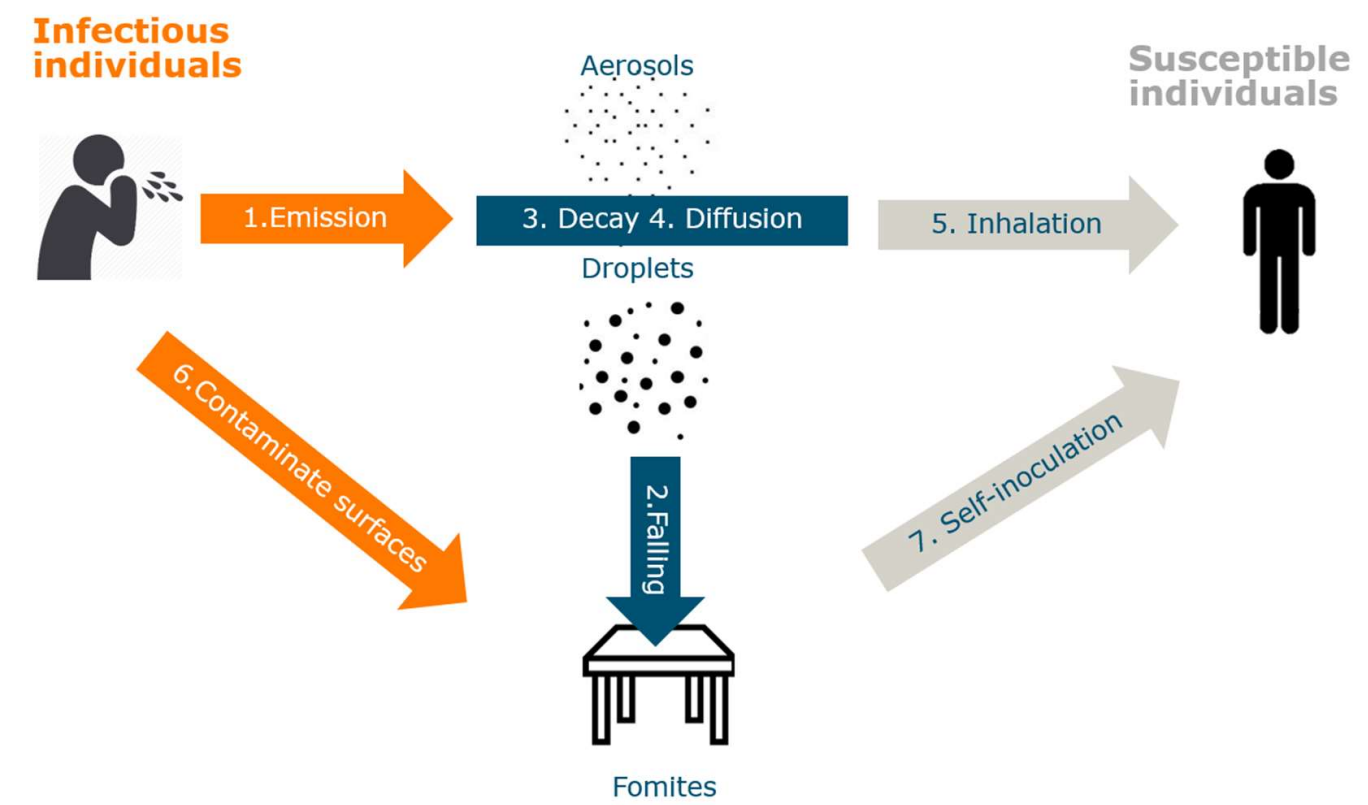

Environment

Figure 4. Schematic of sub-models of epidemiological model

\subsubsection{State variables and scales}

QVEmod has two classes, the agents (individuals) and the environment. Both classes acquire virus over the course of a simulation. Individuals have 4 variables: virus contamination on hands $\left(V_{\text {hand }}\right)$, and exposure to aerosols, droplets, and fomites ( $\left.E_{\text {aerosols }}, E_{\text {droplets }}, E_{\text {fomites }}\right)$. The environment is composed of two air layers and one surface layer, all of which are two dimensional grids. Each layer has a coordinate variable and a variable to record the virus contamination in space ( $\left.V_{\text {aerosols }}, V_{\text {droplets, }}, V_{\text {fomites }}\right)$, in which $V_{\text {fomites may relate to high-touch surfaces }}$

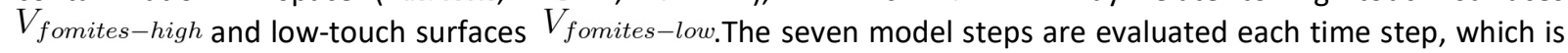
defaulted at one minute (configurable). One-minute time steps provide enough accrued time for virus spread and other modeled behaviours to occur without reaching computational limitations. The environment is divided into equally sized grid cells, the size of which is set to $0.25 \mathrm{~m}^{2}$ : a proximate of the space occupied by a single person. This too can be altered to meet the needs of the user.

\subsubsection{Input and initialization}

QVEmod needs input for individuals' identifiers, and movement scripts, both of which are generated by the activity scheduler and Nomad model. The latter contain the whereabouts and actions of each individual at each simulated time step, hence containing the duration of stay for each individual. In addition, the individuals' infectiousness scaler is generated randomly. Under the default setting only one infected individual enters in a simulation with an infectiousness scaler set to unity. Super shedders can be included as well, through the generation of a higher infectiousness scaler. In the default, an individual's emission rate is based on breathing induced emission rates. Other respiratory activities can be incorporated through the activity infectiousness scaler (Table 1). For environments, the size of the indoor space (width and length), the location, size, and material of objects in the environment, and for each surface whether it is high-touch or low-touch. In addition, interventions such as wearing masks, cleaning surfaces, and 1.5 meter physical distancing can be included as input to the model, which incurs changes in the activity scheduler, environment variables or NOMAD model parameters respectively. (See more details in 4.2). 
medRxiv preprint doi: https://doi.org/10.1101/2021.04.12.21255349; this version posted April 19, 2021. The copyright holder for this preprint

(which was not certified by peer review) is the author/funder, who has granted medRxiv a license to display the preprint in perpetuity.

It is made available under a CC-BY-NC 4.0 International license .

The multi-dimensional challenges of controlling SARS-CoV-2 transmission in indoor spaces

All state variables are initialized at zero, both for the environment ( $V_{\text {droplets }}, V_{\text {aerosols }}, V_{\text {fomites}}$ ) and for individuals' exposure to the virus through either of the three transmission routes ( $E_{\text {droplets }}, E_{\text {aerosols }}, E_{\text {fomites }}$ ). Susceptible individuals are initialized with a virus contamination of zero on their hands ( $V_{\text {hands }}$ ), whereas this parameter is set to one for infectious individuals.

\subsubsection{Submodels}

Here, we describe the details of each of the seven sub-models (Figure 4). All seven events in Figure 4 are continuous processes and modelled in small time step simulation. Hence the equations below require time steps of simulation $(\Delta t)$ to be small (1 minute as the default compared to per hour as the units of parameters).

\section{Infectious individuals emit virus into the air}

Infectious individuals emit viral-laden particles by speaking, coughing, or sneezing. The total amount of virus emitted and the partition of aerosols and droplets varies by respiratory activity. Infectious individuals are initially assumed to emit virus at a constant rate. The activity scaler scales the emission rate relative to the emission rate under breathing condition. In addition, the infectiousness scaler scales different infectiousness of individuals relative to a typical emitter. The unit of viral quantities used in this model therefore follows from the typical emission of one typical infectious individual per time unit (default: hour). The total viruses that infectious individuals shed into the air are distributed over aerosols and droplets (eq. 8):

$$
V_{i}(t)=V_{i}(t-\Delta t)+\omega \delta \sigma p_{i}\left(1-F E_{i}\right) \Delta t
$$

where $i$ denotes the transmission route aerosols or droplets and $V_{i}(t)$ represent viruses in the aerosols and droplets at time $t . \omega$ represents the rate at which a typical infectious individual emits virus, and is scaled to 1 per hour. $\delta$ represents the activity infectiousness scaler for scaling the heterogeneity in emission rates during different respiratory activities, which may be weighted based on the proportion of time an individual engages in a specific behavior. $\sigma$ represents the individual infectiousness scaler for scaling the individual heterogeneity in emission rates. $p_{i}$ represent the proportion of viruses emitted in the form of aerosols and droplets. The two proportions ( $p_{\text {aerosols }}, p_{\text {droplets }}$ ) add up to $1 . F E_{i}$ represent the filter efficiency of face masks against droplets or aerosols.

\section{Viral-laden droplets fall onto surfaces}

Viral-laden droplets can fall onto surfaces through sedimentation. The resulting contaminated surfaces are called fomites. We assume only high-touch surfaces acquire viruses from droplets, while low-touch surfaces only act as vectors and acquire viruses only when being touched by contaminated hands. Viruses are assumed stationary and evenly distributed within the grid cells. The process of viruses transfer from droplets onto fomites is modelled as in eq. 9 , where $\mu_{\text {droplets }}$ represents the deposition rate of viral-laden droplets:

$$
V_{\text {fomites }}(t)=V_{\text {fomites }}(t-\Delta t)+V_{\text {droplet }}(t-\Delta t) u_{\text {droplets }} \Delta t \text {. }
$$

\section{Virus decay in the air and on surfaces}

Decay rates of SARS-CoV-2 vary in aerosols and on different surface materials. Viruses undergo an exponential decay in the environment. Viruses-laden aerosols lose infectivity with a constant rate while floating in the air. In addition, higher air change rate $(\mathrm{ACH})$ indoors can increase the reduction of the virus in the aerosol. Conversely, viruses-laden droplets deposit rapidly, which justifies the inactivation of viruses while airborne in droplets to be neglected. Decay in the droplet layer is therefore driven by the deposition rates. On the fomites, viruses decay with a constant rate which depends on the fomite's material. The aerosols, droplets, and fomites decay equations are identified by eq. 10-12, where $u_{\text {aerosols, }}, u_{\text {droplets }}, u_{\text {fomites }}$ represent decay rate of viruses in aerosols, the deposition rate of viralladen droplets, and decay rate of virus on fomites respectively:

$$
\begin{aligned}
& V_{\text {aerosols }}(t)=V_{\text {aerosols }}(t-\Delta t) e^{-u_{\text {aerosols }} \Delta t-A C H \Delta t} \\
& V_{\text {droplets }}(t)=V_{\text {droplets }}(t-\Delta t) e^{-u_{\text {droplets }} \Delta t} \\
& V_{\text {fomites }}(t)=V_{\text {fomites }}(t-\Delta t) e^{-u_{\text {fomites }} \Delta t}
\end{aligned}
$$


medRxiv preprint doi: https://doi.org/10.1101/2021.04.12.21255349; this version posted April 19, 2021 . The copyright holder for this preprint

(which was not certified by peer review) is the author/funder, who has granted medRxiv a license to display the preprint in perpetuity.

It is made available under a CC-BY-NC 4.0 International license.

The multi-dimensional challenges of controlling SARS-CoV-2 transmission in indoor spaces

\section{Diffusion}

We solve a diffusion equation for the number of virions $V_{(x, y, t)}$. To do so, we assume that all particles are well mixed in the volume of the grid cell, after which the aerosols start to diffuse in $x, y$ directions (see eq. 13). $\Delta x$ and $\Delta y$ represent the length unit of the cell (both $0.5 \mathrm{~m}$ in the default). Here, $D$ is the diffusion coefficient per cell size $\left(0.25 \mathrm{~m}^{2}\right)$ per time step:

$$
V_{(x, y, t)}=D \frac{\left(V_{(x-\Delta x, y, t-\Delta t)}+V_{(x+\Delta x, y, t-\Delta t)}+V_{(x, y-\Delta y, t-\Delta t)}+V_{(x, y+\Delta y, t-\Delta t)}-4 V_{(x, y, t-\Delta t)}\right) \Delta t}{\Delta x \Delta y}
$$

\section{Susceptible individuals inhale air with viral-laden droplets and aerosols}

Human exposure to the virus from aerosols and droplets at each time step is represented by people inhaling a portion of airborne viruses from the cell where they are. We calculated the inhaled viruses per time step and deducted the inhaled viruses from the environment. The inhalation of virus in the forms of aerosols and droplets is the ratio of human tidal volume per time step over the cell volume $(L)$. In this process, exposures to viruses from aerosols and droplets are calculated by eq. 14, where $E_{i}(t)$ represent recipients' exposure to the virus from route $i$ during $(t-\Delta t, t)$ timestep. $i$ denotes the transmission routes via aerosols or droplets. $\rho$ represents the inhalation rate. $F E_{i}$ represents the filter efficiency of face masks against aerosols or droplets.

$$
E_{i}(t)=V_{i}(t) \frac{\rho}{L}\left(1-F E_{i}\right) \Delta t
$$

\section{Infectious individuals contaminate surfaces}

Infectious persons can contaminate surfaces by interacting with them. Virus on people's hands can be transferred to surfaces (Winther et al., 2007). High-touch surfaces, such as tables, countertops, are initially assumed to be touched by proximate individuals at a constant rate, while low-touch surfaces, such as menus, ketchup are modelled as being touched specifically when needed (see the list of high touch surfaces in (CDC, 2021)). For high touch surfaces, the frequency of touching surfaces $\gamma$, transfer efficiency $\theta$, and the ratio of finger pads surface relative to the contaminated area $\pi$ determines the transfer load in a time step (eq. 15).

$$
\left.V_{\text {fomites-high }}(t)=V_{\text {fomites-high }}(t-\Delta t)+V_{\text {hand }}(t-\Delta t)\right) \gamma \theta \pi \Delta t
$$

However, for low-touch surfaces such as menu, cutleries, the touching behaviour is modelled specifically in the NOMAD model, hence the touching frequency is not needed in eq. 16.

$$
\left.V_{\text {fomites-low }}(t)=V_{\text {fomites-low }}(t-\Delta t)+V_{\text {hand }}(t-\Delta t)\right) \theta \pi \Delta t
$$

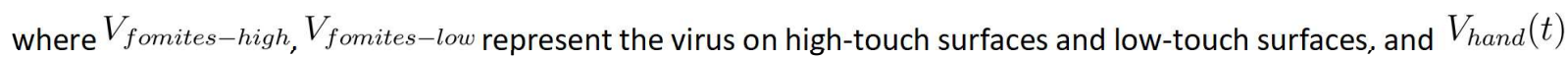
represents the virus on hands at time $t$.

\section{Susceptible individuals touch virus on the surfaces}

Human exposure to the virus from fomites is the amount of virus on fomites being picked up. The virus transfer from surfaces to hands occurs when people touch surfaces. Similarly, to hands contaminating surfaces, the virus transfer from surfaces to hands also varies over two types of surfaces (i.e.high-touch: eq. 17 and low-touch: eq. 18).

$$
\begin{aligned}
& E_{\text {fomites }}(t)=V_{\text {fomites-high }}(t-\Delta t) \gamma \theta \pi \Delta t \\
& E_{\text {fomites }}(t)=V_{\text {fomites-low }}(t-\Delta t) \theta \pi \Delta t
\end{aligned}
$$

where $E_{\text {fomites }}(t)$ represents susceptible individuals exposure to virus from fomites during $(t-\Delta t, t)$ timestep.

\subsubsection{Estimating infection risks}

QVEmod calculates individuals' exposure via three routes. The relationship between the number of viral particles someone is exposed to, and the risk of acquiring infection is likely to differ between transmission routes, because of different deposition locations (hands, lower and upper respiratory tract) and the viability of the virus, among others 
medRxiv preprint doi: https://doi.org/10.1101/2021.04.12.21255349; this version posted April 19, 2021. The copyright holder for this preprint

(which was not certified by peer review) is the author/funder, who has granted medRxiv a license to display the preprint in perpetuity.

It is made available under a CC-BY-NC 4.0 International license.

The multi-dimensional challenges of controlling SARS-CoV-2 transmission in indoor spaces

(Deng et al., 2020). We modeled the relationship between exposure and infection risk using an exponential doseresponse relationship (Nicas (1996))

$$
P=1-e^{-\left(\frac{E_{\text {aerosols }}}{k_{\text {aerosols }}}+\frac{E_{\text {droplets }}}{k_{\text {droplets }}}+\frac{E_{\text {fomites }}}{k_{\text {fomites }}}\right)}
$$

where $P$ represents an individual's probability of getting infected, $E_{\text {droplets }}, E_{\text {aerosols }}, E_{\text {fomites }}$ the individual's accumulated exposure via the three transmission routes and $k_{\text {aerosols }}, k_{\text {droplets }}, k_{\text {fomites }}$ the route specific exposure at which individuals have $63 \%$ chance of getting infected. The latter depends on the infectious dose $D_{\text {inf }}$, for which we consider recent estimates of the founding virus population size required to cause infection in a recipient host

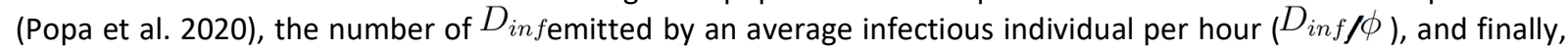
the proportion of viral particles someone is exposed to that reach the respiratory tract cells $\left(c_{\text {route }}\right)$ and thus contribute to the founding population.

$$
k_{\text {route }}=\frac{D_{\text {inf }}}{\phi * c_{\text {route }}}
$$

Here, $c_{\text {route }}$ is an unknown parameter and particularly hard to estimate. We therefore explore a range of different options in section 5.6 .

We then used the estimates for individual exposures to estimate the number of infections that occurred during a specific event: From each individual's cumulative exposure, the dose-response model provides an estimate of the probability that that individual acquired an infection during their stay in the indoor space. The total number of new infections that occurred during a specific scenario was estimated by drawing, for each individual in the simulation, a random number from a uniform distribution $[0,1]$. We compared this number to the individual's infection probability and assumed an infection if the individual's infection probability was larger than the number drawn. We repeated this 10,000 times to obtain a distribution of the number of infections that may have occurred. The mean of this distribution can be regarded as the event-specific reproduction number $\mathrm{R}$ : the average number of new infections that arose from one specific event with an infectious individual present.

\subsubsection{QVEmod parameter settings}

The parameter settings adopted for QVEmod are depicted in table 1. These reflect most recent insights pertaining to SARS-CoV-2 characteristics, and will be updated as new information comes available. For a detailed description of the parameterization, the reader is referred to appendix 1.

\subsection{Sensitivity of QVEmod}

The model assesses individuals' exposure over time and distinguishes the relative contribution of transmission routes to overall exposure in different settings as they arise from human interactions. To disentangle the interplay between the several factors that affect virus transmission, we will first illustrate the working of QVEmod for various types of static contacts. For this, one infectious individual is placed in a space with one susceptible individual. The cumulative exposure of the susceptible individual is recorded by route. Underneath, the impact of the three main factors of QVEmod is studied, namely the impact of i) the intensity of a contact (i.e., as determined by duration, distance, and time the infectious individual has spent indoors prior to the contact) (section 3.5.1), ii) respiratory activities (section 3.5.2), and iii) interventions implemented in the PeDViS model (section 3.5.3). 
medRxiv preprint doi: https://doi.org/10.1101/2021.04.12.21255349; this version posted April 19, 2021. The copyright holder for this preprint (which was not certified by peer review) is the author/funder, who has granted medRxiv a license to display the preprint in perpetuity.

It is made available under a CC-BY-NC 4.0 International license.

The multi-dimensional challenges of controlling SARS-CoV-2 transmission in indoor spaces

Table 1. Parameters for the transmission model

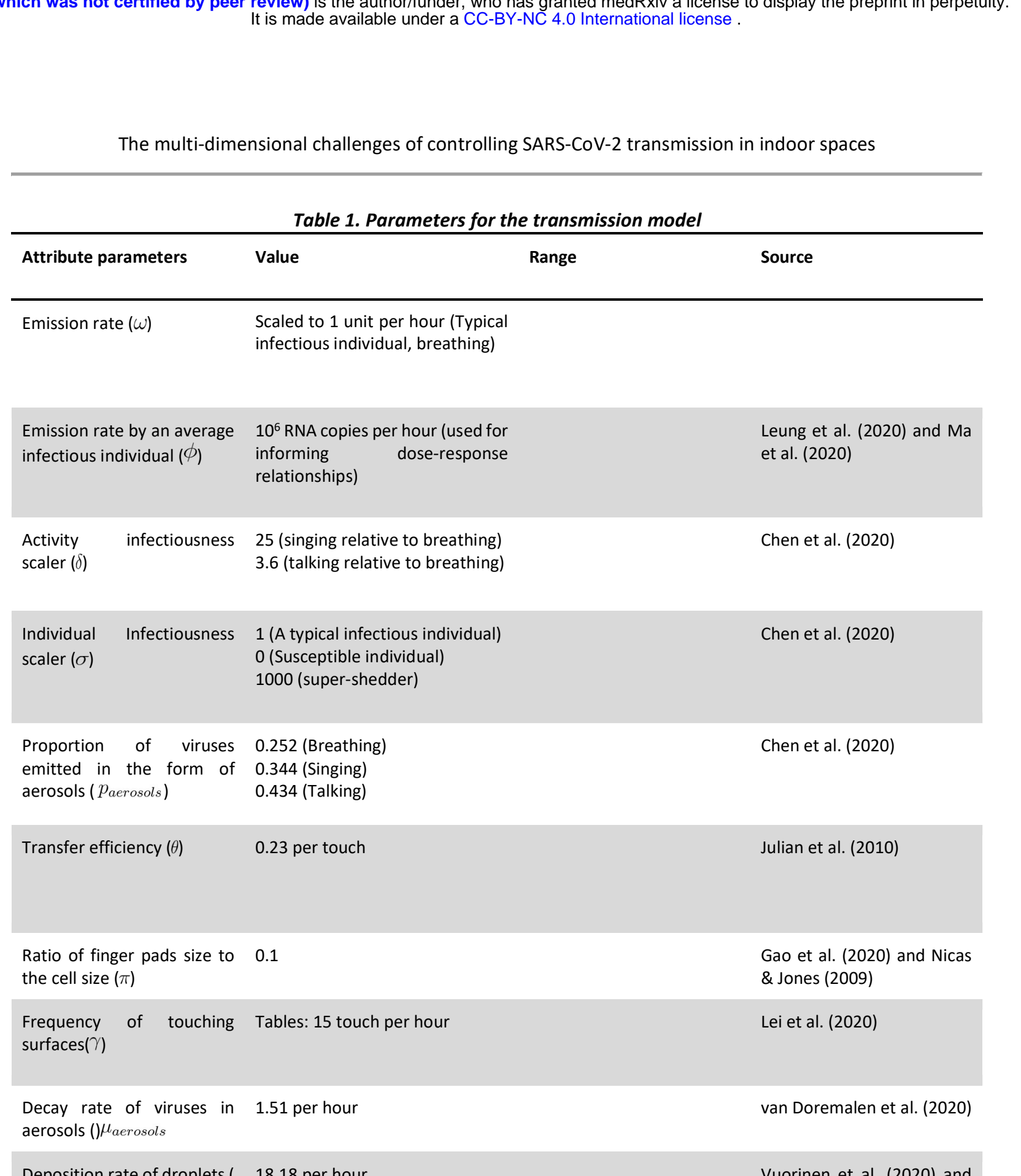
infectious individual, breathing)

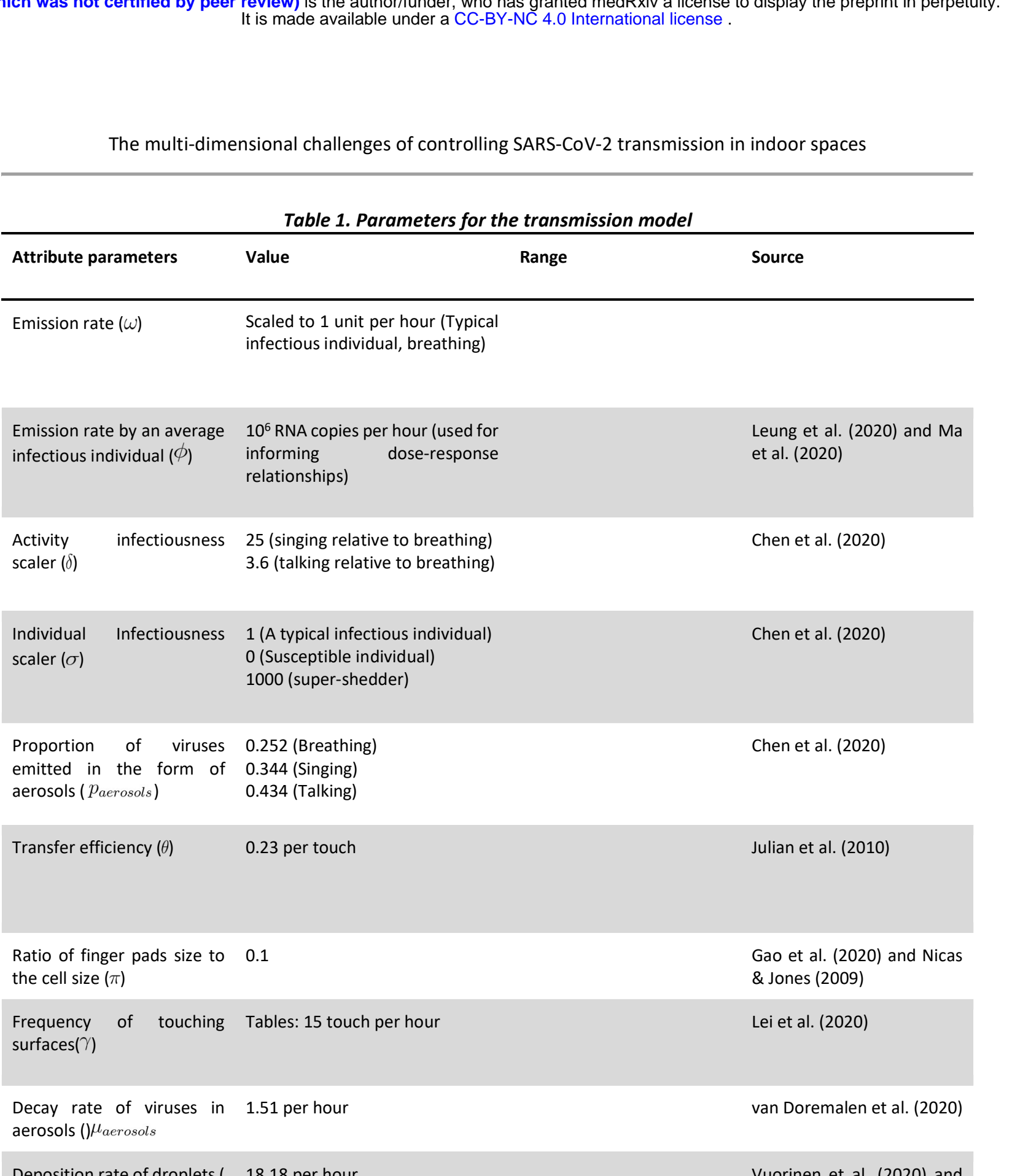

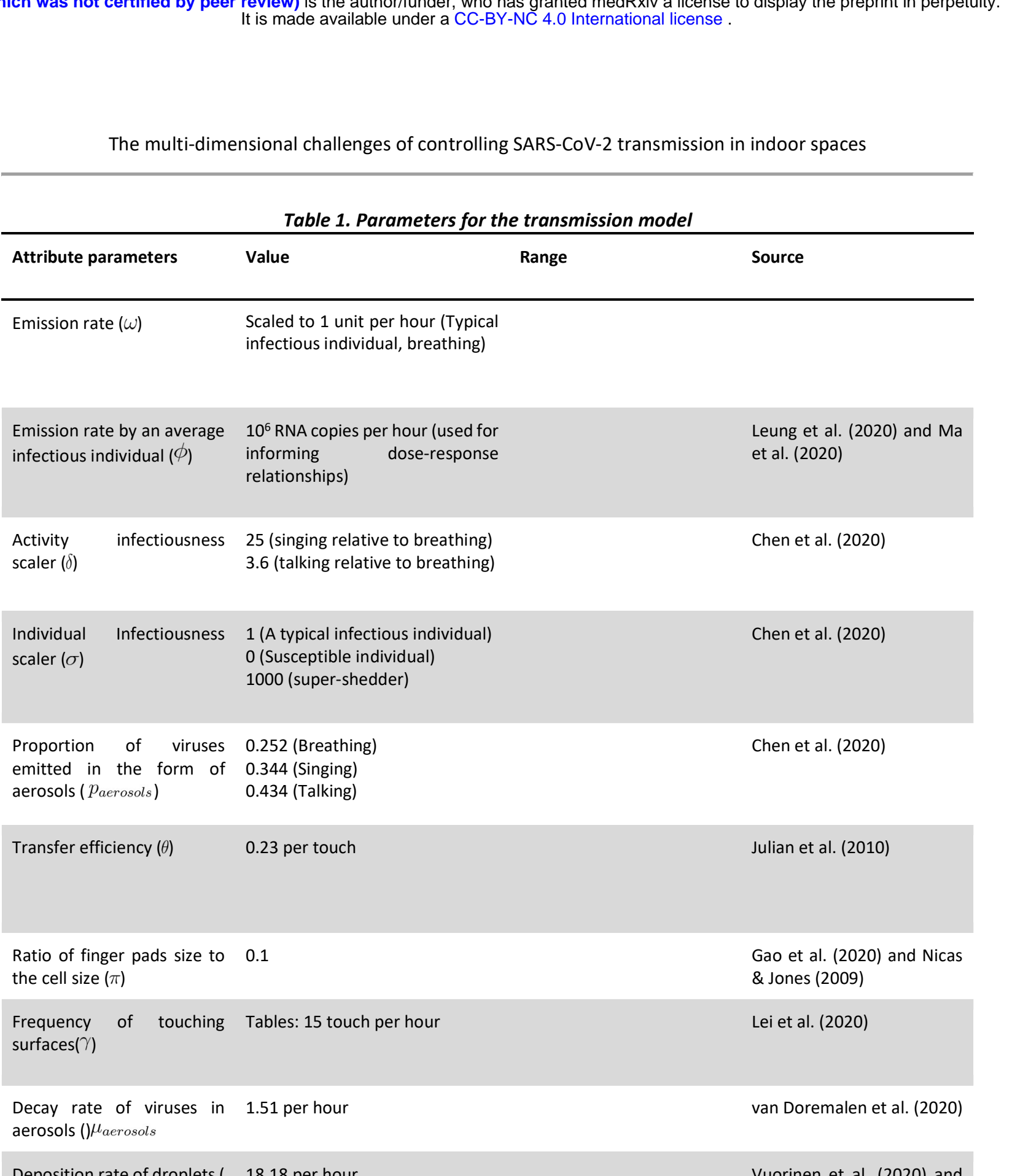

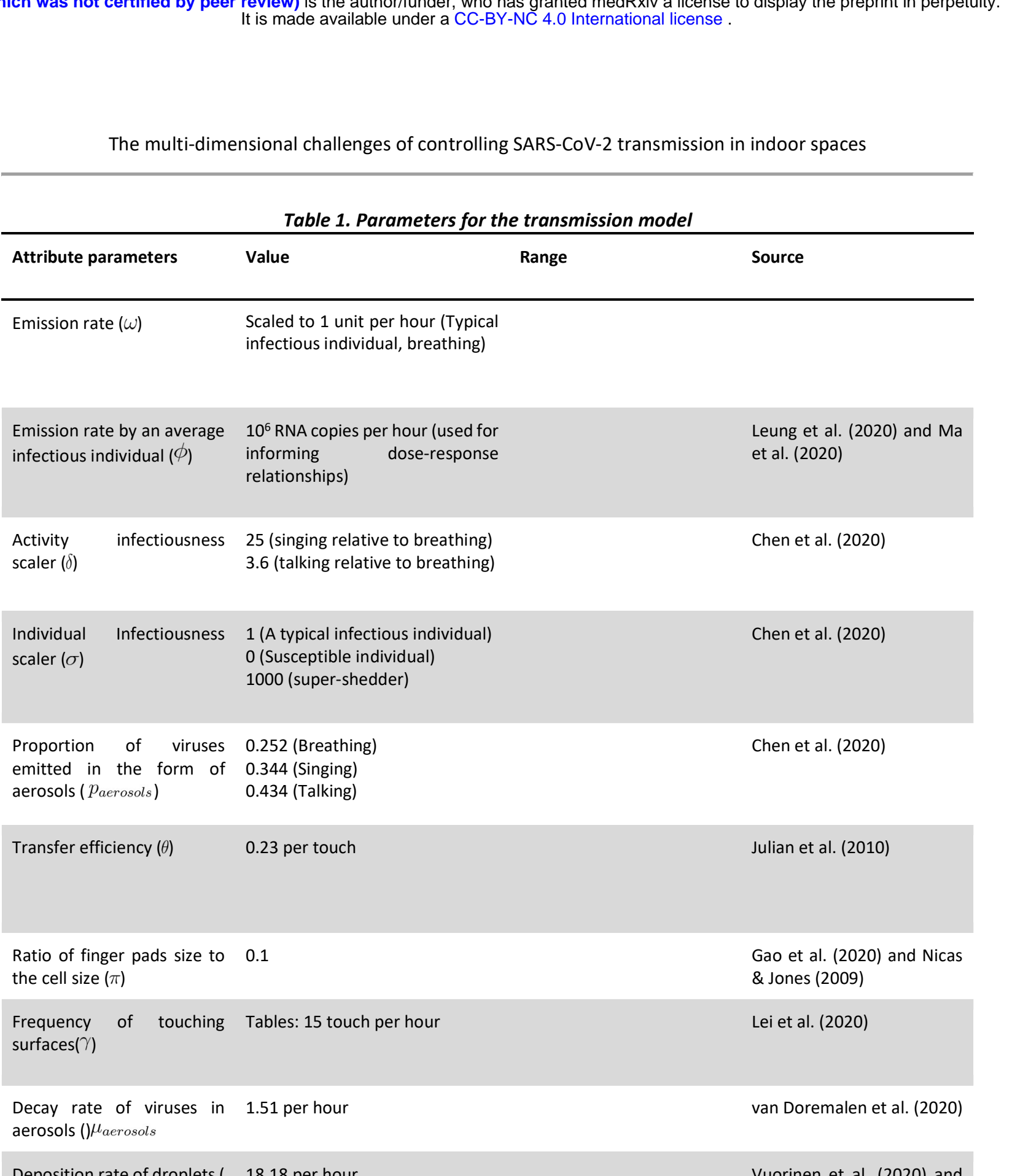

$\begin{array}{ll}\text { Deposition rate of droplets ( } 18.18 \text { per hour } & \text { Vuorinen et al. (2020) and } \\ \mu_{\text {droplets })} & \text { Xie et al. (2007) }\end{array}$

\begin{tabular}{|c|c|}
\hline $\begin{array}{l}\text { Diffusion coefficient of } 0.05 \mathrm{~m}^{2} / \mathrm{s} \\
\text { aerosol (D) }\end{array}$ & $\begin{array}{l}\text { Vuorinen et al. (2020) and } \\
\text { Gorbunov (2020) }\end{array}$ \\
\hline
\end{tabular}

$\begin{array}{lll}\begin{array}{l}\text { Decay rate of viruses on } \\ \text { surfaces }\left(\mu_{\text {surfaces }}\right)\end{array} & \begin{array}{l}\text { Wood: } 0.969 \text { per hour, } \\ \text { Cloth: } 0.275 \text { per hour, } \\ \text { Plastic: } 0.193 \text { per hour, } \\ \text { Steel: } 0.180 \text { per hour, } \\ \text { Glass: } 0.149 \text { per hour, } \\ \text { Paper: } 1.1 \text { per hour, } \\ \text { Copper: } 0.323 \text { per hour, } \\ \text { Cardboard: } 0.119 \text { per hour }\end{array} & \begin{array}{l}\text { Chin et al. (2020), Liu et al. } \\ \text { (2021) and Van Doremalen } \\ \text { et al. (2020) }\end{array} \\ \\ \begin{array}{ll}\text { Inhalation rate }(\rho) & \begin{array}{l}288 \text { L per hour (breathing, } \\ \text { talking) }\end{array}\end{array}\end{array}$


medRxiv preprint doi: https://doi.org/10.1101/2021.04.12.21255349; this version posted April 19, 2021. The copyright holder for this preprint

(which was not certified by peer review) is the author/funder, who has granted medRxiv a license to display the preprint in perpetuity.

It is made available under a CC-BY-NC 4.0 International license .

The multi-dimensional challenges of controlling SARS-CoV-2 transmission in indoor spaces

$432 \mathrm{~L}$ per hour (singing)

\begin{tabular}{lll}
\hline Volume of a cell $(\mathrm{L})$ & $125 \mathrm{~L}$ \\
\hline Infectious dose $\left(D_{\text {inf }}\right)$ & 1000 RNA copies & Popa et al. (2020)
\end{tabular}

\begin{tabular}{|c|c|c|c|}
\hline $\begin{array}{l}\text { The proportion of virions } \\
\text { reaching respiratory cells } \\
{ }_{\text {aerosols, }} C_{\text {droplets, }} C_{\text {fomites }}\end{array}$ & $\begin{array}{l}10 \% \text { (aerosols) } \\
10 \% \text { (droplets) } \\
1 \% \text { (fomites) }\end{array}$ & [1\% - 100\%] & $\begin{array}{l}\text { Zuo et al. (2020), Hinds } \\
\text { (1999), Kraay et al. (n.d.), } \\
\text { Adam et al. (2020). }\end{array}$ \\
\hline Air change rate $(\mathrm{ACH})$ & $\begin{array}{l}\text { Air in a room is replaced } 3 \text { times } \\
\text { per hour }\end{array}$ & [0 - 24] & CIRES (2020) \\
\hline $\begin{array}{l}\text { Face mask filter efficiency } \\
\text { aerosols }\left(F E_{\text {aerosols }}\right)\end{array}$ & $40 \%$ & [0\% - 90\%] & $\begin{array}{l}\text { Pan et al. (2020) and Ueki et } \\
\text { al. (2020) }\end{array}$ \\
\hline $\begin{array}{l}\text { Face mask filter efficiency } \\
\left.\text { droplets ( } F E_{\text {droplets }}\right)\end{array}$ & $10 \%$ of $F E_{\text {aerosols }}$ & & $\begin{array}{l}\text { Pan et al. (2020) and Ueki et } \\
\text { al. (2020) }\end{array}$ \\
\hline
\end{tabular}

\subsubsection{The impact of contact intensity on exposure}

First, we examine the impact of contact intensity on virus exposure resulting from a static contact and assuming the default parameterization (Table 1). As described in 3.4.4, the relationship between exposure and infection risk is likely to be non-linear and different between routes. Relative differences in exposure should therefore not be interpreted as proportion to relative differences in infection risks. We examine three determinants of contact intensity, namely duration, distance, and the time an infectious individual spent in the space prior to the start of the contact. We compared exposure relative to a benchmark contact at a distance of 1.5 meters for 15 minutes, which is broadly used as an indicator of 'a risky contact' (RIVM, 2021). Both infectious and susceptible individuals are assumed to be silent (akin an interaction in a waiting room for instance), thus emission and inhalation result from regular breathing. We distinguish the exposure to three routes, where droplet transmission is considered a direct route, whereas aerosols and fomites are considered indirect: The buildup of these in the environment can potentially contribute to exposure after the infectious individual has left. The extent to which this plays a role in exposure patterns depends on the relative emission and decay rates. Contacts at shorter distance than $1.5 \mathrm{~m}$ result in substantially larger exposures with a 5 -fold increase at 1 meter (26-fold at 0.5 meter). Exposure at these distances is dominated by droplet transmission routes, although short range aerosolized virus may also contribute to overall exposure. Exposure at longer distances decays quickly, with exposure at 2 meters being 4-fold lower than the benchmark of $1.5 \mathrm{~m}$. At $1.5 \mathrm{~m}$ distance, $50 \%$ of exposure is expected to be attributable to aerosolized virus (Figure 5.A ). Prolonged contacts are associated with an increase in exposure. A static contact at 1.5 meters for 1 hour is expected to result in exposure 14-fold higher relative to a 15 minute contact (Figure 5.B). The contribution of indirect transmission routes increases with contact duration, highlighting the impact of virus buildup in environments. $A$ similar effect is seen when the infectious individual has spent time in the space preceding the contact. In such a scenario, exposure following a benchmark contact would be 5 -fold higher than in our default scenario. This increase is largely driven by a buildup of virus (aerosolized or on fomites) in the environment. These particles make up $80 \%$ of the expected exposure versus $50 \%$ under the baseline scenario (Figure 5.C \& 5.D). These first analyses with the QVEmod illustrate that keeping distance and shortening contact duration can reduce the exposure. The current RIVM guidelines, i.e. 1.5 meter distance and less than 15 minutes of exposure, provide good guidance to minimize exposure risks, provided individuals have not convened in the same space for an extended period of time. 
medRxiv preprint doi: https://doi.org/10.1101/2021.04.12.21255349; this version posted April 19, 2021 . The copyright holder for this preprint (which was not certified by peer review) is the author/funder, who has granted medRxiv a license to display the preprint in perpetuity. It is made available under a CC-BY-NC 4.0 International license .
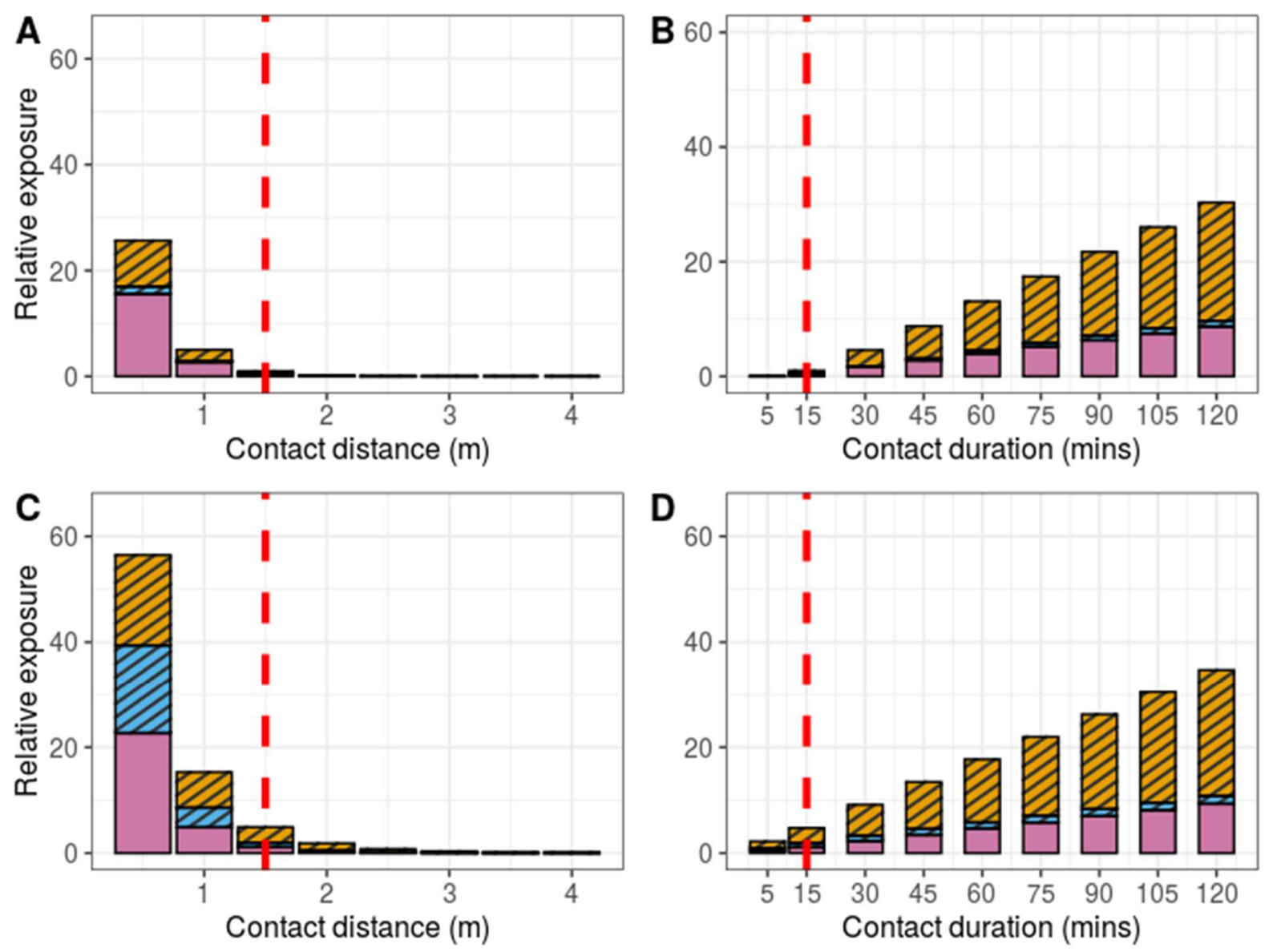
Routes
Direct Indirect
Transmission routes
Aerosols
Fomites
Droplets
Figure 5. Effect of contact intensity on exposure and the relative contribution to exposure of transmission routes, with $A$ ) exposure for 15 minutes at increasing distance, $B$ ) exposure at 1.5 meters for an increasing duration, $($ and $D)$ as $A$ and $B$ but when the infectious individual was present 3 hours prior to the contact occurring, allowing for a buildup of virus in the environment. Red dashed lines show the contact with 1.5 meters and 15 mins. Exposure is shown relative to this benchmark, in a scenario of concurrent arrival of the infectious and susceptible individual (as shown in A and B). For instance, a relative exposure of 50 means that overall exposure is 50 times that of the exposure of a benchmark contact.

\subsubsection{The impact of respiratory activities on exposure}

Compared to breathing, active respiratory activities, such as singing and talking loudly, are associated with increased emission and subsequent exposure to viral particles by proximate susceptible individuals (Hamner et al., 2020). Moreover, active respiratory activities result in higher tidal volume (inhalation rate) which can further increase virus exposure. We used estimates from a systematic literature review by Chen et al. (2020) to parametrize emission, particle composition, and inhalation upon different respiratory activities (Table 1) and simulated exposure upon the benchmark contact ( $1.5 \mathrm{~m}$ for 15 minutes) following 15 minutes of the respective activity. Relative to breathing, exposure upon 15 minutes of talking was four times higher than upon breathing (Figure 6.A). The impact of singing is, with a near 40 -fold increase in exposure, more extreme, mostly owing to the additive effect of both increased emission (25-fold higher than breathing, Table 1) and increased inhalation (1.5-fold higher). Notably, the contribution of aerosols to the overall exposure is higher upon active respiratory activities (Figure 6.B). However, due to different measuring methods and equipment, the quantity and partition of aerosols and droplets generated during different respiratory activities are still inconsistent among studies (Wilson et al. (2021), Hamilton et al. (2021)) and may well differ between individuals of different age and gender (Mürbe et al. (2020), Edwards et al. (2021)). 


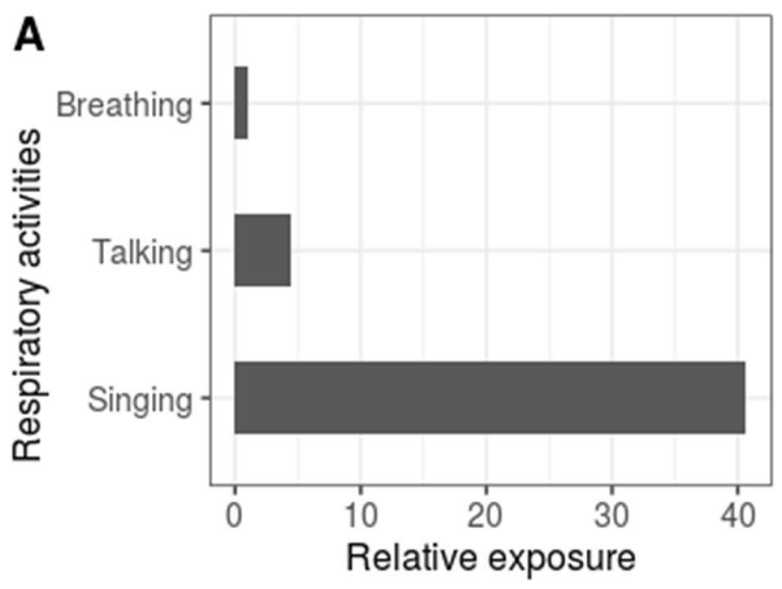

Routes $\square$ Direct $\square$ Indirect Transmission routes
B

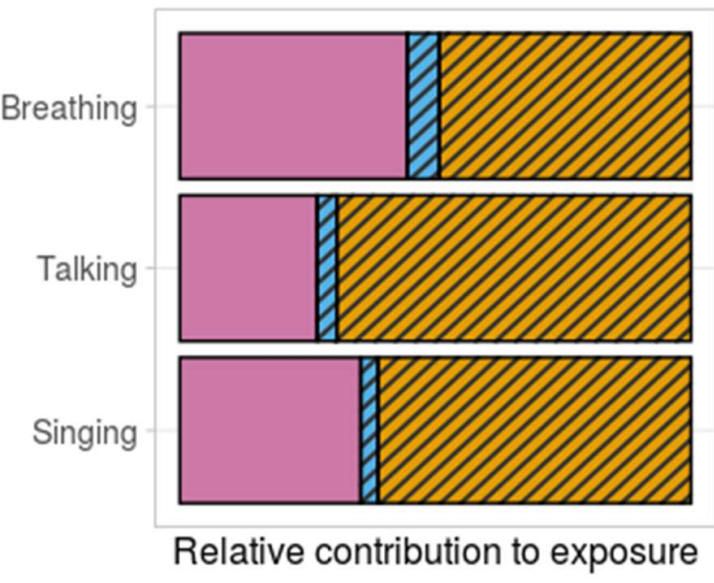

Aerosols

Fomites

Droplets

Figure 6. Effect of different respiratory activities on exposure. A) The relative exposure during talking and singing continuously for 15 mins at $1.5 \mathrm{~m}$ distance, relative to breathing. B) The relative contribution to exposure of three transmission routes in the individuals' exposure while breathing, talking and singing activities. Both the infectious and susceptible individual are assumed to perform the respective respiratory activity.

\subsubsection{The impact of interventions on exposure}

Better ventilation and face masks have been suggested as interventions for indoor spaces. Here, we simulated the impact of these two interventions on exposure upon a static benchmark contact, in a manner similar to that of sections 3.5.1 and 3.5.2. We examined the impact of both intervention measures across a range of possible efficacies.

Ventilation was modeled assuming a constant, spatially homogeneous renewal of air. This is reflected by the air change rate per hour $(\mathrm{ACH})$ which, when considering the air is uniform across the space, is a measure of how many times the air in a defined space is replaced per hour. For reference, the ACH in Dutch residential dwellings is roughly 0.1 1.9 (Van Ginkel \& Hasselaar, 2006) versus 3 in most indoor settings such as class rooms and supermarkets (CIRES, 2020). The recommended ACH in home and business is 6 (Arboportaal (2020) and RIVM (2020)). Increased ventilation is specifically proposed as an intervention measure for those crowded settings with poor ventilation, as these are particularly associated with superspreading events (Lu et al. (2020), Jiang et al. (2021), Kwon et al. (2021), Swadi et al. (2021), Chau et al. (2021), Hwang et al. (2020), Shen (2020)). Exposure through aerosols may play a role in these, as environmental contamination may accumulate particularly in low ventilation settings. Indeed, increasing ventilation affects the amount of viral-laden aerosols someone can get exposed to, with a maximum reduction of overall exposure of about $30 \%$ in this static example (Figure 7.A). The biggest gains can be made in poorly ventilated settings. Increasing from the $\mathrm{ACH}$ common to Dutch indoor places $(3 \mathrm{ACH}$, red line in Figure 7.A) (CIRES, 2020) to the recommended $6 \mathrm{ACH}$ causes more moderate effects and would reduce the exposure by aerosols by $20 \%$ (with the total exposure reduced from $71 \%$ to $51 \%$ ).

We then simulated a benchmark contact with both infectious and susceptible individuals wearing a mask. Face masks can vary in their filter efficiency (FE, the proportion of particles filtered out)(Bezek et al. (2021), Drewnick et al. (2021)). This depends on the materials used, among others, and can range from as low as $20 \%$ for thin acrylic to more than $95 \%$ for $\mathrm{N} 95$ masks or vacuum bags (Pan et al., 2020). Mask fit is also an important indicator of $\mathrm{FE}$ (Darby et al., 2021). Under the assumption that face masks block most of the droplets (i.e., ten times higher FE than that of aerosols) (Asadi et al., 2020), the aerosols route becomes the dominant source of virus exposure (99\%), even at low FE (Figure 7.B). Assuming 40\% filter efficiency for aerosols (96\% efficiency against droplets) (Ueki et al., 2020), masks reduce the overall exposure to $20 \%$ of what exposure without masks would have been. The near perfect protection at highest FE $(>75 \%)$ can be attributed to the additive effect resulting from both mask wearing by both infectious and susceptible individuals, provided the masks are well used and fitted (Clapman et al. (2021), Ueki et al. (2020)). Effectiveness may vary upon longer exposure or in settings with poorer ventilation, for instance. 
medRxiv preprint doi: https://doi.org/10.1101/2021.04.12.21255349; this version posted April 19, 2021 . The copyright holder for this preprint

(which was not certified by peer review) is the author/funder, who has granted medRxiv a license to display the preprint in perpetuity.

It is made available under a CC-BY-NC 4.0 International license.

The multi-dimensional challenges of controlling SARS-CoV-2 transmission in indoor spaces

How these intervention induced reductions in exposure relate to infection risks is not straightforward and critically depends on the dose-response relationships of the several transmission routes. This will be further explored in a sensitivity analysis in section 5.6.
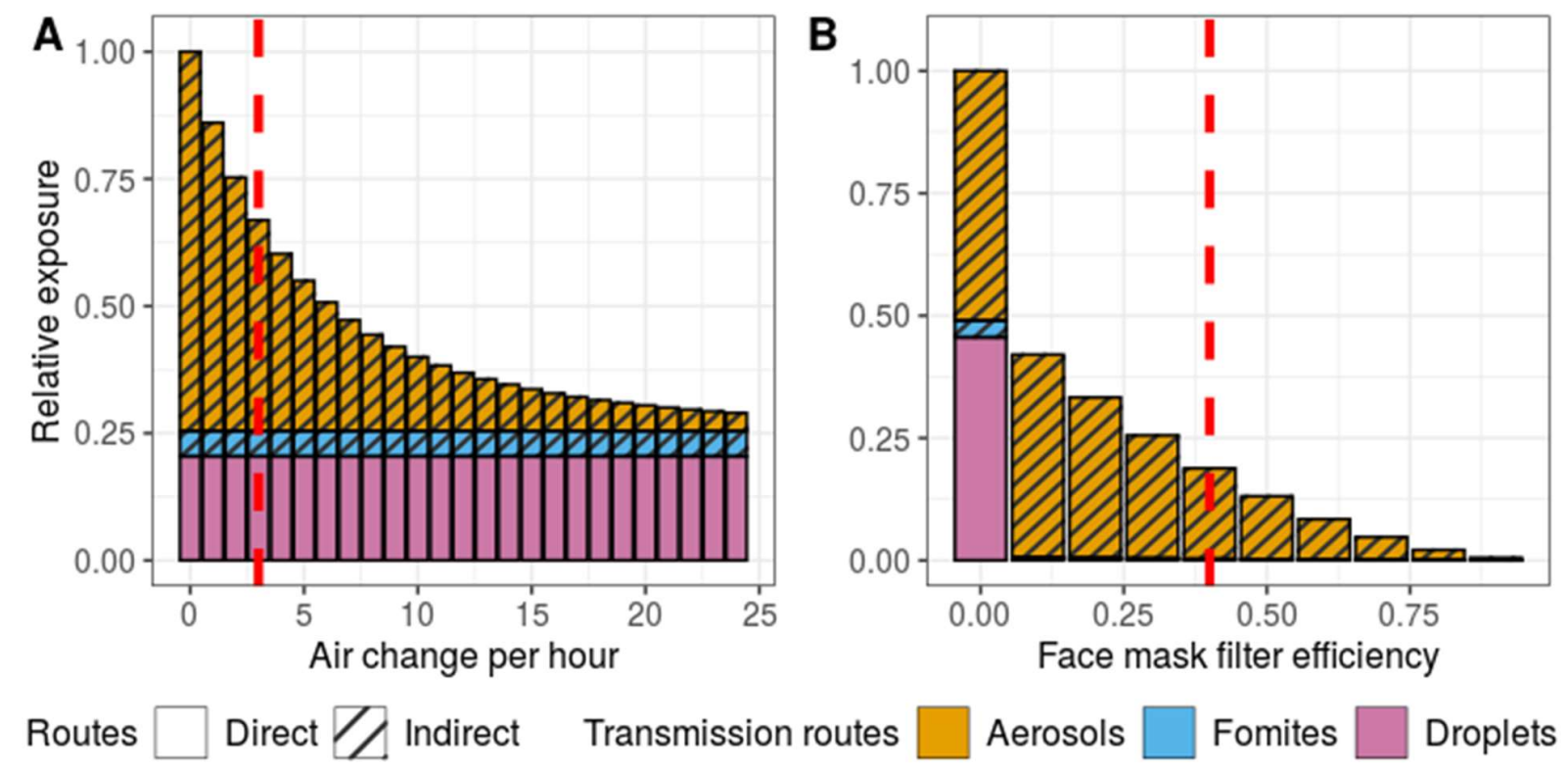

Figure 7. The impact of ventilation and mask wearing on exposure after 15 minutes at a 1.5 meter distance. A) The impact of ventilation ( $A C H$ ) on exposure. The red dashed line shows the baseline $A C H=3$ per hour indoors. B) The impact of mask wearing by both infectious and susceptible individuals on virus exposure. The default filter efficiency is assumed to be $40 \%$ for aerosols (red dashed line). The exposure load for a contact at $1.5 \mathrm{~m}$ and 15 min without mask and with poor ventilation $(\mathrm{ACH}=0)$ is standardized to 1.

\section{CASE STUDY PEDVIS: SIMULATING VIRUS TRANSMISSION AT RESTAURANTS}

PeDViS is put to the test by means of a case study, namely the simulation of virus spread and exposure in a restaurant setting. The following section will provide an introduction to the case study. First, the SamenSlimOpen project is introduced. Next, a description of the case study is presented in section 4.2 . Accordingly, section 4.3 presents a functional description of the user-friendly graphical user interface. For the results and a discussion thereof, the reader is referred to section 5 .

\subsection{Introducing SamenSlimOpen}

The development of PeDViS is part of a research project that develops tools for practitioners to help them to optimize measures to limit SARS-CoV-2 transmission inside their venues. The easier it is for practitioners to use the simulation model, the more likely their adoption of the tool will be. Therefore, an open-access web-based simulation environment was created, named the SamenSlimOpen App (SSO app). The PeDViS model is at the core of this app.

The first version of the tool is specialized for the layout impact assessment of restaurants (see Figure 8). Here, Figure 8.A-8.D are visualizations of the web-based interface via which users can model a restaurant. Users are asked to make a simplified representation of their venue in an accessible manner. The users can select a scenario or make one themselves which determines the length of the simulation and the occupancy over time. After setting up their restaurant the users start the simulation. The output of the simulation is a heatmap of the cumulative virus exposures that occurred over the course of the simulation, as well as summary statistics of the simulation.

The goal for the SamenSlimOpen project is not only to inform users about the virus exposure risks of their current setup but also to encourage them to optimize their venue and protocols to limit SARS-CoV-2 transmission. As such, the SSO app allows users to try different configurations and compare results. Users can change their restaurant layout or change the scenario, how long are guests allowed to stay or what measures are taken. 
medRxiv preprint doi: https://doi.org/10.1101/2021.04.12.21255349; this version posted April 19, 2021 . The copyright holder for this preprint (which was not certified by peer review) is the author/funder, who has granted medRxiv a license to display the preprint in perpetuity. It is made available under a CC-BY-NC 4.0 International license .

The multi-dimensional challenges of controlling SARS-CoV-2 transmission in indoor spaces

In order for the SSO app to simulate, the user input for the PeDVis model is collected in the graphical user interface. The user first identifies the layout of the restaurant. Here, the location of all objects and functional spaces (e.g., toilet, coat rack, cash register) are determined. All objects can be scaled and rotated to best resemble the layout of a real restaurant. The number of tables and chairs placed in the restaurant constrain the number and sizes of groups that can be accommodated in the restaurant. Moreover, their placement and size affects the walking routes of the simulated individuals. Accordingly, the user indicates the actual maximum occupancy, the average duration of stay in the restaurant, and the time slots at which groups are expected to arrive at the restaurant. Lastly, the user can indicate whether to use intervention measures, including the wearing of face masks when walking (table 2).

In the following case study the SSO app (see SamenSlimOpen.nl for the latest release), and as such PeDViS model, is used to simulate and compare the impact of various measures to limit SARS-CoV-2 spread in restaurants.

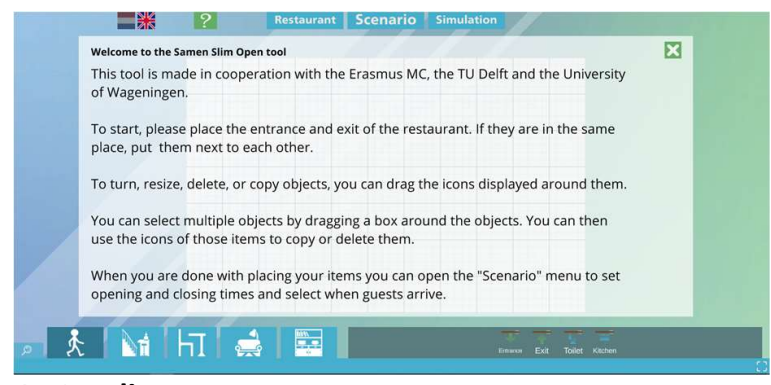

A - Landing page

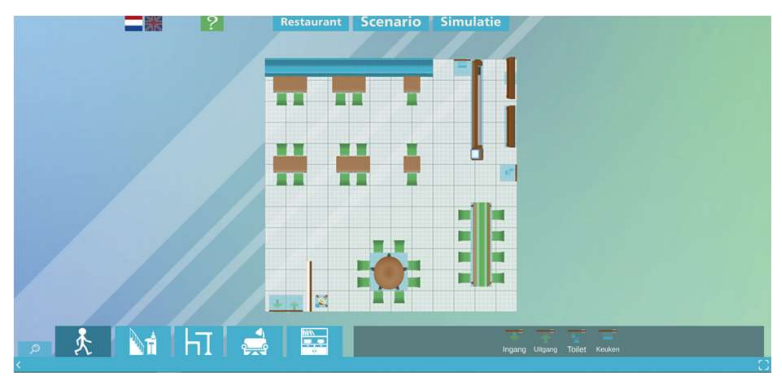

C - Scenario modelling

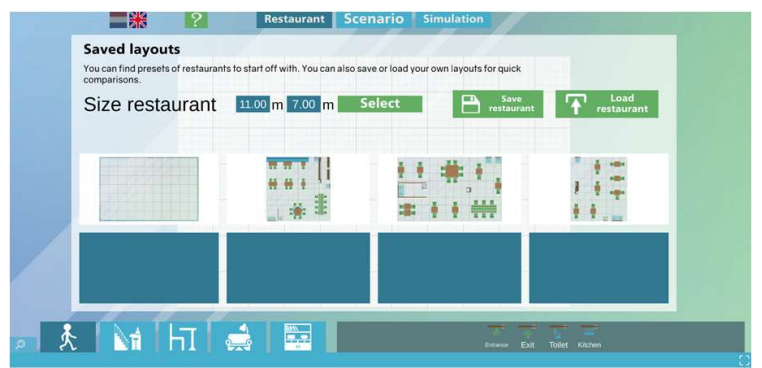

B - Scenario selection

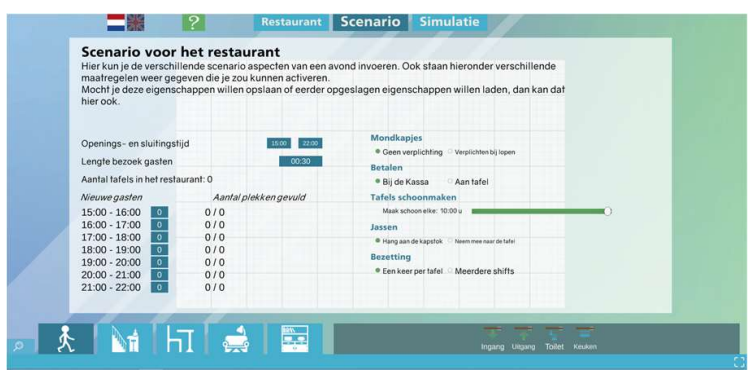

D - Demand input

Figure 8. Screenshots of the SamenSlimOpen app, A) introduction screen, B) scene selection screen, C) scene development screen, $D$ ) developed scenario. 
medRxiv preprint doi: https://doi.org/10.1101/2021.04.12.21255349; this version posted April 19, 2021 . The copyright holder for this preprint (which was not certified by peer review) is the author/funder, who has granted medRxiv a license to display the preprint in perpetuity. It is made available under a CC-BY-NC 4.0 International license .

The multi-dimensional challenges of controlling SARS-CoV-2 transmission in indoor spaces

Table 2. Implemented measures in the SSO app to limit SARS-CoV-2 transmission

\begin{tabular}{lcc}
\hline Measure & Option A & Option B \\
\hline Face masks & Guests don't wear masks & Guests wear masks when they walk \\
Payment & At the register & At the table \\
Coats & On the coat rack & Taken to the table \\
Filling & Tables are used multiple times per evening & Tables are used once per evening \\
Air change rate & A continuous slider which sets the times of air change per hour \\
\hline Cleaning tables & A continuous slider which sets the interval time of tables being cleaned \\
\hline
\end{tabular}

\subsection{Case study description}

For the first case study of PeDVis a small imaginary restaurant is adopted (Figure 9). This restaurant's dimensions are $10 \times 9$ meters. It contains four tables, which are distributed over the space in a way that the space between tables and chairs is maximized. Each table has four chairs, all of which can be simultaneously occupied by visitors. The restaurant also has a bar, with four stools positioned next to it. The restaurant's capacity is determined by the number of chairs in the restaurant, so twenty visitors can be simultaneously present. The main entrance and exit of the restaurant are on the northern side of the restaurant, with a coat rack next to the entrance. The cash register is on the left side of the bar and two toilets are located on the southern side of the restaurant. The material of the chairs, tables, and bar is assumed to be wood. The objects in the room are disinfected one time before the restaurant opens, and not cleaned again during the following four hour shift.

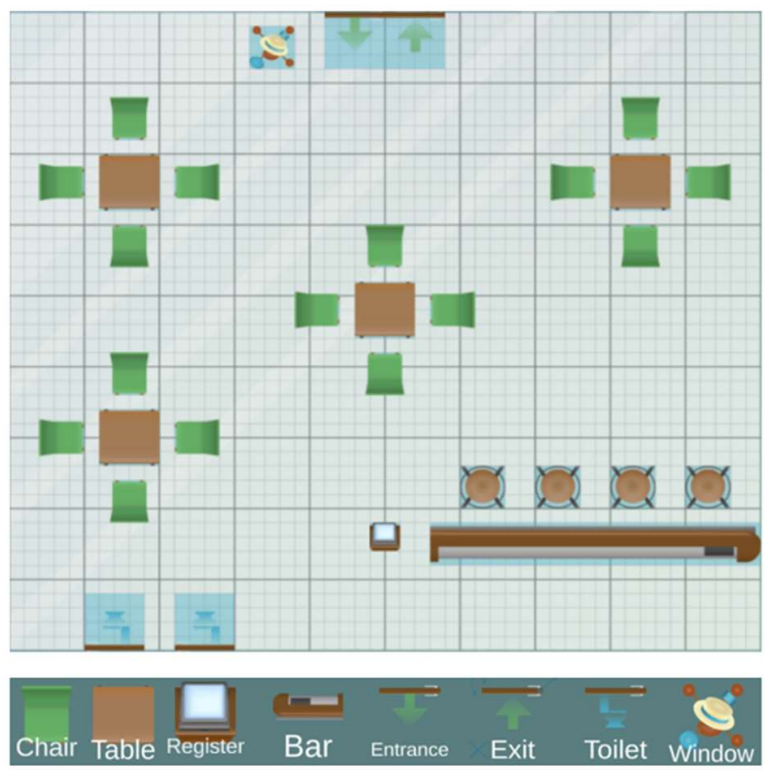

Figure 9. The case study restaurant layout, where the green rectangles and round brown circles identify the seats, the green arrows the entrances, the blue toilets the entrance to the toilets and the brown rectangles the tables.

At the restaurant, the main activity of all individuals is sitting on a chair. When individuals are sitting on a chair, they are physically taken out of the Nomad simulation in order to ensure that the movement dynamics of other individuals are not hampered by their presence. They can however still contribute to the spread and uptake of virus, as modelled 
medRxiv preprint doi: https://doi.org/10.1101/2021.04.12.21255349; this version posted April 19, 2021. The copyright holder for this preprint

(which was not certified by peer review) is the author/funder, who has granted medRxiv a license to display the preprint in perpetuity.

It is made available under a CC-BY-NC 4.0 International license.

The multi-dimensional challenges of controlling SARS-CoV-2 transmission in indoor spaces

by QVEmod. Besides that, individuals can perform one of three intermediate activities. They can hang their coat on the coat rack, go to the toilet, or pay at the cash register. There is a 0.6 probability that an individual will visit the toilet. The timing to go to the toilet is random, and the time spent there is drawn from a normal gaussian distribution with a mean of 120 seconds and a standard deviation of 60 seconds, with a maximum of 240 seconds. The time spent at the cash register and coat rack is set to 0 . Consequently, individuals move to these two locations, and are directly sent back to their main activity location.

The simulated walking behaviour of the population is homogeneous in all aspects, except for the desired walking speed. For each individual, the desired walking speed is drawn from a normal gaussian distribution with a mean speed of $0.9 \mathrm{~m} / \mathrm{s}$ and a standard deviation of $0.2 \mathrm{~m} / \mathrm{s}$. The maximum speed is set to $1.4 \mathrm{~m} / \mathrm{s}$. Their compliance to the 1.5 meter distancing rules is set to 0 , which means they will use all available space to move. As the researchers most often observe that individuals in confined indoor spaces have difficulty complying to these rules, we are confident that the current settings are more in line with reality than full compliance.

The simulation lasts for 4 hours of service at a restaurant, in which all tables are used one time. Thus, one complete simulation run, twenty individuals have entered the simulation. At the end of the simulation, some individuals might still be present in the restaurant, depending on the user-specified settings.

Only one infectious individual will enter the simulation during its runtime, which is randomly assigned at the moment of entrance. All other characteristics are similar to that of other individuals and are randomly drawn at the entrance of the simulation.

\section{RESULTS OF PEDVIS SIMULATION OF RESTAURANT CASE STUDY}

A case study in a restaurant was provided to show how human interactions drive transmission outcomes. The model predicted virus exposure of individuals in the restaurant and the impacts of face masks and ventilation thereon. In a sensitivity analysis we explore different relative dose-response relationships to estimate the number of infections that occurred in this case study and the relative contribution of transmission routes. First the pedestrian movement dynamics are briefly discussed in section 5.1. Section 5.2. discusses the virus spreading through the restaurant's environment. Section 5.3. continues with a discussion of the resulting exposure to the virus for each of the individuals that were present in the restaurant. A sensitivity analysis on infection risk estimation in relation to virus exposure is presented in section 5.4. Section 5.5 presents and discusses the impact of interventions in the restaurant. Finally, section 5.6 discussed how estimates of the impact of interventions on reducing infections depend on the relative dose-response relationships assumed.

\subsection{Pedestrian movement dynamics in a restaurant setting}

To examine how human movement influences the exposure and transmission indoors, PeDVis was used to simulate a real life scenario. The individual trajectories of one run with PeDVis are shown in Figure 10. Due to the stochastic activity scheduler and randomly drawn characteristics of the individuals, each run with PeDViS is different. In order to fully comprehend the impact of infectious pedestrians in one space, one has to consider multiple runs with PeDVis, the exact number depending on the setting, occupancy, and the amount of distinct activities individuals engage in.

In the particular case visualized in Figure 10, the infectious individual (Individual 19) entered and sat next to the bar for 70 mins together with individuals 16,17, 18. Subsequently, individual 19 went to the toilet for 4 mins and went back to their seat. Fourty minutes later, individual 19 left the restaurant. As one can see, the trajectories of Individual 19 are relatively straightforward and direct. Individual 19 has spent most of its time sitting or standing at static locations.

The other individuals walked into the space before individual 19 and spent part of their time in the same room as Individual 19. The trajectories of the other individuals are fairly diverse. Except for the corners, most locations inside the restaurant have been visited by one or more individuals. The main corridor between the entrance and the toilet is highly frequented, as is the route between the table on the right and the toilet. Other than the others at the bar, most other individuals have not come into close vicinity for an elongated period of time with Individual 19 during their stay. 

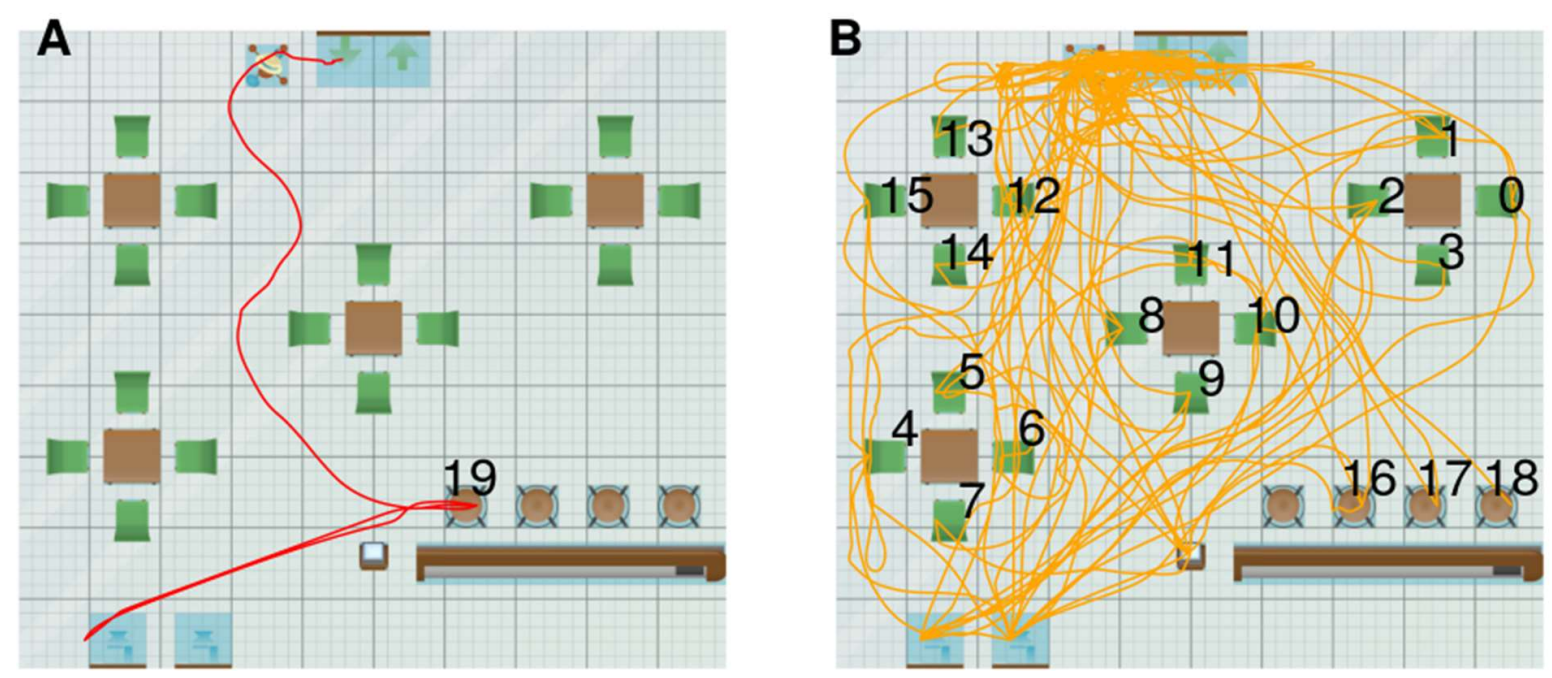

Figure 10. The trajectory of individuals in one simulation and the seats location.(A) the trajectory of the infectious individual. (B) the trajectories of other 19 individuals.

\subsection{Viral spread}

The infectious individual's whereabouts determines the virus distribution in the air and on fomites (Figure 11). Here, the virus spread is determined for the case presented in Figure 9. The cumulative contamination values in heatmaps represent the accrued virus contamination relative to the amount of virus that an average infectious individual emits per hour (Table 1). The three maps illustrate that the contamination is highest near the chair where the infectious individual spends most of its time. This pattern is more clear in droplets (Figure 11.B) and fomites (Figure 11.C) heatmaps because the virus does not travel far in droplets, while viral-laden aerosols can diffuse. While the changes in the concentration of virus in droplets over time is tightly linked to the presence of the infectious individual, aerosols and fomites can build up in their environment and may persist after the infectious person has left (see snapshot heatmaps in Figure S1).

A

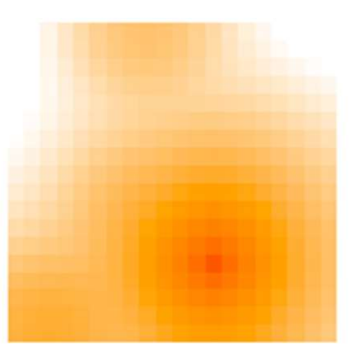

Aerosols
B

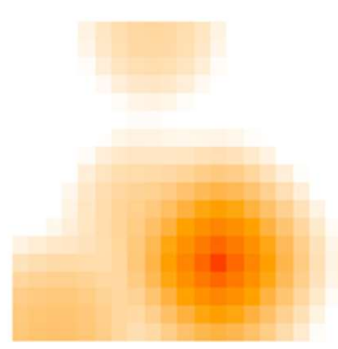

Droplets
C

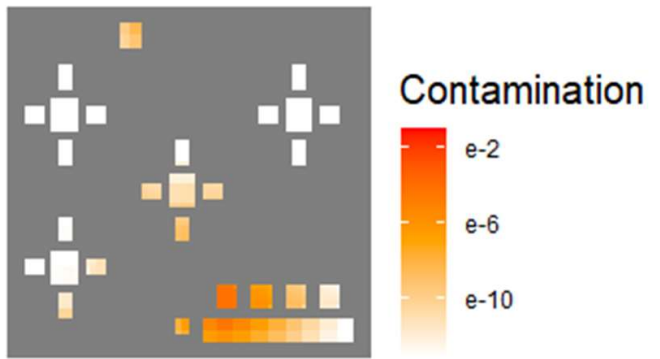

Fomites

Figure 11. Cumulative virus contamination in the environment in (A) aerosols, (B) droplets, and (C) on fomites. Contamination is expressed as the virion quantity relative to an average infectious individual's hourly emission.

\subsection{Individuals' exposure to virus}

The cumulative exposure of susceptible individuals is simulated based on their interaction with their environment (inhalation, touching surfaces) and the virus concentration in that environment. Figure 12.A presents the cumulative exposure to aerosols, droplets, and fomites of each of the individuals in the case study, where the red dashed line depicts the cumulative exposure that would be experienced upon a benchmark contact (15 $\mathrm{min}$ at $1.5 \mathrm{~m})$. The cumulative exposure of five individuals (i.e. Individual 9, 10, 16, 17, 18) surpassed that of the benchmark contact, despite the fact that two of those individuals $(9,10)$ were never within $1.5 \mathrm{~m}$ of the infectious individual. These five 
medRxiv preprint doi: https://doi.org/10.1101/2021.04.12.21255349; this version posted April 19, 2021. The copyright holder for this preprint

(which was not certified by peer review) is the author/funder, who has granted medRxiv a license to display the preprint in perpetuity.

It is made available under a CC-BY-NC 4.0 International license.

The multi-dimensional challenges of controlling SARS-CoV-2 transmission in indoor spaces

individuals either sat at the bar together with the infectious individual (16-18) or sat close to the infectious individual and overlapped sufficiently in time to get exposed to the virus $(9,10)$. Only the nearest neighbour $(16)$ was exposed through droplet spread. Others were predominantly exposed through indirect routes, mainly aerosols. Fomites do not play a meaningful role in this scenario, in part because the table where the infectious person spent most of his time was only occupied once. As a consequence, the neighboring individual was the only one exposed to fomites.

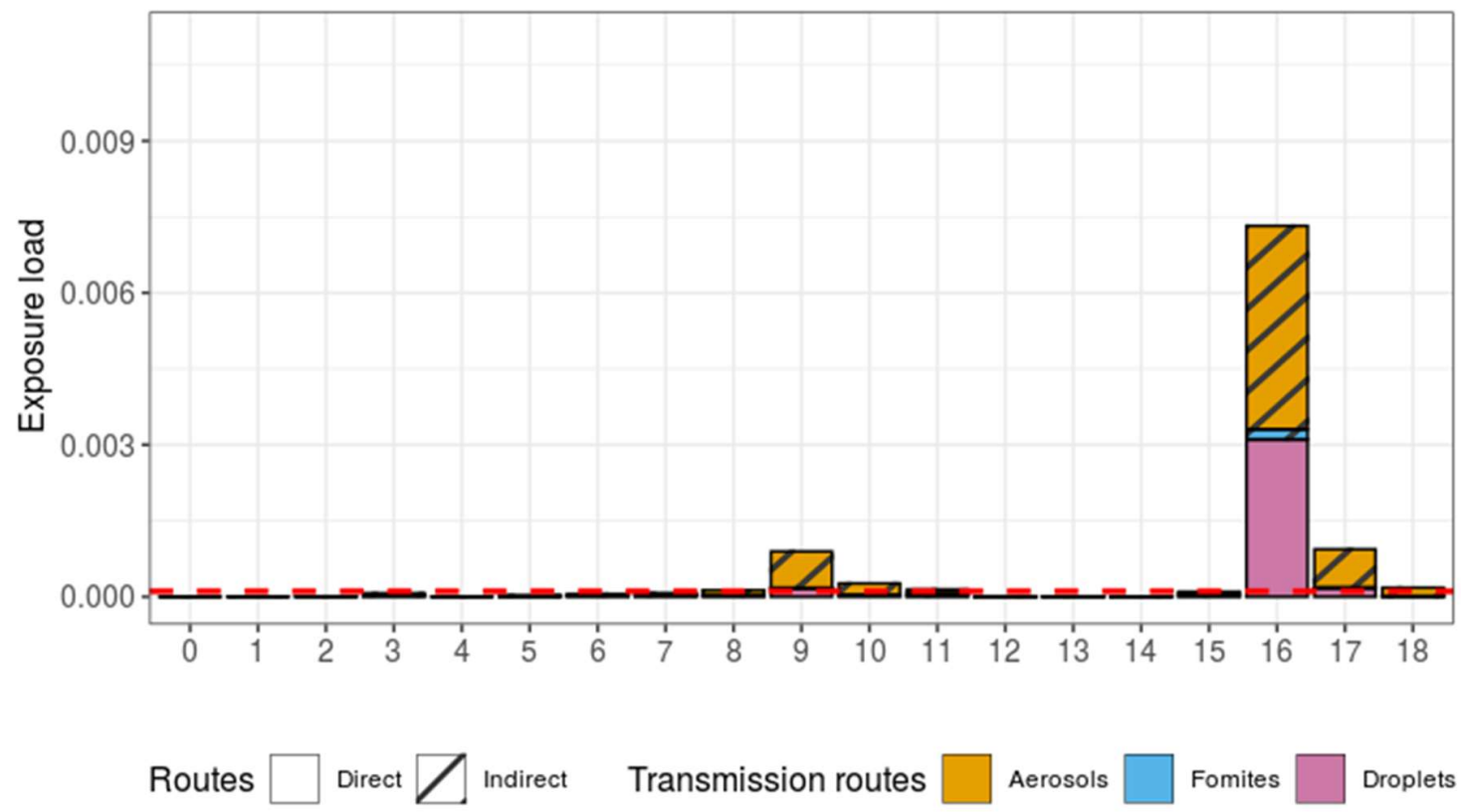

Figure 12. Susceptible individuals' exposure load. Exposure load is expressed as the virion quantity relative to an average infectious individual's hourly emission and is partitioned by transmission route. The exposure of susceptible individuals with the red dashed line showing the exposure for a benchmark contact of $1.5 \mathrm{~m}$ for $15 \mathrm{~min}$.

\subsection{Risks of infection}

An individual's cumulative virus exposure is indicative of someone's risk of becoming infected, although the exact relation and how this differs by exposure route is uncertain. We applied exponential dose-response models, where $k$ determines the number of virions someone is exposed to that results in a $63 \%$ probability of getting infected (see section 3.4.8). The value of $k$ varies between transmission routes due to different deposition location (eg. upper and lower respiratory tract) and deposition efficiency (Samet et al., 2021). It is generally difficult to quantify $k$ by experiments (Watanabe et al., (2010), US Department of Homeland Security (2021), Callaway (2020)). Recent molecular epidemiological studies estimated bottleneck estimates to be around $1000\left(D_{\text {inf }}\right)$. We treat this as a lower limit for $k$ (Popa et al., 2020), considering that virions that contribute to an individual's exposure load, still need to overcome several barriers prior to reaching the cells of the respiratory tract $\left(c_{\text {route }}\right)$. We performed a sensitivity analysis by assessing the number of infected individuals expected to arise in this case study, assuming a range of proportional differences between the three routes $\left(c_{\text {aerosols }}, c_{\text {droplets }}, c_{\text {fomites }}\right)$, and assuming an average infectious person to emit $10^{6}$ viral particles per hour $(\phi)$. The median number of infected individuals varies from 3 with $c_{\text {aerosols }}$ at $100 \%$ to 0 when $c_{\text {aerosolsis }} 1 \%$ (Table 3 ). The value for $c_{\text {fomiteshas little impact on the number of infections under }}$ this specific case study due to limited sharing of surfaces between individuals. We considered a median of 1 infections as a default, plausible scenario, in agreement with data on restaurant clusters (Adam et al., 2020): Of those pairs that resulted in one of more infections, about half resulted in just one infection. More than $80 \%$ of investigated pairs resulted in zero or one secondary infections (under the assumption that pairs with no setting reported were proportionally distributed over the settings) (Adam et al., 2020). The best agreement with these empirical outcomes is achieved when the most efficient exposure route has a $c_{\text {route }}$ of no larger than $10 \%$. We further adopt $c_{\text {aerosols }}=10 \%, C_{\text {droplets }}=10 \%, C_{\text {fomites }}=1 \%$ as our default for comparing the impact of interventions in this case. This is based on the biological underpinning that virus on contaminated hands (i.e. picked up through fomite exposure) has to overcome more barriers prior to reaching the respiratory tract target cells than virus particles that 
medRxiv preprint doi: https://doi.org/10.1101/2021.04.12.21255349; this version posted April 19, 2021. The copyright holder for this preprint

(which was not certified by peer review) is the author/funder, who has granted medRxiv a license to display the preprint in perpetuity.

It is made available under a CC-BY-NC 4.0 International license.

The multi-dimensional challenges of controlling SARS-CoV-2 transmission in indoor spaces

are inhaled (droplets and aerosols). Given the uncertainty surrounding these estimates, several scenarios are considered in the following sections.

Table 3. Sensitivity analysis on the impact of route specific dose-response relationships on the number of infected individuals (default in bold)

\begin{tabular}{|c|c|c|c|c|}
\hline$D_{i n f}$ & $\begin{array}{c}c_{\text {aerosols }}: \\
c_{\text {droplets }}: \\
c_{\text {fomites }}\end{array}$ & 5th percentile & median & 95th percentile \\
\hline \multirow[t]{18}{*}{1,000} & 100\%: 100\% :100\% & 1 & 3 & 5 \\
\hline & $100 \%: 100 \%: 10 \%$ & 1 & 3 & 5 \\
\hline & $100 \%: 10 \%: 100 \%$ & 1 & 3 & 5 \\
\hline & $10 \%: 100 \%: 100 \%$ & 1 & 2 & 3 \\
\hline & $10 \%: 100 \%: 10 \%$ & 1 & 2 & 3 \\
\hline & 100\%: 10\%: $10 \%$ & 1 & 3 & 5 \\
\hline & 10\%: 10\%: $100 \%$ & 0 & 1 & 2 \\
\hline & 10\%:10\%10\% & 0 & 1 & 2 \\
\hline & $10 \%: 10 \%: 1 \%$ & 0 & 1 & 2 \\
\hline & $10 \%: 1 \%: 10 \%$ & 0 & 1 & 2 \\
\hline & $1 \%: 10 \%: 10 \%$ & 0 & 0 & 1 \\
\hline & $1 \%: 10 \%: 1 \%$ & 0 & 0 & 1 \\
\hline & $1 \%: 1 \%: 10 \%$ & 0 & 0 & 1 \\
\hline & $10 \%: 1 \%: 1 \%$ & 0 & 0 & 1 \\
\hline & 1\%: 1\%: $1 \%$ & 0 & 0 & 1 \\
\hline & 1\%: $1 \%: 0.1 \%$ & 0 & 0 & 1 \\
\hline & $1 \%: 0.1 \%: 1 \%$ & 0 & 0 & 1 \\
\hline & $0.1 \%: 1 \%: 1 \%$ & 0 & 0 & 0 \\
\hline
\end{tabular}

\subsection{Impact of interventions on exposure and infections}

We investigated how interventions can reduce the distribution of virus in indoor spaces, the exposure of susceptible individuals, and ultimately the number of infections. We compared five scenarios: i) a 'worst case' scenario in which no interventions are applied and ventilation is poor $(\mathrm{ACH}=0)$, ii) a baseline scenario like i) but with ventilation typical for indoor settings in the Netherlands, including restaurants $(\mathrm{ACH}=3)$, iii) like ii) but with ventilation increased to recommended levels $(\mathrm{ACH}=6)$ ( $\mathrm{RIVM}, 2019)$, iv) like ii) but with individuals wearing face masks when walking into and through the restaurant, and $v$ ) like iv) but with increased ventilation $(\mathrm{ACH}=6)$.

In a poorly ventilated restaurant $(\mathrm{ACH}=0)$, the virus-laden aerosol concentration is higher than the baseline scenario $(\mathrm{ACH}=3)$ (Figure $13 \mathrm{Aa}$ ). Virus concentrations in droplets and fomites do not differ between a poorly and averagely ventilated setting. The increased aerosol concentration is sufficient to expose more people to the virus: three additional individuals had exposures higher than that of a benchmark contact (IDs $8,11,18)$. The mean number of infected individuals in a poorly ventilated indoor space is estimated to be $68.8 \%$ higher than in our baseline scenario ( 1.31 vs 0.77 ) with a $80 \%$ chance that at least one individual gets infected (Figure $14 \mathrm{Ba}, \mathrm{Bb}$ ). Increasing ventilation to Dutch government recommendations $(\mathrm{ACH}=6)$, the virus-laden aerosol distribution is reduced as compared to the baseline scenario (Figure $13 \mathrm{Ca}$ ). Assuming our default dose-response relationship $\left(C_{\text {aerosols }}=10 \%\right.$, $\left., c_{\text {droplets }} 10 \%, C_{\text {fomites }}=1 \%\right)$, this would result in an estimated $24 \%$ reduction of the mean number of infected individuals ( 0.59 vs 0.77 ) (Figure $14 \mathrm{Bc}, \mathrm{Bb}$ ). There is a $45 \%$ chance of zero individuals getting infected, compared to $38 \%$ under the baseline scenario.

The impact of face masks is only notable in the walkways and near the counter and bathroom, and particularly for droplet spread (Figure $13 \mathrm{Bb}, \mathrm{Db}$ ). This is due to the assumption that face masks are only worn while walking, conforming to the guidelines in the Netherlands. The individuals that were at highest risk of exposure in the baseline scenario, were typically exposed while seated at the same or a close table. The face masks therefore had little impact on their exposure (Figure $13 \mathrm{Bd}$, Dd). Under our default assumptions, the estimated mean number of infections was only reduced by $6.7 \%$. ( 0.73 versus 0.77 under baseline). Including face masks to a scenario with increased ventilation has a similar effect, with an estimated $7.1 \%$ reduction in the estimated mean number of infections. Indeed, the impact of both interventions is compounded, owing to the different pathways that ventilation 
medRxiv preprint doi: https://doi.org/10.1101/2021.04.12.21255349; this version posted April 19, 2021 . The copyright holder for this preprint (which was not certified by peer review) is the author/funder, who has granted medRxiv a license to display the preprint in perpetuity.

It is made available under a CC-BY-NC 4.0 International license.

The multi-dimensional challenges of controlling SARS-CoV-2 transmission in indoor spaces

and face masks act on (aerosol vs droplet spread respectively). While the impact of face masks is limited in this scenario, the relative impact of such measures will differ across scenarios. Particularly in settings where individuals have contacts with more individuals, as is likely be true for the restaurant personnel, face masks would play a larger role.

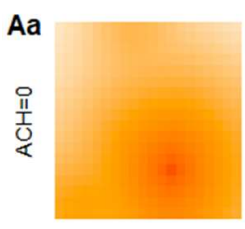

$A b$
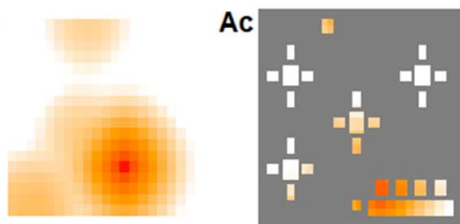

$\mathrm{Bb}$
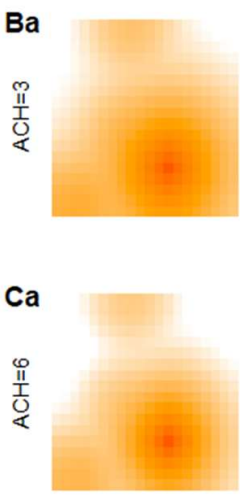

$\mathrm{Cb}$
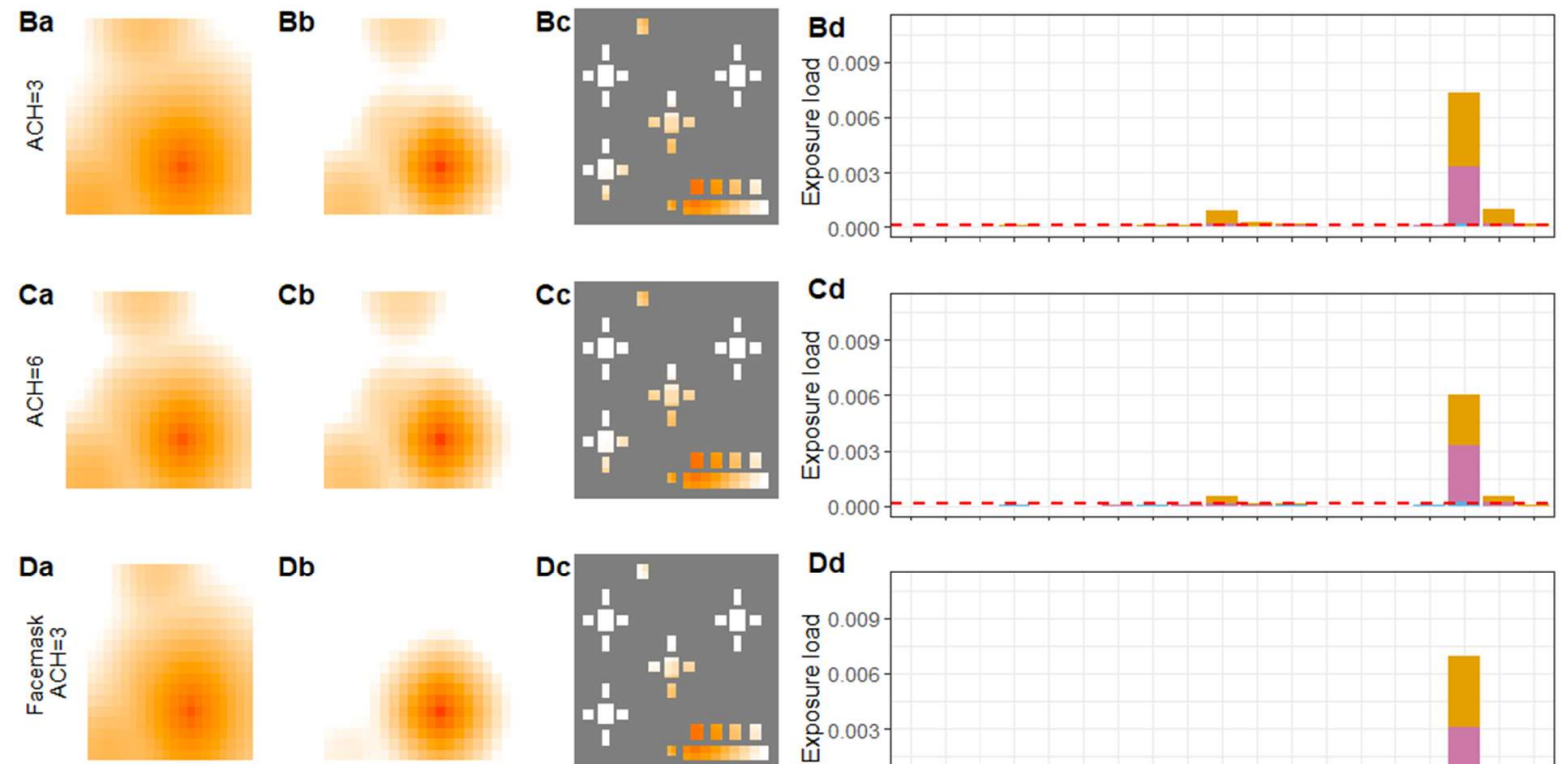

$\mathrm{Db}$

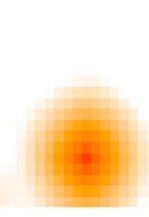

Dc
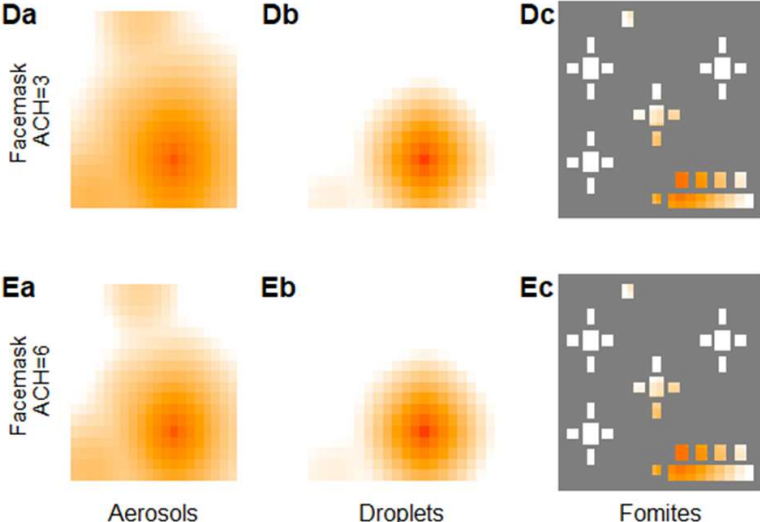

Eb

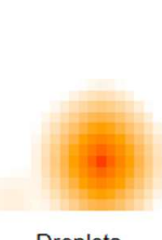

Droplets
Ec

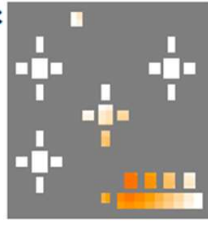

Fomites

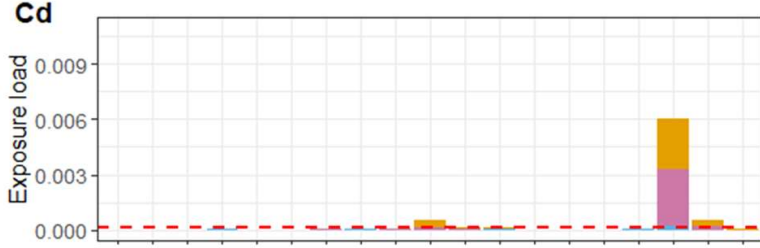

Dd

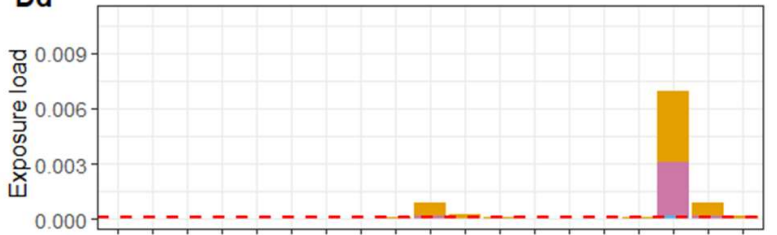

Ed

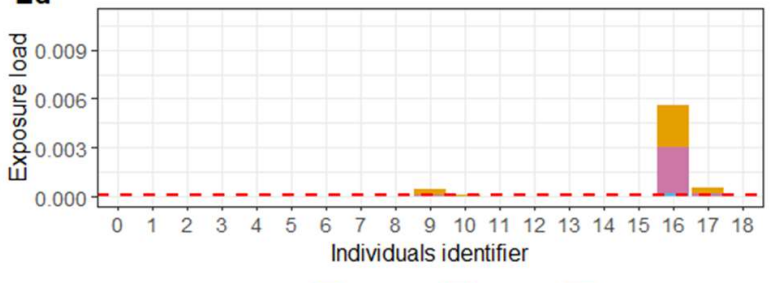

Transmission routes $\square$ Aerosols $\square$ Droplets $\square$ Fomites

Figure 13. The impact of face masks and better ventilation in the case study for $(A, B, C)$ a scenario where individuals do not wear face masks and an $A C H$ is $O(A), 3(B)$, and $6(C)$ per hour in the restaurant, $(D, E)$ a scenario where people wear face masks when moving and an ACH of 3 (D) and 6 (E). Within each scenario, the impact of interventions is assessed by several aspects: $(a, b, c)$ show virus concentration in the aerosols, droplets, and fomites respectively. (d) Shows the individuals' exposure load. The dashed red line indicates the expected exposure of a benchmark contact of $1.5 \mathrm{~m}$ for 15 minutes.

\subsection{The impact of dose-response relationships on the impact of interventions}

Intervention measures are distinct in the transmission routes that they predominantly target. For instance, while ventilation mostly affects concentrations of small aerosolized particles, face masks are particularly effective in reducing emission and inhalation of larger droplets and, by extension, can reduce exposure through fomites. How these and other measures impact the infection risks depends on the setting, the types of interactions people have, 
medRxiv preprint doi: https://doi.org/10.1101/2021.04.12.21255349; this version posted April 19, 2021. The copyright holder for this preprint

(which was not certified by peer review) is the author/funder, who has granted medRxiv a license to display the preprint in perpetuity. It is made available under a CC-BY-NC 4.0 International license.

The multi-dimensional challenges of controlling SARS-CoV-2 transmission in indoor spaces

and on the relative impact each of the three transmission routes have on transmission risks. The latter is affected by the dose-response curves of each route. Here we examine the impact of different assumptions on these doseresponse curves on the impact of interventions. Specifically, we considered the infectious dose ( $D_{\text {inf }}$ ) and its relation to the average emission load known and vary the proportion of virions someone is exposed to reaching the cells of the respiratory tract target cells (Figure 14). We consider four scenarios: i) virions have equal probability of reaching the respiratory tract target cells $\left(c_{\text {route }}\right)$, irrespective of the exposure route, ii) like i but virions that someone is exposed to through fomites have lower $c$ because they have yet to be transferred to the facial mucous layers, iii) like ii but with droplets having a lower $c$ than aerosols, and iv) like ii but with aerosols having a lower $c$ than droplets. We examined the mean number of infections that may have arisen from the described case study, accounting for the stochasticity involved with acquiring infection once exposed to the virus.

Considering the default setting of no intervention (i.e., no face masks) and average ventilation $(\mathrm{ACH}=3)$, the mean number of infections ranges from 0.8 to 0.4 , depending on assumptions on the relative dose-response relationships (Figure 14A-Db). Infection estimates are lowest when aerosol spread is assumed less efficient (mean = $0.4,50 \%$ reduction relative to the default of $\left(c_{\text {aerosols }}=10 \%,{ }, c_{\text {droplets }} 10 \%, c_{\text {fomites }}=1 \%\right)$ (Figure $\left.14 \mathrm{Db}\right)$. Assuming less efficient transmission through droplet exposure results in a lesser reduction (mean $=0.6,25 \%$ reduction relative to the default) (Figure 14Cb). Due to the wider spatial distribution of aerosols, more individuals get exposed to this route. The total number of infections is therefore more sensitive to the aerosol specific dose-response relationship. Whereas aerosols (short and long range) would be accountable for two-thirds of infections under the default assumption $\left(c_{\text {aerosols }}=10 \%\right.$ ) (Figure $15 \mathrm{Bb}$ ), this is reduced to as little as $16 \%$ if aerosol transmission is assumed less efficient $\left(c_{\text {aerosols }}=1 \%\right.$ ) (Figure $15 \mathrm{Db}$ ). The number of infections is not affected by an increased efficiency of fomite transmission (Figure 14Ab). The only individual that shares surfaces considerably with the infectious individual $(I D=16)$ is also heavily exposed to virus through other routes (Figure 12). This person is likely to get infected, irrespective of the assumptions on fomite transmission. Scenarios in which tables are reoccupied are likely to be more sensitive to assumptions on fomite transmission.

The sensitivity on the assumed dose-response relationship further becomes apparent when comparing the impact of ventilation on the estimated number of infections. Whereas a poorly ventilated place $(\mathrm{ACH}=0) \mathrm{would}$ be associated with a $68.8 \%$ increase in the number of infections (Figure 14Ba), a 100\% increase would be expected if aerosols constitute the most efficient route (Figure 14Ca). If virions in aerosols were assumed to infect less efficiently than those in droplets, one would expect little difference (a 17\% increase) in the number of infections between poorly and averagely ventilated places (Figure 14Da and b). The contribution of aerosolized virions to the number of infections would be higher in a poorly ventilated setting than in those with average ventilation (30\% vs $16 \%$ ) (Figure 15Da and b). Similar patterns are seen when $\mathrm{ACH}$ is increased to 6 (Figures 14Dc and 15Dc).

Since the use of face masks while walking was not found to substantially affect individuals' virus exposure, the total number of infections averted is less sensitive to assumptions on the dose-response relationships. The largest impact is seen in a scenario in which droplet spread is the most efficient route of transmission (Figures 14 and $15 \mathrm{Db}$ and $\mathrm{d})$. 
medRxiv preprint doi: https://doi.org/10.1101/2021.04.12.21255349; this version posted April 19, 2021 . The copyright holder for this preprint (which was not certified by peer review) is the author/funder, who has granted medRxiv a license to display the preprint in perpetuity.

It is made available under a CC-BY-NC 4.0 International license.

The multi-dimensional challenges of controlling SARS-CoV-2 transmission in indoor spaces
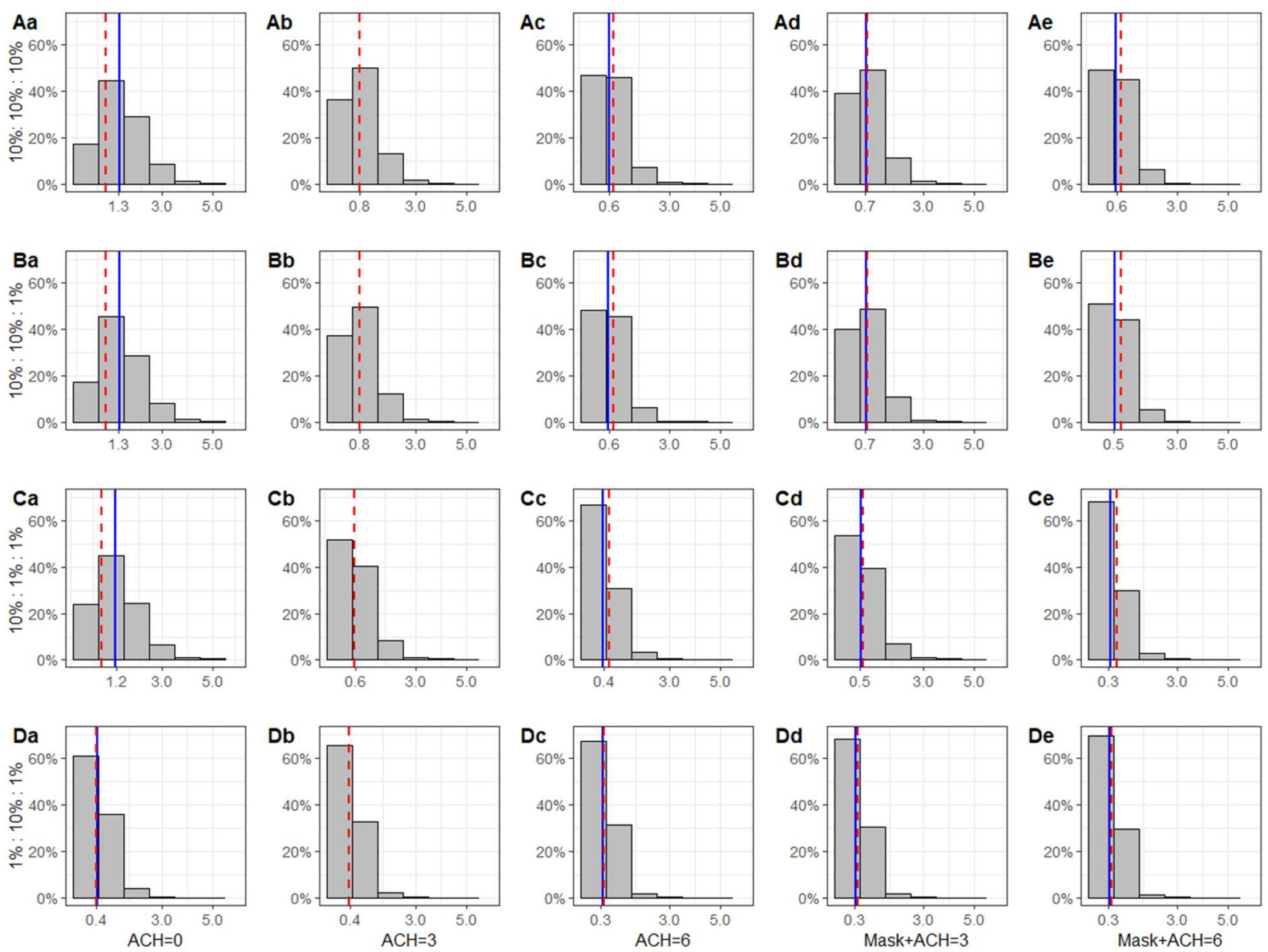

Figure 14. The estimated density distributions of the expected number of secondary infections occurring in the case study. Each row shows a parameters setting for $c_{\text {route: }}(\boldsymbol{A}) c_{\text {route }}$ is the same for all routes ( $c_{\text {aerosols }}: c_{d r o p l e t s}:$ $c_{\text {fomites }}$ is $\left.10 \%: 10 \%: 10 \%\right)$. (B) $c_{\text {route }}$ is smaller for fomites $\left(c_{\text {aerosols }}: c_{\text {droplets }}: c_{\text {fomites }}\right.$ is $\left.10 \%: 10 \%: 1 \%\right)$ (C) $c_{\text {route }}$ is smaller for fomites and droplets ( $c_{\text {aerosols }}: c_{\text {droplets }}: c_{\text {fomites }}$ is1\%:10\%:1\%). (D) $c_{\text {route }}$ is smaller for fomites and

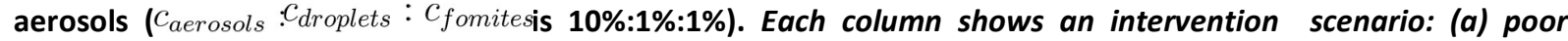
ventilation scenario, $A C H=0$, (b) baseline scenario, $A C H=3$, (c) scenario with recommended ventilation, $A C H=6$, (d) baseline scenario with face masks worn while moving, (e) scenario with recommended ventilation and with face masks worn while moving. The red dashed line indicates the mean value of the infected number in the baseline scenario and the blue solid lines show the mean value corresponding to each respective intervention scenario. 
medRxiv preprint doi: https://doi.org/10.1101/2021.04.12.21255349; this version posted April 19, 2021. The copyright holder for this preprint (which was not certified by peer review) is the author/funder, who has granted medRxiv a license to display the preprint in perpetuity.

It is made available under a CC-BY-NC 4.0 International license .

Aa

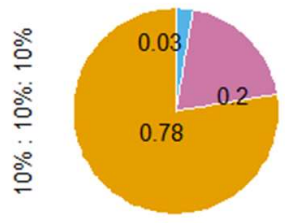

$\mathrm{Ba}$

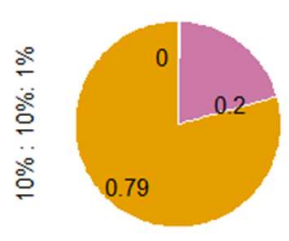

$\mathrm{Ca}$

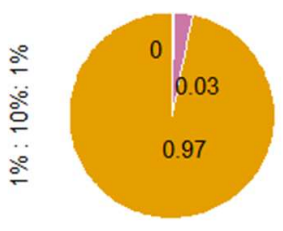

$\mathrm{Da}$

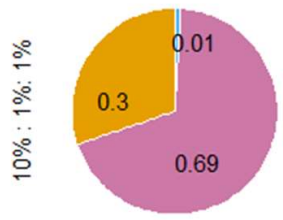

$\mathrm{ACH}=0$
$\mathrm{Ab}$

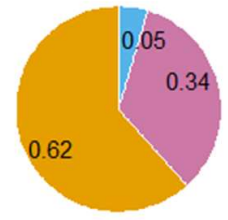

Bb

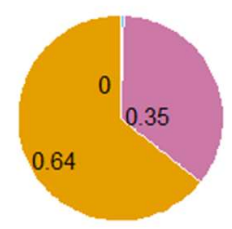

Cb

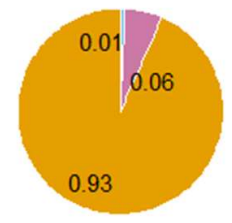

Db

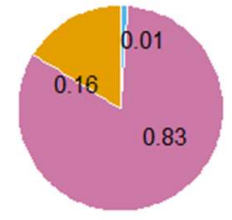

$\mathrm{ACH}=3$
Ac

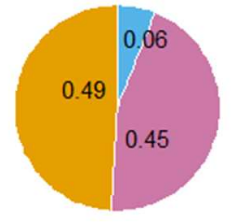

BC

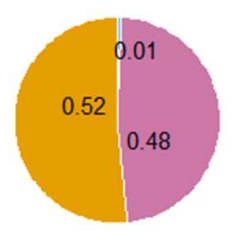

Cc

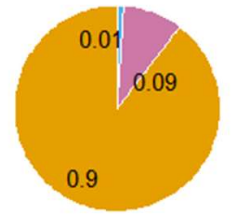

Dc

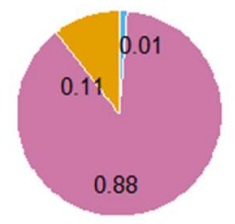

$\mathrm{ACH}=6$
$\mathrm{Ad}$

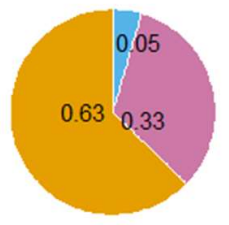

Bd

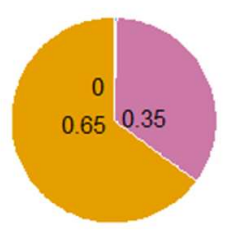

Cd

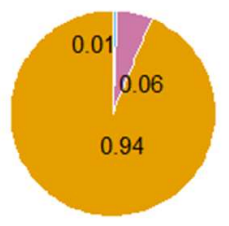

Dd

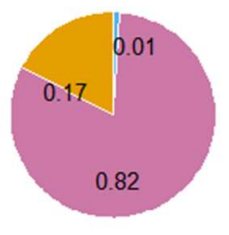

Mask
$\mathrm{ACH}=3$
Ae

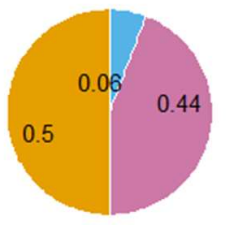

Be

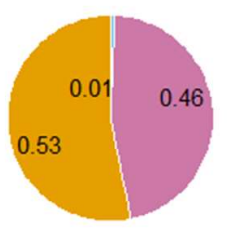

Ce

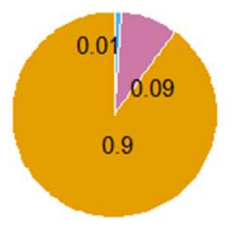

De

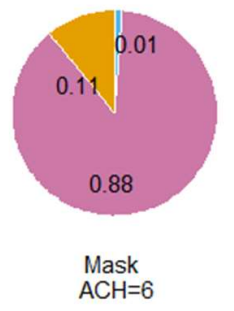

Figure 15. The relative contribution of transmission routes in the case study. Each row shows a parameters setting for $c_{\text {route }}(\boldsymbol{A}) c_{\text {route }}$ is the same for all routes ( $c_{\text {aerosols }}: c_{\text {droplets }}: c_{\text {fomites }}$ is $\mathbf{1 0 \% : 1 0 \% : 1 0 \% ) . ( B )} c_{\text {route }}$ is smaller for fomites ( $c_{\text {aerosols }}: c_{\text {droplets }}: c_{\text {fomites }}$ is $\mathbf{1 0 \% : 1 0 \% : 1 \% ) . ( C ) ~} c_{\text {route }}$ is smaller for fomites and droplets ( $c_{\text {aerosols }}:$ $c_{\text {droplets }}: c_{\text {fomites }}$ is $\left.1 \%: 10 \%: 1 \%\right)$ (D) $c_{\text {route }}$ is smaller for fomites and aerosols $\left(c_{\text {aerosols }}: c_{\text {droplets }}: c_{\text {fomitesis }}\right.$ 10\%:1\%:1\%). Each column shows an intervention scenario: (a) poor ventilation scenario, $A C H=0$, (b) baseline scenario, $\mathrm{ACH}=3$, (c) scenario with recommended ventilation, $\mathrm{ACH}=6$, (d) baseline scenario with face masks worn while moving, (e) scenario with recommended ventilation and with face masks worn while moving.

\section{CONCLUSIONS \& FUTURE WORKS}

Since its recognition in December of 2019, SARS-CoV-2 has rapidly spread across the world. Non-pharmaceutical interventions (NPIs) are currently the most important tools for mitigating the spread of SARS-CoV-2. Evaluating the effect of these interventions is complicated by confounding factors and the dynamic nature of epidemics. Mathematical models can aid in disentangling observed patterns and have been used to assess the impact of NPIs on a population level (Giordano et al.(2020), Prem et al. (2020), Tuite et al. (2020)). However, less has been done to assess their effects at the level that they are implemented and have the biggest impact: indoor spaces. A better understanding is needed of the mechanisms of transmission in indoor spaces, how these relate to human 
medRxiv preprint doi: https://doi.org/10.1101/2021.04.12.21255349; this version posted April 19, 2021. The copyright holder for this preprint

(which was not certified by peer review) is the author/funder, who has granted medRxiv a license to display the preprint in perpetuity. It is made available under a CC-BY-NC 4.0 International license .

The multi-dimensional challenges of controlling SARS-CoV-2 transmission in indoor spaces

interactions and the biology of the virus, and ultimately, how the spread of the virus in these spaces can be controlled. Here, we developed a new hybrid simulation model (PeDViS) that simulates the complex interplay between pedestrian's choice and movement dynamics, in the specific context of indoor spaces, and the spread of respiratory viruses. In particular, an expert-driven activity scheduling model is linked to a microscopic simulation model (Nomad) and a virus spread model (QVEmod). Here, we introduced this new model framework and demonstrated its use in identifying where and when contacts occur in real life scenarios in indoor spaces, what types of contacts lead to most virus exposure. We illustrate how this information can be used to inform intervention measures, and demonstrate that the impact of the interventions on preventing infections crucially depends on the efficiency of different transmission routes. The latter is extremely hard to quantify and subject of ongoing, interdisciplinary research (Richard et al., 2020).

Previous hybrid models of this kind have predominantly determined direct contact transmission risks using simple transmission rules (i.e. a 100\% probability of infection when within 1.5 meters for more than 15 minutes or infection risks linearly declining with distance). PeDViS illustrates that an explicit modelling of the spatial distributions of virions in the environment can help reveal how virus exposure relates to the duration and distance of a potentially infectious contact. Specifically, we illustrated an exponential decay in virus exposure over distance, with little exposure beyond the commonly used benchmark of $1.5 \mathrm{~m}$, provided the contact is of short durations. Longer contact durations may be associated with buildup of virus in the environment, increasing virus exposure, also beyond $1.5 \mathrm{~m}$. The buildup of virus in environments can further contribute to elevated virus exposure when an infectious person has spent a substantial amount of time in a space, before the contact takes place.

As a consequence, counting benchmark contacts (here within $1.5 \mathrm{~m}$ for at least 15 minutes) to assess the risks associated with congregations in indoor spaces, will not always yield representative results. We used PeDViS to assess virus exposure in specific contexts and mapped the potential locations and actions with a high virus exposure risk. The case study shows that the cumulative exposure of five individuals may have surpassed that of a benchmark contact. Two of those had never been within $1.5 \mathrm{~m}$ of the infectious individual but their visits had overlapped sufficiently in time with the infectious individual to accrue virus that had built up and was distributed in the environment. This emphasizes the importance of incorporating detailed human behaviour for understanding and controlling virus spread in indoor spaces. Modelling efforts, such as the ones performed by PeDViS, can help assess the added risks associated with indirect exposure routes (aerosols and fomites) by accounting for the impact of individuals sharing spaces, even if not (entirely) concurrent in time.

Intervention measures typically target specific transmission routes. For instance, face masks predominantly reduce droplet spread and fomites whereas ventilation reduces the buildup of aerosols in the environment. We examined the relative reductions in virus exposure that results from different intervention measures and showed that the impact of these measures may well be context specific. While in poorly ventilated spaces, by increasing ventilation to an average level, great reductions in virus exposure can be achieved, increasing ventilation beyond this level has a smaller accrued effect. Similarly, face masks by the guests likely have little impact if not worn while seated, as this is when longer, static contacts occur. Face masks worn by personnel may however have a much larger impact on virus exposure.

How the route specific exposure to the virus relates to infection risks remains an open question (US Department of Homeland Security (2021), Callaway (2020)). Beyond the challenges of estimating and validating the emission and spread of viruses in environments, empirically measuring the rates at which virus is inhaled and/or picked up and subsequently reach the respiratory tract target cells typically relies on indirect estimations (Azimi, 2021; Evan, 2020). Subsequently, as different target cells present different populations of receptors (Hou et al., 2020), the infection success of a virion may well depend on where in the respiratory tract it deposits. The mucous layer also likely differs in terms of permeability and clearance mechanisms across the respiratory tract (Thomas, 2013). We captured these different levels of uncertainty in a single parameter $c$, which determines what proportion of virions, after exposure, successfully reaches the respiratory tract target cells (Popa et al. (2020), Zwart \& Elena (2015)). The order of magnitude was scaled such that the distribution of cases matches that of a large infector-pair study in restaurant settings (Adam et al., 2020). While this was not intended as a formal calibration, it should result in a rough ballpark estimation that harbours realistic numbers of infections. The main purpose of this effort, examining the relative impact of intervention measures, is particularly sensitive to the assumed magnitudes and differences in transmission efficiency between routes (Figure 15). In particular the uncertainties in the efficiency of aerosol transmission affect the impact of interventions. As aerosols can both disperse and accumulate over time, they may contribute to transmission over distances longer than $1.5 \mathrm{~m}$, especially if the infectious person is present in the space for a prolonged duration. Superspreading events associated with poorly ventilated spaces are indicative of a role for aerosols in transmission (Lu et al. (2020), Jiang et al. (2021), Kwon et al. (2021), Swadi et al. (2021), Chau 
medRxiv preprint doi: https://doi.org/10.1101/2021.04.12.21255349; this version posted April 19, 2021. The copyright holder for this preprint

(which was not certified by peer review) is the author/funder, who has granted medRxiv a license to display the preprint in perpetuity. It is made available under a CC-BY-NC 4.0 International license .

The multi-dimensional challenges of controlling SARS-CoV-2 transmission in indoor spaces

et al.(2021), Hwang et al. (2020)). The extent to which aerosols contribute to transmission in spaces with adequate ventilation depends on the efficiency of this route (Figure 15) and will differ between settings (Gao et al. (2020), Azimi et al. (2021)). Similarly, while the case study examined did not present a large contribution of fomites to transmission, other scenarios with conditions more favourable to fomite transmission should be examined to better understand the potential for contribution by this route. For instance, in the case study, individuals sit relatively short at their table and they are not succeeded by other guests. A larger range of settings and scenarios will be explored in further studies (Meyerowitz et al. (2021), Mondelli et al. (2020)).

There are limitations to this study. Some parameters are hard to quantify empirically or may be setting specific, whereas for others data are too sparse to draw strong conclusions. The model presents what we believe to be the currently available empirical evidence and shall be updated whenever new, valuable data become available. While many of the model parameters may affect the absolute virus exposure, estimates pertaining to the relative impact of measures were robust to changes in the parameters explored. Specifically, the division of droplets and aerosols can be regarded as somewhat arbitrary (National Academies of Sciences, 2020). We used the conventional discrete cut-off size to classify droplets and aerosols (10um), in an effort to align with the definitions in public health guidance. In addition, airflows are modelled to be homogeneous across the spaces. This simplification is intentional and aims to provide more generic results. This model is, however, being paired with more detailed airflow models. We will therefore be able to model specific cases of indoor spaces with space specific airflows. Moreover, the datadriven activity choice model has limited functionality, predominantly focussed on restaurant visits. Future efforts will enhance the current activity choice, routing and operational movement behaviour in order to allow the modelling of more complex indoor spaces (e.g. theaters, stadiums, bars). Lastly, we assessed a single iteration of our case study restaurant. This was done for illustrative purposes and to ensure the tractability of the simulation, which is just one of many different resulting movement patterns the underlying stochastic pedestrian choice and movement models generate. The model and accompanying application are set up to readily expand the types and configurations of restaurants, and can be used to compare findings over large sets of iterations.

To gain a better understanding of transmission in indoor spaces and the impact of human interactions therein, we will further develop and expand the model. Heterogeneity in infectiousness and respiratory activities will be examined to better understand the potential for supershedders and superspreading events. Similarly, in current simulations, only guests to the restaurant are simulated. This resulted in a relatively easy, tangible example in which the index case is among guests, which are mostly stationary. The numerous short range contacts and movements made by potentially infected personnel will result in different dynamics of spread and consequently a different set of interventions. They may further spend more time in the space, thereby increasing the potential for viruses to build up in the environment. Next iterations of the model will aim to answer these questions.

Moreover, the case study shows that the relative comparison between scenarios can already produce actionable information. In particular, measures regarding the limitation of infection risks by changing the spatial layout of venues, the measures that are applied, and the general routing through spaces can be compared. Based on the model results we conclude that, keeping $1.5 \mathrm{~m}$ distance, reducing contact duration to 15 mins and having contact in a clean environment (i.e. an indoor place that has not yet been occupied) has relatively the lowest exposure risk. These findings are in line with the current policies in the Netherlands.

This model provides a tool to assess virus exposure that emerges from human interactions in indoor spaces. It can be used to characterize the infection risks in any indoor space and with any specific human movement and behaviour. While the uncertainties surrounding many of the model parameters limits the ability to estimate actual numbers of infections arising from a scenario, estimating relative changes in response to interventions is more robust and is what the model is designed for. More human movement data under the pandemic situation will be collected to further calibrate the pedestrian model. In particular, a combination of superspreading event analysis and cluster analyses are adopted to validate the parameters controlling the transmission of SARS-CoV-2. Moreover, pedestrian field studies are underway to empirically assess the changes in movement behaviour, route choice behaviour, and activity scheduling behaviour as a result of the physical distancing rules. Nonetheless, we are confident that the SSO app can already provide much needed insights into SARS-CoV-2 spreading in indoor spaces and help practitioners decrease SARS-CoV-2 spreading in their venues when they open up shop again.

\section{CREDIT AUTHOR STATEMENT}

Dorine Duives: Conceptualization, Methodology, Writing - Original Draft, Writing - Review \& Editing, Supervision, Funding acquisition, You Chang: Conceptualization, Methodology, Data Curation, Writing - Original Draft, Visualization, Martijn Sparnaaij: Methodology, Software, Berend Wouda: Methodology, Software, Doris Boschma: 
medRxiv preprint doi: https://doi.org/10.1101/2021.04.12.21255349; this version posted April 19, 2021. The copyright holder for this preprint

(which was not certified by peer review) is the author/funder, who has granted medRxiv a license to display the preprint in perpetuity. It is made available under a CC-BY-NC 4.0 International license .

The multi-dimensional challenges of controlling SARS-CoV-2 transmission in indoor spaces

Methodology, Software, Linda van Veen: Conceptualization, Methodology, Writing - Review \& Editing, Supervision, Funding acquisition, Yufei Yuan: Writing - Review \& Editing, Winnie Daamen: Writing - Review \& Editing, Mart C.M. de Jong: Methodology, Writing - Review \& Editing, Reina S. Sikkema: Methodology, Writing - Review \& Editing, Funding acquisition, Colin Teberg: Methodology, Software, Kevin Schachtschneider: Methodology, Software, Yangfan Liu: Methodology, Data Curation, Quirine ten Bosch: Conceptualization, Methodology, Writing Original Draft, Writing - Review \& Editing, Supervision, Funding acquisition.

\section{ACKNOWLEDGEMENTS}

We thank Wim van der Poel, Rineke de Jong, Marion Koopmans, Sander Herfst, Alexander Verbraeck, Yilin Huang, and Els van Daalen for their discussions and support in both research and acquisition. Moreover, we thank the testers of the SSO app for their enthusiasm and critical notes. This publication is part of the project SamenSlimOpen (with project number 10430022010018 of the research programme COVID-19 Programma, which is financed by the Dutch Research Council (NWO) and ZonMw.

\section{REFERENCES}

Adam, D. C., Wu, P., Wong, J. Y., Lau, E. H. Y., Tsang, T. K., Cauchemez, S., Leung, G. M., \& Cowling, B. J. (2020). Clustering and superspreading potential of SARS-CoV-2 infections in Hong Kong. Nature Medicine, 26(11), 1714-1719.

Antonini, G., Bierlaire, M., \& Weber, M. (2004). Simulation of pedestrian behaviour using a discrete choice model calibrated on actual motion data. 4th Swiss Transport Research Conference. https://infoscience.epfl.ch/record/87094

Arav, Y., Klausner, Z., \& Fattal, E. (2020). Understanding the indoor pre-symptomatic transmission mechanism of COVID-19. medRxiv. https://www.medrxiv.org/content/10.1101/2020.05.12.20099085v1.abstract

Arboportaal. (2020, April 16). Luchtverversing. Arboportaal. https://www.arboportaal.nl/onderwerpen/luchtverversing

Asadi, S., Cappa, C. D., Barreda, S., Wexler, A. S., Bouvier, N. M., \& Ristenpart, W. D. (2020). Efficacy of masks and face coverings in controlling outward aerosol particle emission from expiratory activities. Scientific Reports, 10(1), 15665.

Asano, M., Iryo, T., \& Kuwahara, M. (2010). Microscopic pedestrian simulation model combined with a tactical model for route choice behaviour. Transportation Research Part C: Emerging Technologies, 18(6), 842-855.

Atkinson, M. P., \& Wein, L. M. (2008). Quantifying the routes of transmission for pandemic influenza. Bulletin of Mathematical Biology, 70(3), 820-867.

Azimi, P., Keshavarz, Z., Cedeno Laurent, J. G., Stephens, B., \& Allen, J. G. (2021). Mechanistic transmission modeling of COVID19 on the Diamond Princess cruise ship demonstrates the importance of aerosol transmission. Proceedings of the National Academy of Sciences of the United States of America, 118(8). https://doi.org/10.1073/pnas.2015482118

Bandini, S., Rubagotti, F., Vizzari, G., \& Shimura, K. (2011). A Cellular Automata Based Model for Pedestrian and Group Dynamics: Motivations and First Experiments. Parallel Computing Technologies, 125-139.

Barreda, S., Asadi, S., Cappa, C. D., Wexler, A. S., Bouvier, N. M., \& Ristenpart, W. D. (2020). The Impact of Vocalization Loudness on COVID-19 Transmission in Indoor Spaces. In arXiv [q-bio.QM]. arXiv. http://arxiv.org/abs/2009.04060

Bazant, M. Z., \& Bush, J. W. M. (2020). Beyond six feet: A guideline to limit indoor airborne transmission of covid-19. medRxiv. https://www.medrxiv.org/content/10.1101/2020.08.26.20182824v2.abstract

Bernardi, N. F., Snow, S., Peretz, I., Orozco Perez, H. D., Sabet-Kassouf, N., \& Lehmann, A. (2017). Cardiorespiratory optimization during improvised singing and toning. Scientific Reports, 7(1), 8113.

Bezek, L. B., Pan, J., Harb, C., Zawaski, C. E., Molla, B., Kubalak, J. R., Marr, L. C., \& Williams, C. B. (2021). Additively manufactured respirators: quantifying particle transmission and identifying system-level challenges for improving filtration efficiency. Journal of Manufacturing Systems. https://doi.org/10.1016/j.jmsy.2021.01.002

Blue, V. J., \& Adler, J. L. (1998). Emergent Fundamental Pedestrian Flows from Cellular Automata Microsimulation. Transportation Research Record, 1644(1), 29-36.

Borgers, A., \& Timmermans, H. (2010). A model of pedestrian route choice and demand for retail facilities within inner-city shopping areas. Geographical Analysis, 18(2), 115-128.

Borgers, A., \& Timmermans, H. J. P. (2005). Modelling pedestrian behaviour in downtown shopping areas. 10th International Conference on Computers in Urban Planning and Urban Management, London, United Kingdom.

https://www.researchgate.net/profile/Aloys_Borgers/publication/229057270_Modelling_pedestrian_behaviour_in_down town_shopping_areas/links/0deec51cc27bc3eb4e000000.pdf

Bouchnita, A., \& Jebrane, A. (2020). A multi-scale model quantifies the impact of limited movement of the population and mandatory wearing of face masks in containing the COVID-19 epidemic in Morocco. Mathematical Modelling of Natural Phenomena, 15, 31.

Callaway, E. (2020). Dozens to be deliberately infected with coronavirus in UK "human challenge" trials. In Nature (Vol. 586, Issue 7831, pp. 651-652). https://doi.org/10.1038/d41586-020-02821-4

Campanella, M. (2016). Microscopic modelling of walking behaviour (H. S. Daamen W. (ed.)) [Phd]. Delft University of Technology.

Campanella, M. Daamen, W. Hoogendoorn, S.P. (2009). User manual of the microscopic pedestrian simulation model Nomad 
medRxiv preprint doi: https://doi.org/10.1101/2021.04.12.21255349; this version posted April 19, 2021. The copyright holder for this preprint

(which was not certified by peer review) is the author/funder, who has granted medRxiv a license to display the preprint in perpetuity. It is made available under a CC-BY-NC 4.0 International license .

The multi-dimensional challenges of controlling SARS-CoV-2 transmission in indoor spaces

(No. 1.2.1.). Delft University of Technology.

Campanella, M., Hoogendoorn, S., \& Daamen, W. (2009). Improving the Nomad microscopic walker model. IFAC Proceedings Volumes, 42(15), 12-18.

Campanella, M., Hoogendoorn, S., \& Daamen, W. (2014). The Nomad Model: Theory, Developments and Applications. Transportation Research Procedia, 2, 462-467.

CDC. (2020, November 17). Social Distancing - Keep a safe distance to slow down the spread. Centrum for Disease Control. https://www.cdc.gov/coronavirus/2019-ncov/prevent-getting-sick/socialdistancing.html\#: :text=To\%20practice\%20social\%20or\%20physical,both\%20indoor\%20and\%20outdoor\%20spaces.

CDC. (2021, January 5). Disinfecting your facility. Centers for Disease Control and Prevention. https://www.cdc.gov/coronavirus/2019-ncov/community/disinfecting-building-facility.html

Chalmet, L. G., Francis, R. L., \& Saunders, P. B. (1982). Network Models for Building Evacuation. In Management Science (Vol. 28, Issue 1, pp. 86-105). https://doi.org/10.1287/mnsc.28.1.86

Chau, N. V. V., Hong, N. T. T., Ngoc, N. M., Thanh, T. T., Khanh, P. N. Q., Nguyet, L. A., Nhu, L. N. T., Ny, N. T. H., Man, D. N. H., Hang, V. T. T., \& Others. (2021). Superspreading event of SARS-CoV-2 infection at a bar, Ho Chi Minh City, Vietnam. Emerging Infectious Diseases, 27(1), 310.

Chen, F., Gao, Y., Wang, Z., \& Liu, Y. (2020). Analysis on Alighting and Boarding Movement Laws in Subway Using Modified Social Force Model. Collective Dynamics, 5(0), 307-315.

Chen, J., \& Bierlaire, M. (2015). Probabilistic Multimodal Map Matching With Rich Smartphone Data. In Journal of Intelligent Transportation Systems (Vol. 19, Issue 2, pp. 134-148). https://doi.org/10.1080/15472450.2013.764796

Chen, P. Z., Bobrovitz, N., Premji, Z., Koopmans, M., Fisman, D. N., \& Gu, F. X. (2020). Heterogeneity in transmissibility and shedding SARS-CoV-2 via droplets and aerosols. medRxiv. https://www.medrxiv.org/content/10.1101/2020.10.13.20212233v2.abstract

Cheung C. Y., \& Lam William H. K. (1998). Pedestrian Route Choices between Escalator and Stairway in MTR Stations. Journal of Transportation Engineering / American Society of Civil Engineers, 124(3), 277-285.

Chin, A. W. H., Chu, J. T. S., Perera, M. R. A., Hui, K. P. Y., Yen, H.-L., Chan, M. C. W., Peiris, M., \& Poon, L. L. M. (2020). Stability of SARS-CoV-2 in different environmental conditions. The Lancet. Microbe, 1(1), e10.

CIRES. (2020, June 25). COVID-19 Airborne Transmission Tool Available. CIRES. https://cires.colorado.edu/news/covid-19airborne-transmission-tool-available

Clapham, H. E., \& Cook, A. R. (2021). Face masks help control transmission of COVID-19. The Lancet. Digital Health. https://doi.org/10.1016/S2589-7500(21)00003-0

Clifton, K. J., Singleton, P. A., Muhs, C. D., \& Schneider, R. J. (2016). Development of destination choice models for pedestrian travel. Transportation Research Part A: Policy and Practice, 94, 255-265.

Daamen, W., Bovy, P. H. L., Hoogendoorn, S. P., \& Van de Reijt, A. (2005). Passenger route choice concerning level changes in railway stations. Transportation Research Board Annual Meeting, 1930, 12-20.

Danalet, A., \& Bierlaire, M. (2014). A path choice approach to activity modeling with a pedestrian case study. 14th Swiss Transport Research Conference. https://infoscience.epfl.ch/record/199478

Danalet, A., Farooq, B., \& Bierlaire, M. (2014). A Bayesian approach to detect pedestrian destination-sequences from WiFi signatures. Transportation Research Part C: Emerging Technologies, 44, 146-170.

Darby, S., Chulliyallipalil, K., Przyjalgowski, M., McGowan, P., Jeffers, S., Giltinan, A., Lewis, L., Smith, N., \& Sleator, R. D. (2021). COVID-19: mask efficacy is dependent on both fabric and fit. Future Microbiology, 16, 5-11.

Delikhoon, M., Guzman, M. I., Nabizadeh, R., \& Norouzian Baghani, A. (2021). Modes of Transmission of Severe Acute Respiratory Syndrome-Coronavirus-2 (SARS-CoV-2) and Factors Influencing on the Airborne Transmission: A Review. International Journal of Environmental Research and Public Health, 18(2). https://doi.org/10.3390/ijerph18020395

Deng, W., Bao, L., Gao, H., Xiang, Z., Qu, Y., Song, Z., Gong, S., Liu, J., Liu, J., Yu, P., Qi, F., Xu, Y., Li, F., Xiao, C., Lv, Q., Xue, J., Wei, Q., Liu, M., Wang, G., ... Qin, C. (2020). Ocular conjunctival inoculation of SARS-CoV-2 can cause mild COVID-19 in rhesus macaques. Nature Communications, 11(1), 4400.

Dias, C., Abdullah, M., Sarvi, M., Lovreglio, R., \& Alhajyaseen, W. (2019). Modeling and Simulation of Pedestrian Movement Planning Around Corners. Sustainability: Science Practice and Policy, 11(19), 5501.

Dijkstra, J., \& Jessurun, A. J. (2016). Pedestrian activity simulation in shopping environments: an irregular network approach. SIMUL2016, The Eighth International Conference on Advances in System Simulation, 21-25 August 2016, Roma, Italy, 3339.

Drewnick, F., Pikmann, J., Fachinger, F., Moormann, L., Sprang, F., \& Borrmann, S. (2021). Aerosol filtration efficiency of household materials for homemade face masks: Influence of material properties, particle size, particle electrical charge, face velocity, and leaks. In Aerosol Science and Technology (Vol. 55, Issue 1, pp. 63-79). https://doi.org/10.1080/02786826.2020.1817846

Duives, D. C., Daamen, W., \& Hoogendoorn, S. P. (2013). State-of-the-art crowd motion simulation models. Transportation Research Part C: Emerging Technologies, 37, 193-209.

Edwards, D. A., Ausiello, D., Salzman, J., Devlin, T., Langer, R., Beddingfield, B. J., Fears, A. C., Doyle-Meyers, L. A., Redmann, R. K., Killeen, S. Z., Maness, N. J., \& Roy, C. J. (2021). Exhaled aerosol increases with COVID-19 infection, age, and obesity. Proceedings of the National Academy of Sciences of the United States of America, 118(8). https://doi.org/10.1073/pnas.2021830118 
medRxiv preprint doi: https://doi.org/10.1101/2021.04.12.21255349; this version posted April 19, 2021. The copyright holder for this preprint

(which was not certified by peer review) is the author/funder, who has granted medRxiv a license to display the preprint in perpetuity. It is made available under a CC-BY-NC 4.0 International license .

The multi-dimensional challenges of controlling SARS-CoV-2 transmission in indoor spaces

Endo, A., Centre for the Mathematical Modelling of Infectious Diseases COVID-19 Working Group, Abbott, S., Kucharski, A. J., \& Funk, S. (2020). Estimating the overdispersion in COVID-19 transmission using outbreak sizes outside China. Wellcome Open Research, 5, 67.

Evans, S., Agnew, E., Vynnycky, E., \& Robotham, J. V. (2020). The impact of testing and infection prevention and control strategies on within-hospital transmission dynamics of COVID-19 in English hospitals. medRxiv. https://www.medrxiv.org/content/10.1101/2020.05.12.20095562v2.abstract

Fang, Z., Huang, Z., Li, X., Zhang, J., Lv, W., Zhuang, L., Xu, X., \& Huang, N. (2020). How many infections of COVID-19 there will be in the "Diamond Princess"-Predicted by a virus transmission model based on the simulation of crowd flow. In arXiv [physics.soc-ph]. arXiv. http://arxiv.org/abs/2002.10616

Flaxman, S., Mishra, S., Gandy, A., Unwin, H. J. T., Mellan, T. A., Coupland, H., Whittaker, C., Zhu, H., Berah, T., Eaton, J. W., Monod, M., Imperial College COVID-19 Response Team, Ghani, A. C., Donnelly, C. A., Riley, S., Vollmer, M. A. C., Ferguson, N. M., Okell, L. C., \& Bhatt, S. (2020). Estimating the effects of non-pharmaceutical interventions on COVID-19 in Europe. Nature, 584(7820), 257-261.

Fouda, B., Tram, H. P. B., Makram, O. M., Abdalla, A. S., Singh, T., Hung, I.-C., Raut, A., Hemmeda, L., Alahmar, M., ElHawary, A. S., Awad, D., \& Huy, N. T. (2021). Identifying SARS-CoV2 transmission cluster category: An analysis of country government database. In Journal of Infection and Public Health. https://doi.org/10.1016/j.jiph.2021.01.006

Gao, C. X., Li, Y., Wei, J., Cotton, S., Hamilton, M., Wang, L., \& Cowling, B. J. (2020). Multi-route respiratory infection: when a transmission route may dominate. https://doi.org/10.1101/2020.04.06.20055228

Gao, X., Wei, J., Lei, H., Xu, P., Cowling, B. J., \& Li, Y. (2016). Building Ventilation as an Effective Disease Intervention Strategy in a Dense Indoor Contact Network in an Ideal City. PloS One, 11(9), e0162481.

Giordano, G., Blanchini, F., Bruno, R., Colaneri, P., Di Filippo, A., Di Matteo, A., \& Colaneri, M. (2020). Modelling the COVID-19 epidemic and implementation of population-wide interventions in Italy. Nature Medicine. https://doi.org/10.1038/s41591020-0883-7

Gorbunov, B. (2020). Aerosol particles laden with viruses that cause COVID-19 travel over 30m distance. In Preprints. https://doi.org/10.20944/preprints202004.0546.v2

Guo, Z., \& Loo, B. P. Y. (2013). Pedestrian environment and route choice: evidence from New York City and Hong Kong. Journal of Transport Geography, 28, 124-136.

Hallett, S., Toro, F., \& Ashurst, J. V. (2020). Physiology, Tidal Volume. In StatPearls. StatPearls Publishing.

Hamilton, F. W., Gregson, F., Arnold, D. T., Sheikh, S., Ward, K., Brown, J., Moran, E., White, C., Morley, A., Bzdek, B. R., \& Others. (2021). Aerosol emission from the respiratory tract: an analysis of relative risks from oxygen delivery systems. Medrxiv. https://www.medrxiv.org/content/10.1101/2021.01.29.21250552v1.abstract

Hamner, L., Dubbel, P., Capron, I., Ross, A., Jordan, A., Lee, J., Lynn, J., Ball, A., Narwal, S., Russell, S., Patrick, D., \& Leibrand, H. (2020). High SARS-CoV-2 attack rate following exposure at a choir practice - Skagit County, Washington, March 2020. MMWR. Morbidity and Mortality Weekly Report, 69(19), 606-610.

Hänseler, F. S., Lam, W. H. K., Bierlaire, M., Lederrey, G., \& Nikolić, M. (2017). A dynamic network loading model for anisotropic and congested pedestrian flows. Transportation Research Part B: Methodological, 95, 149-168.

Harweg, T., Bachmann, D., \& Weichert, F. (2020). Agent-based Simulation of Pedestrian Dynamics for Exposure Time Estimation in Epidemic Risk Assessment. In arXiv [physics.soc-ph]. arXiv. http://arxiv.org/abs/2007.04138

Helbing, D., \& Molnár, P. (1995). Social force model for pedestrian dynamics. Physical Review. E, Statistical Physics, Plasmas, Fluids, and Related Interdisciplinary Topics, 51(5), 4282-4286.

Hill, M. R. (1984). Spatial structure and decisionmaking aspects of pedestrian route selection through an urban environment. University Microfilms.

Hinds, W. C. (1999). Aerosol Technology: Properties, Behavior, and Measurement of Airborne Particles. John Wiley \& Sons.

Homeland Security. (2021, February 23). Master Question List for COVID-19 (caused by SARS-CoV-2). Homeland Security Science and Technology. https://www.dhs.gov/publication/st-master-question-list-covid-19

Hoogendoorn, S. P., \& Bovy, P. H. L. (2004). Pedestrian route-choice and activity scheduling theory and models. Transportation Research Part B: Methodological, 38(2), 169-190.

Hoogendoorn, S. P., \& Bovy, P. H. L. (2005). Pedestrian travel behavior modeling. Networks and Spatial Economics, 5(2), 193216.

Hoogendoorn, S. P., van Wageningen-Kessels, F. L. M., Daamen, W., \& Duives, D. C. (2014). Continuum modelling of pedestrian flows: From microscopic principles to self-organised macroscopic phenomena. In Physica A: Statistical Mechanics and its Applications (Vol. 416, pp. 684-694). https://doi.org/10.1016/j.physa.2014.07.050

Hou, Y. J., Okuda, K., Edwards, C. E., Martinez, D. R., Asakura, T., Dinnon, K. H., 3rd, Kato, T., Lee, R. E., Yount, B. L., Mascenik, T. M., Chen, G., Olivier, K. N., Ghio, A., Tse, L. V., Leist, S. R., Gralinski, L. E., Schäfer, A., Dang, H., Gilmore, R., ... Baric, R. S. (2020). SARS-CoV-2 Reverse Genetics Reveals a Variable Infection Gradient in the Respiratory Tract. Cell, 182(2), 429446.e14.

Hughes, R. L. (2000). The flow of large crowds of pedestrians. Mathematics and Computers in Simulation, 53(4), 367-370.

Hughes, R. L. (2002). A continuum theory for the flow of pedestrians. Transportation Research Part B: Methodological, 36(6), 507-535.

Hwang, S. E., Chang, J. H., Oh, B., \& Heo, J. (2020). Possible aerosol transmission of COVID-19 associated with an outbreak in an apartment in Seoul, South Korea, 2020. International Journal of Infectious Diseases: IIID: Official Publication of the 
medRxiv preprint doi: https://doi.org/10.1101/2021.04.12.21255349; this version posted April 19, 2021. The copyright holder for this preprint

(which was not certified by peer review) is the author/funder, who has granted medRxiv a license to display the preprint in perpetuity. It is made available under a CC-BY-NC 4.0 International license .

The multi-dimensional challenges of controlling SARS-CoV-2 transmission in indoor spaces

International Society for Infectious Diseases, 104, 73-76.

Jiang, G., Wang, C., Song, L., Wang, X., Zhou, Y., Fei, C., \& Liu, H. (2021). Aerosol transmission, an indispensable route of COVID19 spread: case study of a department-store cluster. Frontiers of Environmental Science \& Engineering in China, 15(3), 46.

Jones, B., Sharpe, P., Iddon, C., Hathway, E. A., Noakes, C. J., \& Fitzgerald, S. (2021). Modelling uncertainty in the relative risk of exposure to the SARS-CoV-2 virus by airborne aerosol transmission in well mixed indoor air. Building and Environment, $191,107617$.

Julian, T. R., Leckie, J. O., \& Boehm, A. B. (2010). Virus transfer between fingerpads and fomites. Journal of Applied Microbiology, 109(6), 1868-1874.

Kalakou, S., Bierlaire, M. Moura, F. (2014). Effects of terminal planning on passenger choices. 14th Swiss Transport Research Conference. 14th Swiss Transport Research Conference (STRC), Monte Verita.

Kalakou, S., \& Moura, F. (2014). Bridging the Gap in Planning Indoor Pedestrian Facilities. Transport Reviews, 34(4), 474-500.

Karamouzas, I., \& Overmars, M. (2010). A Velocity-Based Approach for Simulating Human Collision Avoidance. Intelligent Virtual Agents, 180-186.

Kraay, A. N. M., Hayashi, M. A. L., Berendes, D. M., Sobolik, J. S., Leon, J. S., \& Lopman, B. A. (n.d.). Risk of fomite-mediated transmission of SARS-CoV-2 in child daycares, schools, and offices: a modeling study. https://doi.org/10.1101/2020.08.10.20171629

Kretz, T., Große, A., Hengst, S., Kautzsch, L., Pohlmann, A., \& Vortisch, P. (2011). QUICKEST PATHS IN SIMULATIONS OF PEDESTRIANS. Advances in Complex Systems, 14(05), 733-759.

Kriegel, M., Buchholz, U., Gastmeier, P., Bischoff, P., Abdelgawad, I., \& Hartmann, A. (2020). Predicted Infection Risk for Aerosol Transmission of SARS-CoV-2. medRxiv. https://www.medrxiv.org/content/10.1101/2020.10.08.20209106v5.abstract

Kwon, K.-S., Park, J.-I., Park, Y. J., Jung, D.-M., Ryu, K.-W., \& Lee, J.-H. (2021). Erratum: Correction of Text in the Article "Evidence of Long-Distance Droplet Transmission of SARS-CoV-2 by Direct Air Flow in a Restaurant in Korea." In Journal of Korean Medical Science (Vol. 36, Issue 2). https://doi.org/10.3346/jkms.2021.36.e23

Lei, H., Xiao, S., Cowling, B. J., \& Li, Y. (2020). Hand hygiene and surface cleaning should be paired for prevention of fomite transmission. Indoor Air, 30(1), 49-59.

Lelieveld, J., Helleis, F., Borrmann, S., Cheng, Y., Drewnick, F., Haug, G., Klimach, T., Sciare, J., Su, H., \& Pöschl, U. (2020). Model Calculations of Aerosol Transmission and Infection Risk of COVID-19 in Indoor Environments. International Journal of Environmental Research and Public Health, 17(21). https://doi.org/10.3390/ijerph17218114

Leung, N. H. L., Chu, D. K. W., Shiu, E. Y. C., Chan, K.-H., McDevitt, J. J., Hau, B. J. P., Yen, H.-L., Li, Y., Ip, D. K. M., Malik Peiris, J. S., Seto, W.-H., Leung, G. M., Milton, D. K., \& Cowling, B. J. (2020). Author Correction: Respiratory virus shedding in exhaled breath and efficacy of face masks. In Nature Medicine (Vol. 26, Issue 6, pp. 981-981). https://doi.org/10.1038/s41591-0200946-9

Li, S., Eisenberg, J. N. S., Spicknall, I. H., \& Koopman, J. S. (2009). Dynamics and control of infections transmitted from person to person through the environment. American Journal of Epidemiology, 170(2), 257-265.

Liu, X., Usher, J. M., \& Strawderman, L. (2014). An analysis of activity scheduling behavior of airport travelers. Computers \& Industrial Engineering, 74, 208-218.

Liu, Y., Li, T., Deng, Y., Liu, S., Zhang, D., Li, H., Wang, X., Jia, L., Han, J., Bei, Z., Li, L., \& Li, J. (2021). Stability of SARS-CoV-2 on environmental surfaces and in human excreta [Review of Stability of SARS-CoV-2 on environmental surfaces and in human excreta]. The Journal of Hospital Infection, 107, 105-107.

Lue, G., \& Miller, E. J. (2019). Estimating a Toronto pedestrian route choice model using smartphone GPS data. In Travel Behaviour and Society (Vol. 14, pp. 34-42). https://doi.org/10.1016/j.tbs.2018.09.008

Lu, J., Gu, J., Li, K., Xu, C., Su, W., Lai, Z., Zhou, D., Yu, C., Xu, B., \& Yang, Z. (2020). COVID-19 Outbreak Associated with Air Conditioning in Restaurant, Guangzhou, China, 2020. Emerging Infectious Diseases, 26(7), 1628-1631.

Ma, J., Qi, X., Chen, H., Li, X., Zhang, Z., Wang, H., Sun, L., Zhang, L., Guo, J., Morawska, L., Grinshpun, S. A., Biswas, P., Flagan, R. C., \& Yao, M. (2020). Coronavirus Disease 2019 Patients in Earlier Stages Exhaled Millions of Severe Acute Respiratory Syndrome Coronavirus 2 Per Hour. Clinical Infectious Diseases: An Official Publication of the Infectious Diseases Society of America. https://doi.org/10.1101/2020.05.31.20115154

Meyerowitz, E. A., Richterman, A., Gandhi, R. T., \& Sax, P. E. (2021). Transmission of SARS-CoV-2: A Review of Viral, Host, and Environmental Factors. Annals of Internal Medicine, 174(1), 69-79.

Mondelli, M. U., Colaneri, M., Seminari, E. M., Baldanti, F., \& Bruno, R. (2020). Low risk of SARS-CoV-2 transmission by fomites in real-life conditions. The Lancet Infectious Diseases. https://doi.org/10.1016/S1473-3099(20)30678-2

Moussaïd, M., Helbing, D., \& Theraulaz, G. (2011). How simple rules determine pedestrian behavior and crowd disasters. Proceedings of the National Academy of Sciences of the United States of America, 108(17), 6884-6888.

Mürbe, D., Fleischer, M., Lange, J., Rotheudt, H., \& Kriegel, M. (2020). Aerosol emission is increased in professional singing. Technische Universität Berlin. https://doi.org/10.14279/DEPOSITONCE-10375.3

National Academies of Sciences. (2020). Airborne Transmission of SARS-CoV-2: Proceedings of a Workshopin Brief. In Airborne Transmission of SARS-CoV-2: Proceedings of a Workshop-in Brief (2020). The National Academies Press.

Nicas, M. (1996). An analytical framework for relating dose, risk, and incidence: an application to occupational tuberculosis infection. Risk Analysis: An Official Publication of the Society for Risk Analysis, 16(4), 527-538.

Nicas, M., \& Jones, R. M. (2009). Relative contributions of four exposure pathways to influenza infection risk. Risk Analysis: An Official Publication of the Society for Risk Analysis, 29(9), 1292-1303. 
medRxiv preprint doi: https://doi.org/10.1101/2021.04.12.21255349; this version posted April 19, 2021. The copyright holder for this preprint

(which was not certified by peer review) is the author/funder, who has granted medRxiv a license to display the preprint in perpetuity. It is made available under a CC-BY-NC 4.0 International license .

The multi-dimensional challenges of controlling SARS-CoV-2 transmission in indoor spaces

Nicas, M., \& Sun, G. (2006). An integrated model of infection risk in a health-care environment. Risk Analysis: An Official Publication of the Society for Risk Analysis, 26(4), 1085-1096.

Oyama, Y., \& Hato, E. (2018). Pedestrian activity model based on implicit path enumaration. 21st International Conference of Hong Kong Society for Transportation Studies: Smart Transportation, HKSTS 2016, 331-338.

Pan, J., Harb, C., Leng, W., \& Marr, L. C. (2020). Inward and outward effectiveness of cloth masks, a surgical mask, and a face shield. https://vtechworks.lib.vt.edu/handle/10919/100918

Parisi, D. R., Gilman, M., \& Moldovan, H. (2009). A modification of the Social Force Model can reproduce experimental data of pedestrian flows in normal conditions. Physica A: Statistical Mechanics and Its Applications, 388(17), 3600-3608.

Paris, S., Pettré, J., \& Donikian, S. (2007). Pedestrian reactive navigation for crowd simulation: a predictive approach. Computer Graphics Forum: Journal of the European Association for Computer Graphics. https://onlinelibrary.wiley.com/doi/abs/10.1111/j.1467-8659.2007.01090.x?casa_token=Jq6NAUJx3SIAAAAA:eXTNo-mna9_Rysya4C60InIMdqJJ-1d1_jxhcy8oETVvn8Nwci7urkEPdn8IUKg_Ih9FgmLiF-fKKM

Popa, A., Genger, J.-W., Nicholson, M. D., Penz, T., Schmid, D., Aberle, S. W., Agerer, B., Lercher, A., Endler, L., Colaço, H., Smyth, M., Schuster, M., Grau, M. L., Martínez-Jiménez, F., Pich, O., Borena, W., Pawelka, E., Keszei, Z., Senekowitsch, M., ... Bergthaler, A. (2020). Genomic epidemiology of superspreading events in Austria reveals mutational dynamics and transmission properties of SARS-CoV-2. Science Translational Medicine, 12(573). https://doi.org/10.1126/scitranslmed.abe2555

Prem, K., Liu, Y., Russell, T. W., Kucharski, A. J., Eggo, R. M., Davies, N., Jit, M., Klepac, P., Flasche, S., Clifford, S., Pearson, C. A. B., Munday, J. D., Abbott, S., Gibbs, H., Rosello, A., Quilty, B. J., Jombart, T., Sun, F., Diamond, C., ... Hellewell, J. (2020). The effect of control strategies to reduce social mixing on outcomes of the COVID-19 epidemic in Wuhan, China: a modelling study. In The Lancet Public Health (Vol. 5, Issue 5, pp. e261-e270). https://doi.org/10.1016/s2468-2667(20)30073-6

Qian, H., Li, Y., Nielsen, P. V., \& Huang, X. (2009). Spatial distribution of infection risk of SARS transmission in a hospital ward. Building and Environment, 44(8), 1651-1658.

Qu, Y., Gao, Z., Xiao, Y., \& Li, X. (2014). Modeling the pedestrian's movement and simulating evacuation dynamics on stairs. Safety Science, 70, 189-201.

Richard, M., Kok, A., de Meulder, D., Bestebroer, T. M., Lamers, M. M., Okba, N. M. A., van Vlissingen, M. F., Rockx, B., Haagmans, B. L., Koopmans, M. P. G., Fouchier, R. A. M., \& Herfst, S. (2020). SARS-CoV-2 is transmitted via contact and via the air between ferrets. In Nature Communications (Vol. 11, Issue 1). https://doi.org/10.1038/s41467-020-17367-2

RIVM. (2019, July 7). Hygienerichtlijn voor GGD'en. RIVM. https://www.rivm.nl/hygienerichtlijnen/GGD\#bijlage-2reinigingsschemas

RIVM. (2020, August 21). Ventilatie en COVID-19. RIVM. https://lci.rivm.nl/ventilatie-en-covid-19

RIVM. (2021, January 25). Nederlandse aanpak en maatregelen tegen het coronavirus. Rijksoverheid.nl. https://www.rijksoverheid.nl/onderwerpen/coronavirus-covid-19/algemene-coronaregels

Robin, T., Antonini, G., Bierlaire, M., \& Cruz, J. (2009). Specification, estimation and validation of a pedestrian walking behavior model. Transportation Research Part B: Methodological, 43(1), 36-56.

Romero, V., Stone, W. D., \& Ford, J. D. (2020). COVID-19 indoor exposure levels: An analysis of foot traffic scenarios within an academic building. Transportation Research Interdisciplinary Perspectives, 7, 100185.

Ronchi, E., \& Lovreglio, R. (2020). EXPOSED: An occupant exposure model for confined spaces to retrofit crowd models during a pandemic. Safety Science, 130, 104834.

Sallah, K., Giorgi, R., Bengtsson, L., Lu, X., Wetter, E., Adrien, P., Rebaudet, S., Piarroux, R., \& Gaudart, J. (2017). Mathematical models for predicting human mobility in the context of infectious disease spread: introducing the impedance model. In International Journal of Health Geographics (Vol. 16, Issue 1). https://doi.org/10.1186/s12942-017-0115-7

Samet, J. M., Prather, K., Benjamin, G., Lakdawala, S., Lowe, J.-M., Reingold, A., Volckens, J., \& Marr, L. (2021). Airborne Transmission of SARS-CoV-2: What We Know. Clinical Infectious Diseases: An Official Publication of the Infectious Diseases Society of America. https://doi.org/10.1093/cid/ciab039

Sarmady, S., Haron, F., \& Talib, A. Z. (2010). Simulating Crowd Movements Using Fine Grid Cellular Automata. 201012 th International Conference on Computer Modelling and Simulation, 428-433.

Schadschneider, A., Kirchner, A., \& Nishinari, K. (2002). CA Approach to Collective Phenomena in Pedestrian Dynamics. Cellular Automata, 239-248.

Shatu, F., Yigitcanlar, T., \& Bunker, J. (2019). Objective vs. subjective measures of street environments in pedestrian route choice behaviour: Discrepancy and correlates of non-concordance. Transportation Research Part A: Policy and Practice, 126, 1-23.

Shelat, S., Daamen, W., Kaag, B., Duives, D., \& Hoogendoorn, S. (2020). A Markov-chain Activity-based Model for Pedestrians in Office Buildings. Collective Dynamics, 5(0), 423-430.

Shen, Y., Li, C., Dong, H., Wang, Z., Martinez, L., Sun, Z., Handel, A., Chen, Z., Chen, E., Ebell, M. H., Wang, F., Yi, B., Wang, H., Wang, X., Wang, A., Chen, B., Qi, Y., Liang, L., Li, Y., ... Xu, G. (2020). Community Outbreak Investigation of SARS-CoV-2 Transmission Among Bus Riders in Eastern China. JAMA Internal Medicine, 180(12), 1665-1671.

Song, W., Yu, Y., Fan, W., \& Zhang, H. (2005). A cellular automata evacuation model considering friction and repulsion. Science in China. Series E: Engineering \& Materials Science, 48(4), 403-413.

Spicknall, I. H., Koopman, J. S., Nicas, M., Pujol, J. M., Li, S., \& Eisenberg, J. N. S. (2010). Informing optimal environmental influenza interventions: how the host, agent, and environment alter dominant routes of transmission. PLoS Computational 
medRxiv preprint doi: https://doi.org/10.1101/2021.04.12.21255349; this version posted April 19, 2021. The copyright holder for this preprint

(which was not certified by peer review) is the author/funder, who has granted medRxiv a license to display the preprint in perpetuity. It is made available under a CC-BY-NC 4.0 International license.

The multi-dimensional challenges of controlling SARS-CoV-2 transmission in indoor spaces

Biology, 6(10), e1000969.

Stadnytskyi, V., Bax, C. E., Bax, A., \& Anfinrud, P. (2020). The airborne lifetime of small speech droplets and their potential importance in SARS-CoV-2 transmission. Proceedings of the National Academy of Sciences of the United States of America, $117(22), 11875-11877$.

Stubenschrott, M., Kogler, C., Matyus, T., \& Seer, S. (2014). A Dynamic Pedestrian Route Choice Model Validated in a High Density Subway Station. Transportation Research Procedia, 2, 376-384.

Swadi, T., Geoghegan, J. L., Devine, T., McElnay, C., Sherwood, J., Shoemack, P., Ren, X., Storey, M., Jefferies, S., Smit, E., Hadfield, J., Kenny, A., Jelley, L., Sporle, A., McNeill, A., Reynolds, G. E., Mouldey, K., Lowe, L., Sonder, G., ... de Ligt, J. (2021). Genomic Evidence of In-Flight Transmission of SARS-CoV-2 Despite Predeparture Testing. Emerging Infectious Diseases, 27(3), 687-693.

Sze To, G. N., \& Chao, C. Y. H. (2010). Review and comparison between the WellsâRiley and dose-response approaches to risk assessment of infectious respiratory diseases. Indoor Air, 20(1), 2-16.

Tang, S., Mao, Y., Jones, R. M., Tan, Q., Ji, J. S., Li, N., Shen, J., Lv, Y., Pan, L., Ding, P., Wang, X., Wang, Y., Maclntyre, C. R., \& Shi, X. (2020). Aerosol transmission of SARS-CoV-2? Evidence, prevention and control. Environment International, 144, 106039.

Thomas, R. J. (2013). Particle size and pathogenicity in the respiratory tract. Virulence, 4(8), 847-858.

Ton, D., van den Heuvel, J., Daamen, W., \& Hoogendoorn, S. (2015). Route and activity location choice behaviour of departing passengers in train stations. hEART (European Association for Research in Transportation) 2015 Conference. Copenhagen, Denmark, 9-11.

Tordeux, A., Lämmel, G., Hänseler, F. S., \& Steffen, B. (2018). A mesoscopic model for large-scale simulation of pedestrian dynamics. Transportation Research Part C: Emerging Technologies, 93, 128-147.

Treuille, A., Cooper, S., \& Popović, Z. (2006). Continuum crowds. ACM Transactions on Graphics, 25(3), 1160-1168.

Tuite, A. R., Fisman, D. N., \& Greer, A. L. (2020). Mathematical modelling of COVID-19 transmission and mitigation strategies in the population of Ontario, Canada. In Canadian Medical Association Journal (Vol. 192, Issue 19, pp. E497-E505). https://doi.org/10.1503/cmaj.200476

Ueki, H., Furusawa, Y., Iwatsuki-Horimoto, K., Imai, M., Kabata, H., Nishimura, H., \& Kawaoka, Y. (2020). Effectiveness of Face Masks in Preventing Airborne Transmission of SARS-CoV-2. mSphere, 5(5). https://doi.org/10.1128/mSphere.00637-20

Usher, J. M., Kolstad, E., \& Liu, X. (2010). Simulation of Pedestrian Behavior in Intermodal Facilities. International Journal of Agent Technologies and Systems (IJATS), 2(3), 66-82.

van Doremalen, N., Bushmaker, T., Morris, D. H., Holbrook, M. G., Gamble, A., Williamson, B. N., Tamin, A., Harcourt, J. L., Thornburg, N. J., Gerber, S. I., Lloyd-Smith, J. O., de Wit, E., \& Munster, V. J. (2020). Aerosol and surface stability of SARSCoV-2 as compared with SARS-CoV-1. The New England Journal of Medicine, 382(16), 1564-1567.

Van Ginkel, J. T., \& Hasselaar, E. (2006). Indoor air quality influenced by ventilation system design. ENHR Conference 2006: Housing in an Expanding Europe. Theory, Policy, Implementation and Participation, Ljubljana, July 2-5, 2006. http://citeseerx.ist.psu.edu/viewdoc/download?doi=10.1.1.548.5862\&rep=rep1\&type=pdf

Vukadinovic, V., Dreier, F., \& Mangold, S. (2011). A simple framework to simulate the mobility and activity of theme park visitors. Proceedings of the 2011 Winter Simulation Conference (WSC), 3248-3260.

Vuorinen, V., Aarnio, M., Alava, M., Alopaeus, V., Atanasova, N., Auvinen, M., Balasubramanian, N., Bordbar, H., Erästö, P., Grande, R., Hayward, N., Hellsten, A., Hostikka, S., Hokkanen, J., Kaario, O., Karvinen, A., Kivistö, I., Korhonen, M., Kosonen, R., ... Österberg, M. (2020). Modelling aerosol transport and virus exposure with numerical simulations in relation to SARSCoV-2 transmission by inhalation indoors. Safety Science, 130, 104866.

Watanabe, T., Bartrand, T. A., Weir, M. H., Omura, T., \& Haas, C. N. (2010). Development of a dose-response model for SARS coronavirus: Dose-response model for SARS-CoV. Risk Analysis: An Official Publication of the Society for Risk Analysis, 30(7), 1129-1138.

Wells, W. F., \& Others. (1955). Airborne Contagion and Air Hygiene. An Ecological Study of Droplet Infections. Airborne Contagion and Air Hygiene. An Ecological Study of Droplet Infections. https://www.cabdirect.org/cabdirect/abstract/19562701497

WHO. (2021, January 25). WHO Coronavirus Disease (COVID-19) Dashboard. World Health Organisation. https://covid19.who.int/

Wilson, N., Marks, G., Eckhardt, A., Clarke, A., Young, F., Garden, F., Stewart, W., Cook, T., \& Tovey, E. (2021). The effect of respiratory activity, ventilatory therapy and facemasks on total aerosol emissions. medRxiv. https://www.medrxiv.org/content/10.1101/2021.02.07.21251309v2.abstract

Winther, B., McCue, K., Ashe, K., Rubino, J. R., \& Hendley, J. O. (2007). Environmental contamination with rhinovirus and transfer to fingers of healthy individuals by daily life activity. Journal of Medical Virology, 79(10), 1606-1610.

Xiao, Y., Yang, M., Zhu, Z., Yang, H., Zhang, L., \& Ghader, S. (2020). Modeling indoor-level non-pharmaceutical interventions during the COVID-19 pandemic: a pedestrian dynamics-based microscopic simulation approach. In arXiv [physics.soc-ph]. arXiv. http://arxiv.org/abs/2006.10666

Xie, X., Li, Y., Chwang, A. T. Y., Ho, P. L., \& Seto, W. H. (2007). How far droplets can move in indoor environments--revisiting the Wells evaporation-falling curve. Indoor Air, 17(3), 211-225.

$\mathrm{Xu}, \mathrm{Q} .$, \& Chraibi, M. (2020). On the Effectiveness of the Measures in Supermarkets for Reducing Contact among Customers during COVID-19 Period. Sustainability: Science Practice and Policy, 12(22), 9385.

Zhang, J., Litvinova, M., Liang, Y., Wang, Y., Wang, W., Zhao, S., Wu, Q., Merler, S., Viboud, C., Vespignani, A., Ajelli, M., \& Yu, H. 
medRxiv preprint doi: https://doi.org/10.1101/2021.04.12.21255349; this version posted April 19, 2021. The copyright holder for this preprint (which was not certified by peer review) is the author/funder, who has granted medRxiv a license to display the preprint in perpetuity. It is made available under a CC-BY-NC 4.0 International license.

The multi-dimensional challenges of controlling SARS-CoV-2 transmission in indoor spaces

(2020). Changes in contact patterns shape the dynamics of the COVID-19 outbreak in China. Science. https://doi.org/10.1126/science.abb8001

Zuo, Y. Y., Uspal, W. E., \& Wei, T. (2020). Airborne Transmission of COVID-19: Aerosol Dispersion, Lung Deposition, and VirusReceptor Interactions. ACS Nano. https://doi.org/10.1021/acsnano.0c08484

Zwart, M. P., \& Elena, S. F. (2015). Matters of Size: Genetic Bottlenecks in Virus Infection and Their Potential Impact on Evolution. Annual Review of Virology, 2(1), 161-179. 
medRxiv preprint doi: https://doi.org/10.1101/2021.04.12.21255349; this version posted April 19, 2021. The copyright holder for this preprint

(which was not certified by peer review) is the author/funder, who has granted medRxiv a license to display the preprint in perpetuity. It is made available under a CC-BY-NC 4.0 International license .

The multi-dimensional challenges of controlling SARS-CoV-2 transmission in indoor spaces

\section{APPENDIX 1. PARAMETER DESCRIPTION IN QVE-MOD}

Emission rate $(\omega)$ represents the viral load of an infector emitting per hour while breathing. In the case study, $\omega$ is scaled to 1 per hour for a typical infectious person. For other respiratory activities, the emission rate is calculated based on the relative difference of particle volume associated with different respiratory activities. This is represented by the activity scaler $\delta$. For example, singing emits 25 units per hour and talking emits 3.6 units per hour (P. Z. Chen et al., 2020). The infectious scaler $(\sigma)$ is used to scale individual infectiousness. 0 represents a susceptible individual who cannot emit the virus and 1 represents a "typical infectious" individual. This number roughly represents $10^{6}$ copies per hour $(\phi)$, which is used to compare exposure to infectious dose estimates from literature (Leung et al. (2020), Ma et al. (2020)). Values of $\sigma$ that are greatly larger than one reflect super-shedding individuals.

$p_{\text {aerosols, }} p_{\text {droplets }}$ determine how emitted virus is partitioned in aerosols and droplets respectively. These were parameterized based on three factors: i) a predetermined cut-off size between aerosols and droplets, ii) the relative amounts of aerosols and droplets expelled by humans, and iii) the difference in viral copies carried by aerosol and droplet particles. In this study, we defined aerosol particles as having a dry size of $<10$ um.

Decay rates of virus in aerosols and on different surface materials were investigated in studies about the stability of SARS-CoV-2 in the environment (Chin et al. (2020), Liu et al. (2021), Van Doremalen et al. (2020)). The virus loses infectiousness at decay rates ( $u_{\text {fomites }}$ ) that depend on the surface material. These were represented by regression models fitted to experimental data from persistence studies.

The decay rate of viruses in droplets ( $\left.u_{\text {droplets }}\right)$ can be regarded as the sedimentation rate of droplets in static air (Xie et al., 2007). When height is $1.625 \mathrm{~m}$ and under the gravity of $9.8 \mathrm{~m} \mathrm{~s}^{-2}$, particles with size 10 um settle down in 8 minutes. This would take approximately 2 minutes for 20 um particles (Vuorinen et al., 2020). The settling time is proportional to $\left(1 / \mathrm{d}^{-2}\right)$, with $\mathrm{d}$ denoting the particle size. The droplets are particles with dry size $>10 \mathrm{um}$. The original size is larger than 10 um but the particles evaporate when deposited. Taking this evaporation into account results into an estimated deposition time of droplets of 3.3 mins (Vuorinen et al., 2020).

Both droplets and aerosols can disperse to their surroundings. We adapted a model from Vuorinen et al. (2020), who investigated aerosol transport in indoor spaces and built a Monte-Carlo model to incorporate spatialtemporal aerosol dispersion. Here, aerosols diffuse over time in $\mathrm{x}$, $\mathrm{y}$ directions $C(x, y, t)$. We modeled this the diffusion according to $\partial \mathrm{C} / \partial \mathrm{t}=\mathrm{D} \Delta \mathrm{c}+\mathrm{S}$, where $D$ is the diffusion coefficient (diffusivity) and $S$ is the source. The diffusivity coefficient was $D=0.05 \mathrm{~m}^{2} / \mathrm{s}$. Contrary to Vuorinen et al, we did not include ventilation here since ventilation was considered in the virus decay submodel.

Pickup rates of virus from the air $(\rho)$ are defined as the ratio of human tidal volume over the cell volume per timestep (here hour). The tidal volume is defined as the amount of air that moves in or out of the lungs with each respiratory cycle and measures on average $0.4 \mathrm{~L}$ for an adult (Hallett et al., 2020). The respiratory rate per minute is on average 12 times (Hallett et al., 2020). Thus, the human ventilation volume is calculated as $0.4 * 12=$ $4.8 \mathrm{~L}$ per minute or $288 \mathrm{~L}$ per hour. Individuals are thus assumed to inhale 2.304 times the cell volume (125L) each hour. The human ventilation volume increases 1.5 times while singing (Bernardi et al. (2017)), hence $\rho$ is $432 \mathrm{~L}$ per hour if an individual were to be singing continuously for one hour.

Lastly, there are three parameters that determine the transfer of viruses between hands and surfaces. The ratio of finger pads size over cell size ratio $(\pi)$ is calculated as $10 \mathrm{~cm}^{2}$ over the $10 * 10 \mathrm{~cm}^{2}$, which is 0.1 (Gao et al., 2020). The transfer efficiency $(\theta)$ depends on materials. Julian et al. (2010) conducted an experiment on transfer of virus between hands and glass in both directions and found the mean transfer efficiency is 0.23 . The frequency of touching surface $(\gamma)$ in a restaurant is estimated as 0.25 per minute (Lei et al., 2020). Monitoring data are currently being collected to get a more thorough and empirical understanding of this parameter in various settings and between individuals. 
medRxiv preprint doi: https://doi.org/10.1101/2021.04.12.21255349; this version posted April 19, 2021. The copyright holder for this preprint (which was not certified by peer review) is the author/funder, who has granted medRxiv a license to display the preprint in perpetuity. It is made available under a CC-BY-NC 4.0 International license.

\section{APPENDIX 2: THE SNAPSHOT HEATMAPS IN THE CASE STUDY}

$\stackrel{\text { LI }}{\text { II }}$
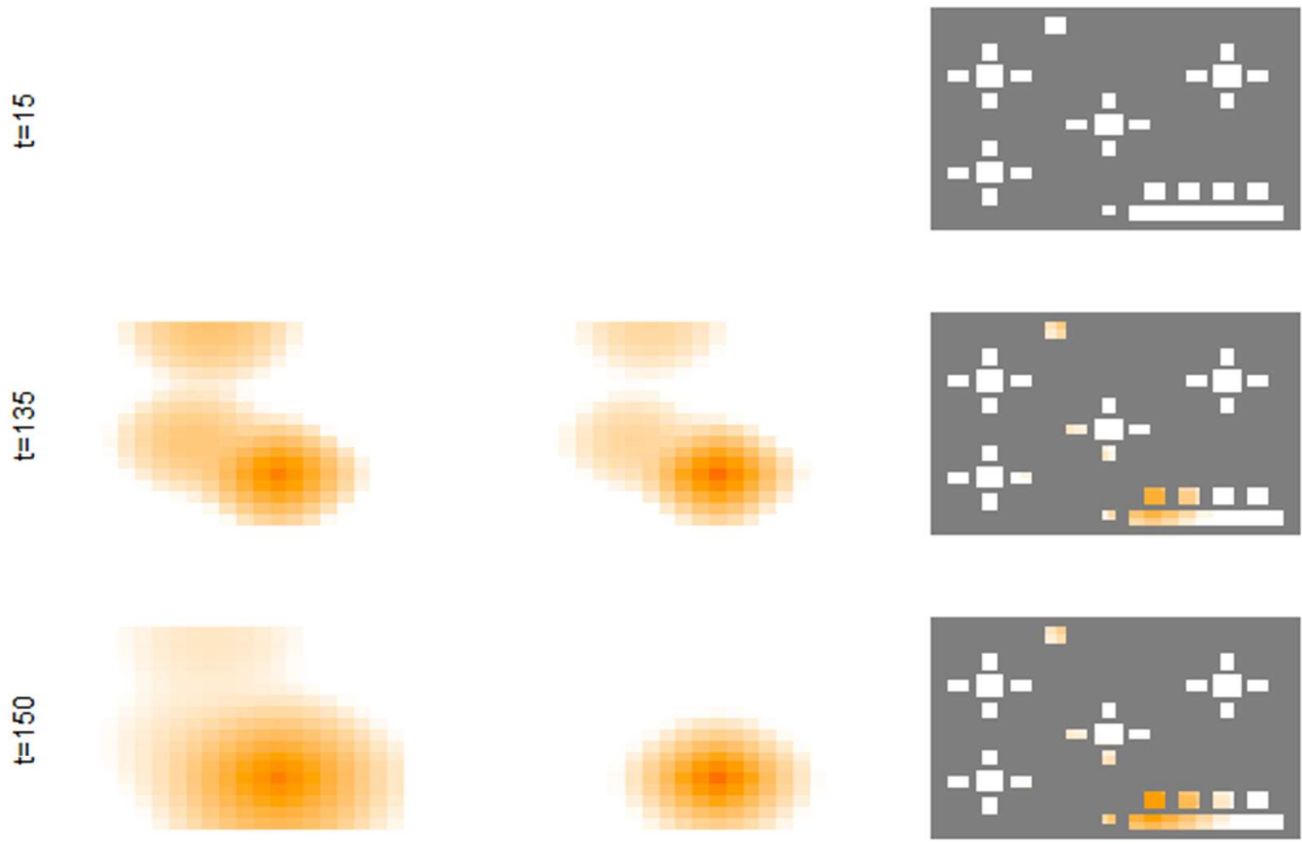

Contamination
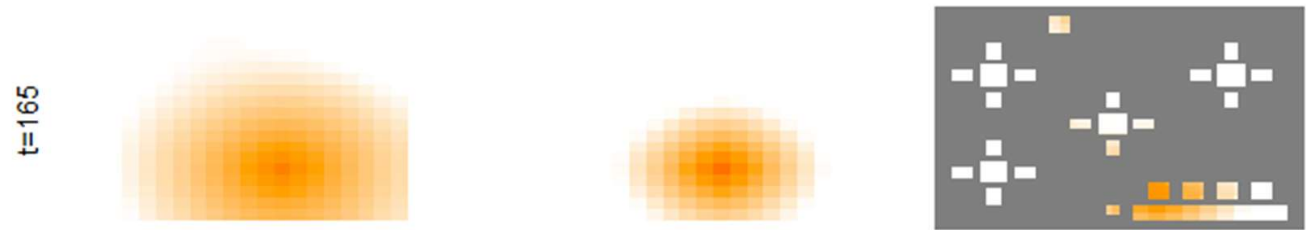

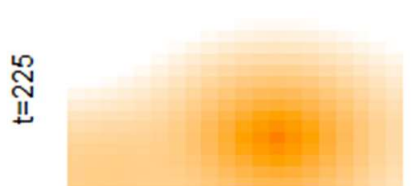

Aerosols
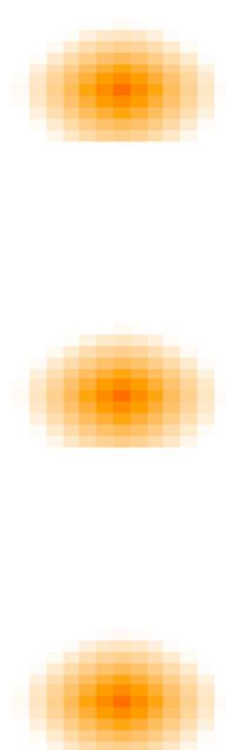

Droplets

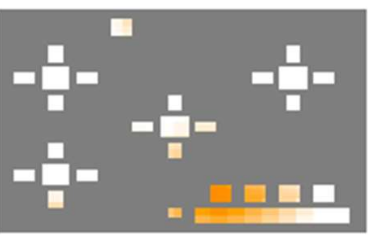

Fomites

Figure S1. Snapshot of heatmaps. Virus contamination in the environment in aerosols, droplets, and on fomites over time in minutes. Contamination is expressed as the virion quantity relative to an average infectious individual's hourly emission. 